\title{
ORNL Interim Progress Report on Hydride Reorientation CIRFT Tests
}

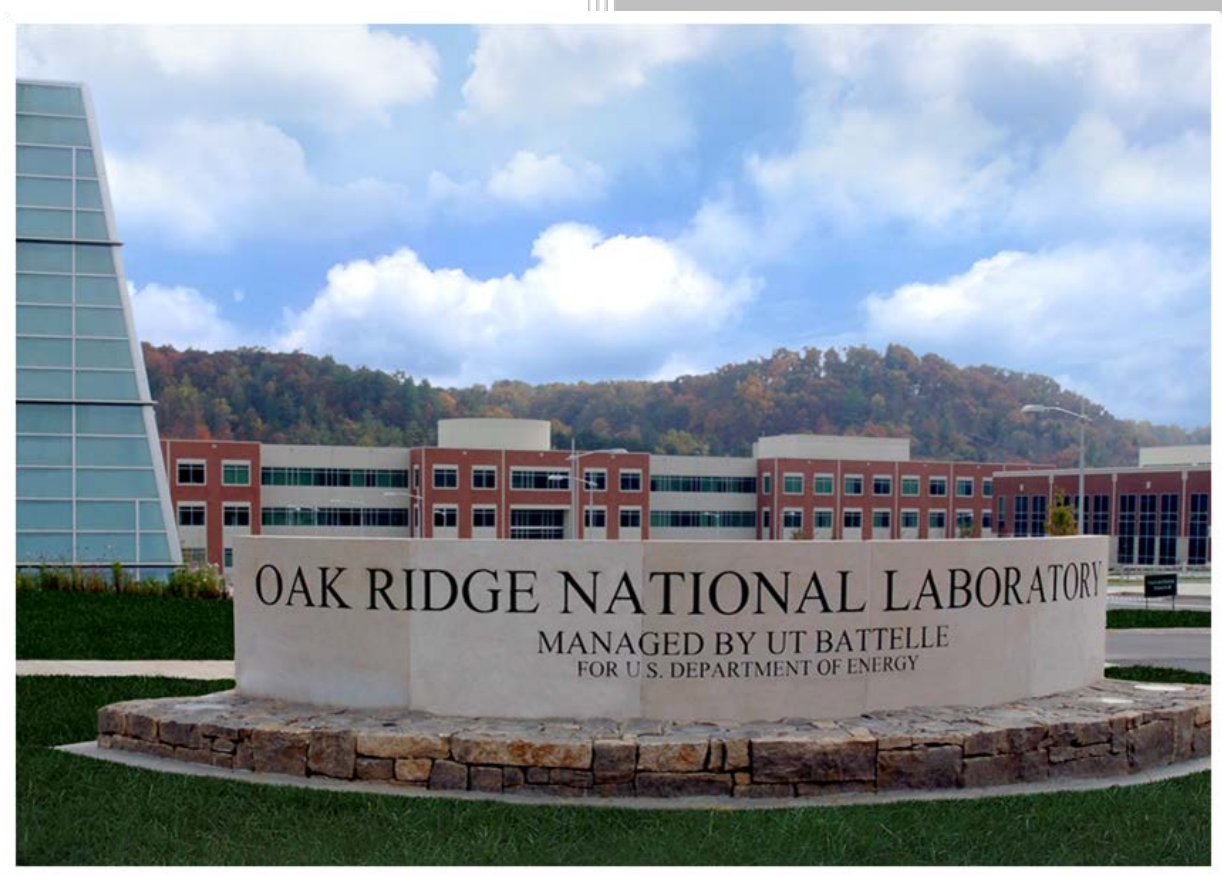

Approved for public release. Distribution is unlimited.
Jy-An John Wang Hong Wang Yong Yan

October 28, 2016 


\section{DOCUMENT AVAILABILITY}

Reports produced after January 1, 1996, are generally available free via the U.S. Department of Energy (DOE) Information Bridge.

Web site http://www.osti.gov/bridge

Reports produced before January 1, 1996, may be purchased by members of the public from the following source.

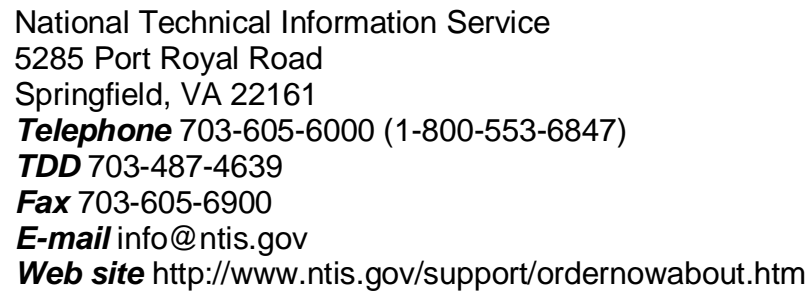

Reports are available to DOE employees, DOE contractors, Energy Technology Data Exchange (ETDE) representatives, and International Nuclear Information System (INIS) representatives from the following source.

Office of Scientific and Technical Information

P.O. Box 62

Oak Ridge, TN 37831

Telephone 865-576-8401

Fax 865-576-5728

E-mail reports@osti.gov

Web site http://www.osti.gov/contact.html

This report was prepared as an account of work sponsored by an agency of the United States Government. Neither the United States Government nor any agency thereof, nor any of their employees, makes any warranty, express or implied, or assumes any legal liability or responsibility for the accuracy, completeness, or usefulness of any information, apparatus, product, or process disclosed, or represents that its use would not infringe privately owned rights. Reference herein to any specific commercial product, process, or service by trade name, trademark, manufacturer, or otherwise, does not necessarily constitute or imply its endorsement, recommendation, or favoring by the United States Government or any agency thereof. The views and opinions of authors expressed herein do not necessarily state or reflect those of the United States Government or any agency thereof. 
Materials Science and Technology Division

Oak Ridge National Laboratory

\section{ORNL Interim Progress Report on Hydride Reorientation CIRFT Tests}

Jy-An Wang, Hong Wang, and Yong Yan

NRC Program Manager: Michelle Bales ORNL Program Manager: Bruce Bevard

Date Published: October 28, 2016

Prepared by

OAK RIDGE NATIONAL LABORATORY

Oak Ridge, Tennessee 37831-6283

managed by

UT-BATTELLE, LLC

for the

US DEPARTMENT OF ENERGY

under contract DE-AC05-00OR22725 
This page intentionally left blank. 


\section{CONTENTS}

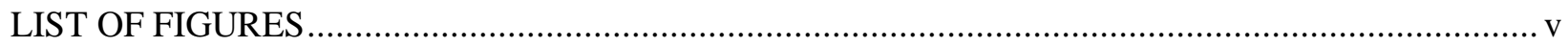

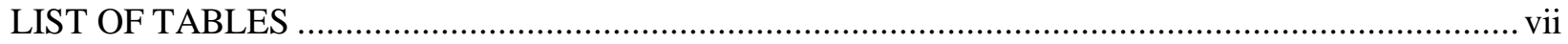

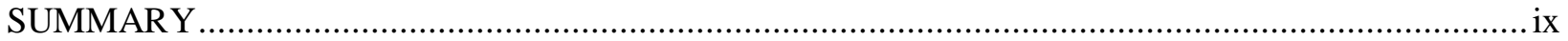

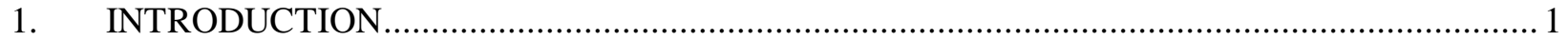

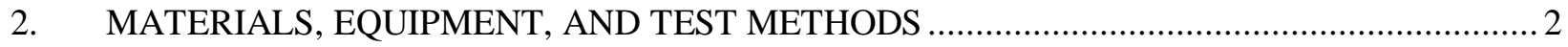

2.1 Description of Cladding Material and High-Burnup Fuel Segments ................................. 2

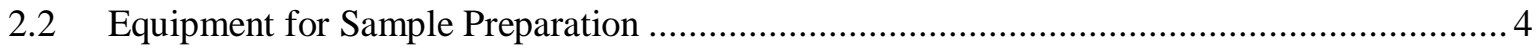

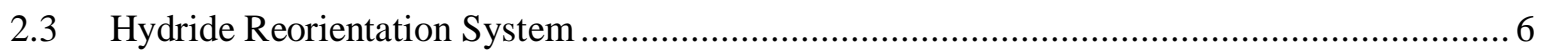

3. MATERIALS HYDRIDING AND CHARACTERIZATION …................................................. 8

4. OUT-OF-CELL HYDRIDE REORIENTATION TESTING .................................................... 9

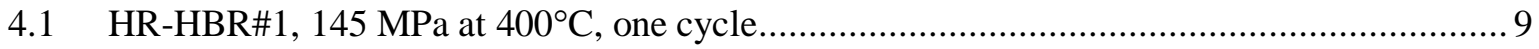

4.2 HR-HBR\#2, $145-150 \mathrm{MPa}$ at $400^{\circ} \mathrm{C}$, five cycles ........................................................ 12

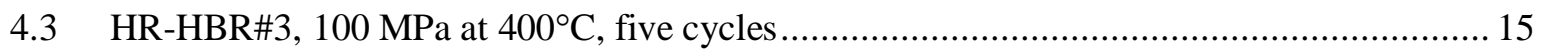

$4.4 \quad \mathrm{HR}-\mathrm{HBR} \# 4,120 \mathrm{MPa}$ at $400^{\circ} \mathrm{C}$, five cycles.............................................................. 18

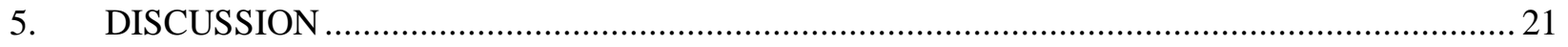

6. CIRFT EVALUATIONS OF HBR FUEL FOR HYDRIDE REORIENTATION STUDY ............ 22

6.1 Overview of CIRFT Evaluations and Results for HBR Fuel Rods .................................... 22

6.2 FY 2016 PHASE II CIRFT HR Test Results (Appendix A) .......................................... 23

6.2.1 Hydride Reorientation Test Samples Preparation ................................................ 23

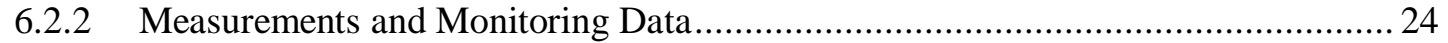

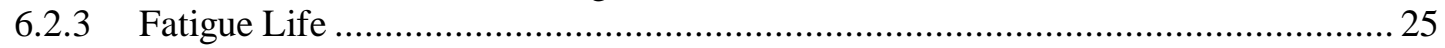

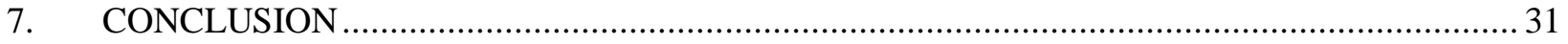

General observations from Phase II CIRFT test data evaluations are: .............................................. 31

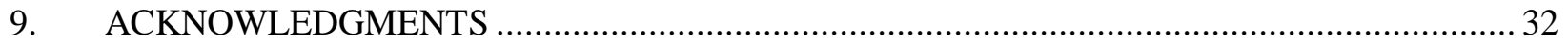

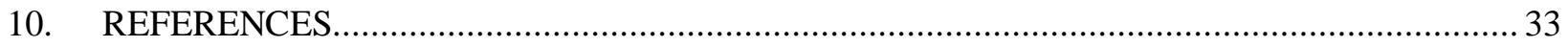

APPENDIX A: CIRFT TESTING RESULTS OF HBR SNF- Phase II............................. 
This page intentionally left blank. 


\section{LIST OF FIGURES}

Fig. 1. High-burnup H. B. Robinson fuel morphology for Sample 607D4A........................................ 4

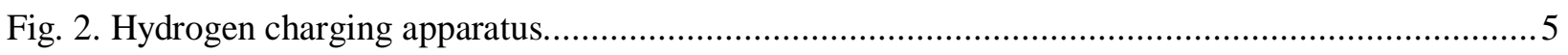

Fig. 3. A typical pressure and temperature profile of the hydrogen charging process. ............................ 5

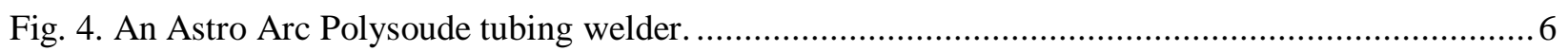

Fig. 5 The hydride reorientation system (a) before and (b) after installed into the hot cell...................... 7

Fig. 6. Micrographs showing typical, uniform circumferential hydride distributions in hydrogen

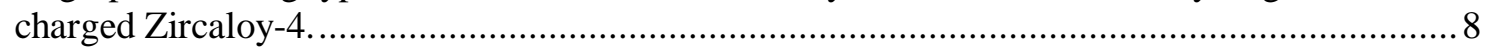

Fig. 7. Pressure and sample temperature as a function of time for Test HR-HBR\#1............................ 9

Fig. 8. High magnification micrograph showing radial hydrides of Sample HR-HBR\#1 with

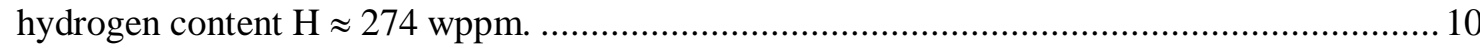

Fig. 9. Radial hydride distribution shown in eight areas in different circumferential directions of

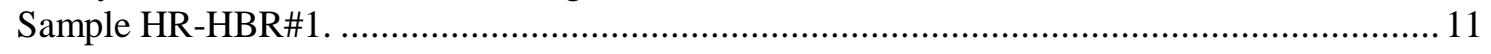

Fig. 10. Pressure and sample temperature as a function of time for Test HR-HBR\#2 ......................... 12

Fig. 11. High magnification micrograph showing radial hydrides of Sample HR-HBR\#2 with

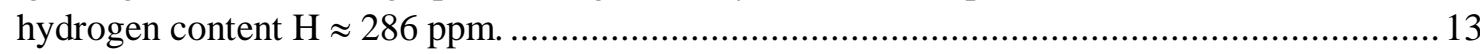

Fig. 12. Radial hydride distribution shown in eight areas in different circumferential directions of

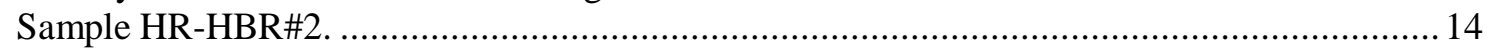

Fig. 13. Pressure and sample temperature as a function of time for Test HR-HBR\#3.......................... 15

Fig. 14. High magnification micrograph showing radial hydrides of Sample HR-HBR\#3 with

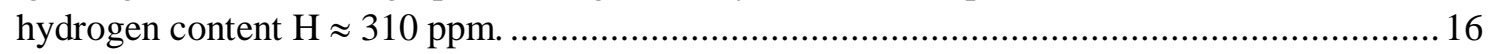

Fig. 15. Radial hydride distribution shown in eight areas in different circumferential directions of

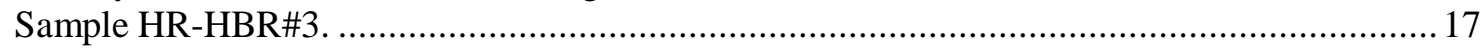

Fig. 16. Pressure and sample temperature as a function of time for Test HR-HBR\#4..........................18

Fig. 17. High magnification micrograph showing radial hydrides of Sample HR-HBR\#4 with hydrogen content $\mathrm{H} \approx 312 \mathrm{ppm}$.

Fig. 18. Radial hydride distribution shown in eight areas in different circumferential directions of Sample HR-HBR\#4. . 20

Fig. 20. Terminal solid solubility for dissolution (TSSd) of hydrogen in Zircaloy................................221

Fig. 21. Sample temperature as a function of time for in-cell HR test HR-1. .23

Fig. 22. (a) High magnification micrograph showing radial hydrides of Sample HR-1 $(\mathrm{H} \approx 360$ $400 \mathrm{ppm}$ ). The HBU HBR specimen was pressurized to $145 \mathrm{MPa}$ at $400^{\circ} \mathrm{C}$ with five thermal cycles. (b) High magnification micrograph showing radial hydrides of Sample HR-HBR\#2 ( $\mathrm{H} \approx 286 \mathrm{ppm})$. The specimen was sectioned at the midplane of a 6 in.long sample.

Fig. 23. (a) Moment amplitude, (b) stress amplitude, (c) curvature amplitude, and (d) strain amplitude rigidity as a function of cycles or cycles to failure.

Fig. 24. Images showing the failure modes for (a) (b) (c) (d) HR1, (e) (f) (g) (h) HR2, (i) (j) HR3, and $(\mathrm{k})(\mathrm{l})(\mathrm{m})(\mathrm{n})$ HR4. 


\section{LIST OF TABLES}

Table 1. Dimensions and chemistry of H. B. Robinson (HBR) type Zircaloy-4 used in the Oak Ridge National Laboratory test program (--- = below the detection limit)

Table 2. Characteristics of high-burnup H. B. Robinson fuel rods for the Oak Ridge National Laboratory hydride reorientation test ${ }^{a}$....

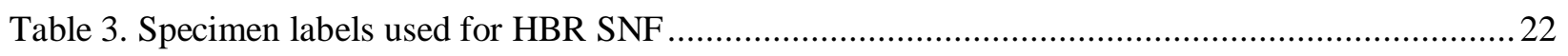

Table 4a. Dynamic test results for HBR SNF rods, FY 2016 .........................................................25 
This page intentionally left blank. 


\section{SUMMARY}

A systematic study of H. B. Robinson (HBR) high burnup spent nuclear fuel (SNF) vibration integrity was performed in Phase I project under simulated transportation environments, using the Cyclic Integrated Reversible-Bending Fatigue Tester (CIRFT) hot cell testing technology developed at Oak Ridge National Laboratory in 2013-14. The data analysis on the as-irradiated HBR SNF rods demonstrated that the load amplitude is the dominant factor that controls the fatigue life of bending rods. However, previous studies have shown that the hydrogen content and hydride morphology has an important effect on zirconium alloy mechanical properties. To address the effect of radial hydrides in SNF rods, in Phase II a test procedure was developed to simulate the effects of elevated temperatures, pressures, and stresses during transfer-drying operations. Pressurized and sealed fuel segments were heated to the target temperature for a preset hold time and slow-cooled at a controlled rate. The procedure was applied to both non-irradiated/prehydrided and high-burnup Zircaloy-4 fueled cladding segments using the Nuclear Regulatory Commission-recommended $400^{\circ} \mathrm{C}$ maximum temperature limit at various cooling rates.

Before testing high-burnup cladding, four out-of-cell tests were conducted to optimize the hydride reorientation $(\mathrm{R})$ test condition with pre-hydride Zircaloy-4 cladding, which has the same geometry as the high burnup fuel samples. Test HR-HBR\#1 was conducted at the maximum hoop stress of $145 \mathrm{MPa}$, at a $400^{\circ} \mathrm{C}$ maximum temperature and a $5^{\circ} \mathrm{C} / \mathrm{h}$ cooling rate. On the other hand, thermal cycling was performed for tests HR-HBR\#2, HR-HBR\#3, and HR-HBR\#4 to generate more radial hydrides. It is clear that thermal cycling increases the ratio of the radial hydride to circumferential hydrides. The internal pressure also has a significant effect on the radial hydride morphology. This report describes a procedure and experimental results of the four out-of-cell hydride reorientation tests of hydrided Zircaloy-4 cladding, which served as a guideline to prepare in-cell hydride reorientation samples with high burnup HBR fuel segments.

This report also provides the Phase II CIRFT test data for the hydride reorientation irradiated samples. The variations in fatigue life are provided in terms of moment, equivalent stress, curvature, and equivalent strain for the tested SNFs. The CIRFT results appear to indicate that hydride reoriented treatment (HRT) have a negative effect on fatigue life, in addition to hydride reorientation effect. For HR4 specimen that had no pressurization procedure applied, the thermal annealing treatment alone showed a negative impact on the fatigue life compared to the HBR rod. 
This page intentionally left blank. 


\section{INTRODUCTION}

Hydrogen embrittlement of zirconium alloys is a growing concern in the United States because of the lack of a long-term solution for disposal of spent nuclear fuel (SNF). Normal operation of nuclear fuel in a reactor results in the formation of a waterside corrosion layer (oxide) and the introduction of hydrogen into the zirconium cladding via the reaction $2 \mathrm{H}_{2} \mathrm{O}+\mathrm{Zr} \rightarrow \mathrm{ZrO}_{2}+4 \mathrm{H}$. With increasing corrosion, the hydrogen concentration in the cladding will exceed its terminal solid solubility, and brittle zirconium hydrides $\left(\mathrm{Zr}+2 \mathrm{H} \rightarrow \mathrm{ZrH}_{2}\right)$ may precipitate as the cladding cools. The formation of these hydride precipitates causes cladding ductility and failure energy to decrease [1, 2] and increases the likelihood of failure during very long-term storage and/or transportation of SNF. However, failure because of embrittlement is highly dependent upon the microstructural condition, especially the orientation of the zirconium hydride precipitates.

Under pool-storage conditions after fuel is discharged from reactors, the precipitated hydride platelets are oriented in a circumferential direction. Circumferential hydrides - in combination with hardening caused by irradiation effects-will decrease cladding ductility in response to axial and hoop loads; however, even with circumferential hydrides, the cladding still retains some ductility. At elevated temperatures during drying-transfer operations, some of the hydrogen may go into solution (up to $200 \mathrm{wppm}$ at $400^{\circ} \mathrm{C}$ ). The pressure-induced cladding tensile hoop stress during drying-transfer operations is high relative to inreactor and pool-storage conditions. During cooling under tensile hoop stress, some of the dissolved hydrogen will precipitate in the radial direction across the cladding wall when the hoop stress is sufficient. Further cooling during storage may result in radial-hydride-induced embrittlement. This was confirmed by some recent research [3-7] that featured hydrided Zircaloy-4 cladding and high burnup zirconium alloy samples that were exposed to a tensile hoop stress from the internally pressurized cladding at $\approx 400^{\circ} \mathrm{C}$ - conditions similar to drying operations of the SNF.

The objective of the program is to collect experimental data on hydride reorientation testing of HBR Zircaloy-4 high burnup fuels under simulated drying operation conditions of the SNF. This report describes a procedure and test results of out-of-cell hydride reoriented tests of hydrided HBR cladding; that procedure will be used as a guideline for preparing in-cell hydride reorientation samples with high burnup fuel segments. This report also provides the Phase II CIRFT test data for the hydride reorientation samples. 


\section{MATERIALS, EQUIPMENT, AND TEST METHODS \\ 2.1 Description of Cladding Material and High-Burnup Fuel Segments}

The out-of-cell experiments were conducted with unirradiated, $15 \times 15$ pressurized water reactor (PWR) Zircaloy-4 cladding material provided by AREVA; the material has dimensions, oxygen content, and mechanical properties similar to those of the HBR cladding. After the cladding was received by Oak Ridge National Laboratory (ORNL), measurements were performed to determine the outer diameter (OD) and wall thickness. Table 1 summarizes the dimensions and chemical compositions of the unirradiated AREVA-provided clad (similar to HBR clad) compared with the nominal commercial Zircaloy-4 cladding alloys.

Table 1. Dimensions and chemistry of H. B. Robinson (HBR) type Zircaloy-4 used in the Oak Ridge National Laboratory test program (--- = below the detection limit)

\begin{tabular}{|c|c|c|}
\hline Parameter & $\begin{array}{l}15 \times 15 \text { Zircaloy-4 } \\
\text { HBR-type cladding }^{a}\end{array}$ & $\begin{array}{c}\text { Nominal composition of } \\
\text { commercial Zircaloy- } 4, c, c \\
\text { cladding alloys }\end{array}$ \\
\hline Outer diameter, mm & 10.76 & 10.72 \\
\hline Wall thickness, mm & 0.76 & 0.617 \\
\hline Tin, wt \% & --- & $1.29 \pm 0.1$ \\
\hline Niobium, wt \% & --- & --- \\
\hline Oxygen, wt \% & $\approx 0.13$ & 0.120 \\
\hline Iron, wt \% & --- & --- \\
\hline Chromium, wt \% & --- & --- \\
\hline Nickel, wppm & --- & --- \\
\hline Sulfur, wppm & --- & --- \\
\hline Carbon, wppm & --- & --- \\
\hline Hafnium, wppm & --- & --- \\
\hline Silicon, wppm & --- & --- \\
\hline Nitrogen, wppm & --- & --- \\
\hline Hydrogen, wppm & $\approx 20$ & 5 \\
\hline
\end{tabular}

${ }^{a}$ ORNL data based on AREVA lots received in 2014.

${ }^{b}$ ASTM B811. Source: M. C. Billone, T. Burtseva, and Y. Yan. "Overview of Spent Nuclear Fuel Program: Test Plan and High Burnup Cladding at ANL,” NRC Program Review Meeting, Argonne National Laboratory, Argonne, IL, July 7, 2010.

'ORNL/TM-9591/V1\&R1, "Physical and Dccay Characteristics of Commerical LWR Spent Fuel, January 1986. 
Irradiated materials used in the ORNL test program are high-burnup HBR PWR fuel rods received by ORNL in 2008. They were from a $15 \times 15$ assembly of the HBR plant Unit 2 [8] that was operated for seven cycles and reached a rod-average burnup of $67 \mathrm{GWd} / \mathrm{MTU}$ ( $73 \mathrm{GWd} / \mathrm{MTU}$ peak pellet). The fuel enrichment is $2.90 \%$. The nominal fuel pellet dimensions are $9.06 \mathrm{~mm}$ diameter $\times 9.93 \mathrm{~mm}$ height, and the active fuel height is $3.66 \mathrm{~m}$. The cladding is cold-worked/stress-relieved Zircaloy-4, measuring $10.77 \mathrm{~mm}$ OD and $9.25 \mathrm{~mm}$ inner diameter (ID), with a nominal tin content of $1.42 \%$. The rods were pressurized with helium to $2.0 \mathrm{MPa}$ during initial fabrication. A detailed description of the as-fabricated cladding, the irradiation history, and the nondestructive testing results (eddy current, profilometry, fission-gas release, etc.) is provided in a 2001 Electric Power Research Institute report [8].

Irradiated HBR fuel used in the ORNL test program is summarized in Table 2. Detailed characterization was performed to determine the fuel morphology, fuel-cladding bond, corrosion layer, and hydride morphology. Figure 1 shows a low magnification image of the fuel morphology, which reveals the typical reactor start-up and shut-down cracks.

Table 2. Characteristics of high-burnup H. B. Robinson fuel rods for the Oak Ridge National Laboratory hydride reorientation test ${ }^{a}$

\begin{tabular}{|l|l|}
\hline Parameter & H. B. Robinson \\
\hline Reactor & Pressurized water reactor \\
\hline Enrichment, wt \% & 2.90 \\
\hline Rod average burnup, GWd/MTU & $63-67$ \\
\hline Discharge date & 1995 \\
\hline Fast fluence, $10^{25} \mathrm{n} / \mathrm{m}^{2}$ & 14 \\
\hline Cladding & $15 \times 15$ Zircaloy-4 \\
\hline Initial wall thickness, $\mathrm{mm}$ & 0.76 \\
\hline Outer diameter oxide, $\mu \mathrm{m}$ & $\leq 100$ \\
\hline Hydrogen pickup, wppm & $\leq 800$ \\
\hline Fueled & Yes \\
\hline
\end{tabular}




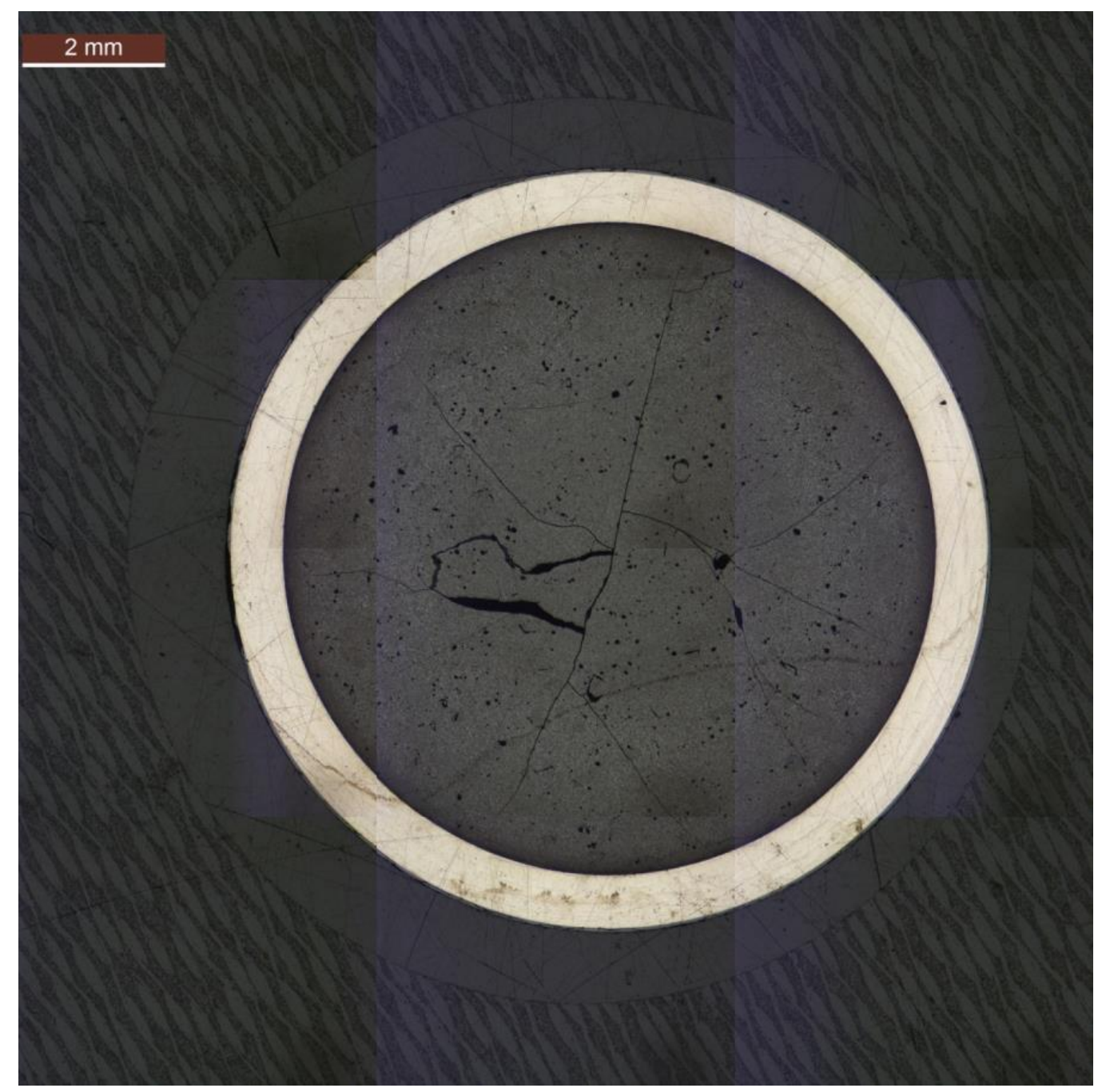

Fig. 1. High-burnup H. B. Robinson fuel morphology for Sample 607D4A.

\subsection{Equipment for Sample Preparation}

Hydride reorientation tests were conducted with 152-mm-long Zircaloy-4 cladding samples (see Table 1 for cladding geometry), which were hydrogen charged for a target hydrogen concentration of $300 \mathrm{wppm}$. After hydrogen charging, the hydrided samples were subject to hydride reorientation to simulate dry cask storage drying conditions, which consists of a high pressure piping system and test chamber within a programmable crucible furnace. The hydrided sample was sealed (end-cap welded) at one end and connected to the high pressure piping system within the test chamber at the other end. The piping system was used to internally pressurize the sample to cause a hoop stress ranging up to $150 \mathrm{MPa}$.

The hydriding apparatus consists of a closed stainless steel tube that contains zirconium alloy specimens and hydrogen gas, as shown in Fig. 2. The tube is heated to facilitate hydrogen absorption by the metal. By controlling the initial hydrogen gas pressure in the vessel and the temperature profile, hydrogen concentration can be processed selectively. A typical pressure and temperature profile is shown in Fig. 3. 


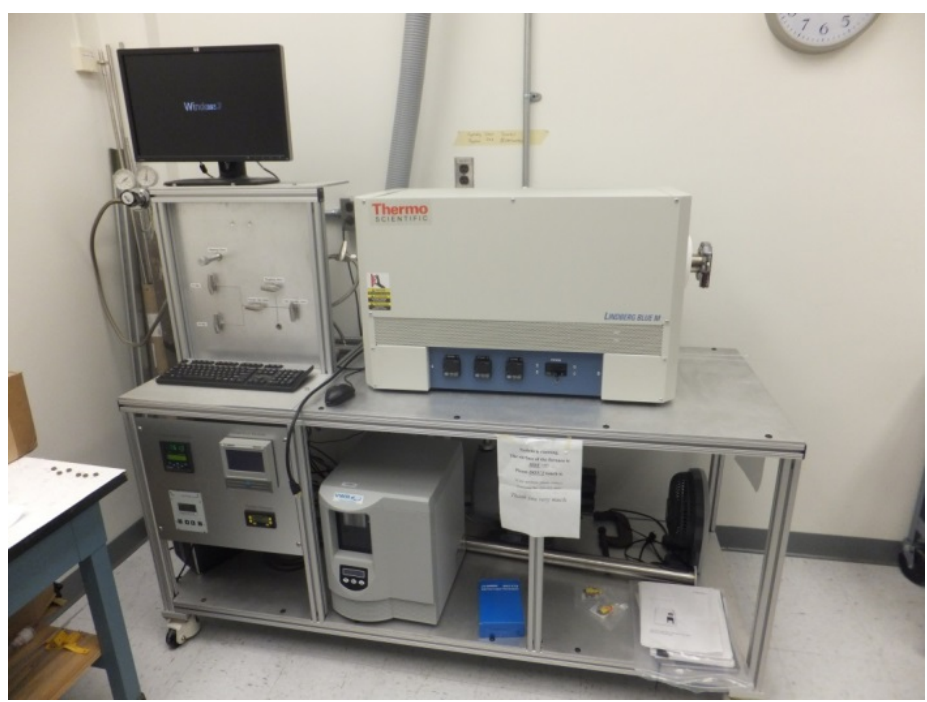

Fig. 2. Hydrogen charging apparatus.

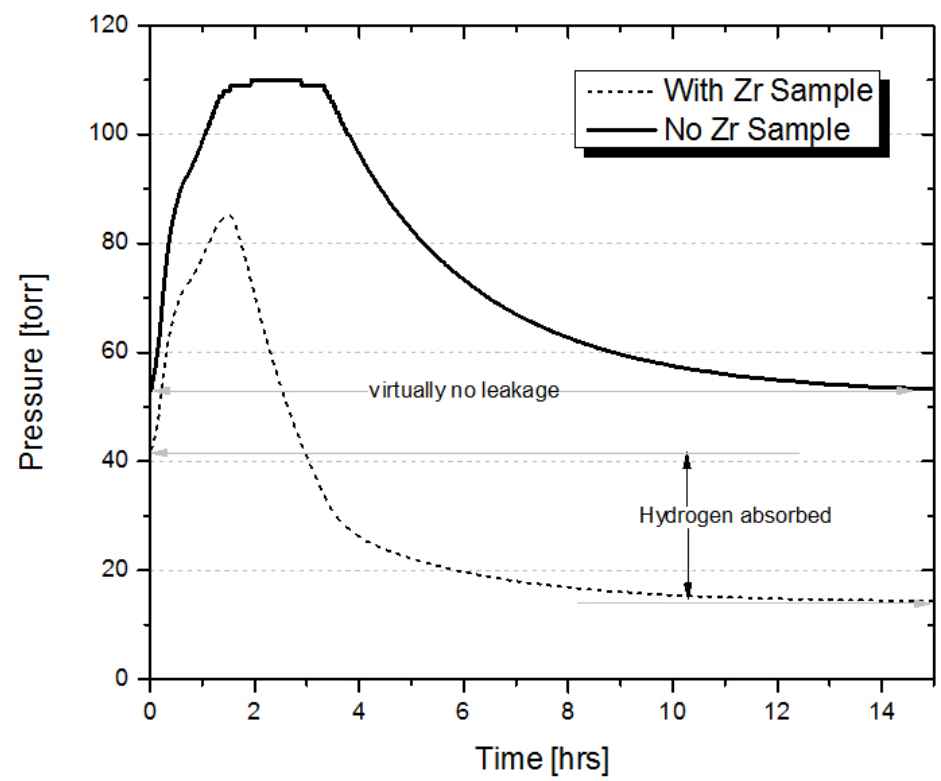

Fig. 3. A typical pressure and temperature profile of the hydrogen charging process.

An Astro Arc Polysoude welder (see Fig. 4) was used for automatic orbital welding of the cladding. A circular movement of the welding torch/electrode around fuel cladding, controlled by the welder power source, creates an orbital weld. This welder can be operated remotely with manipulators in a hot cell. 


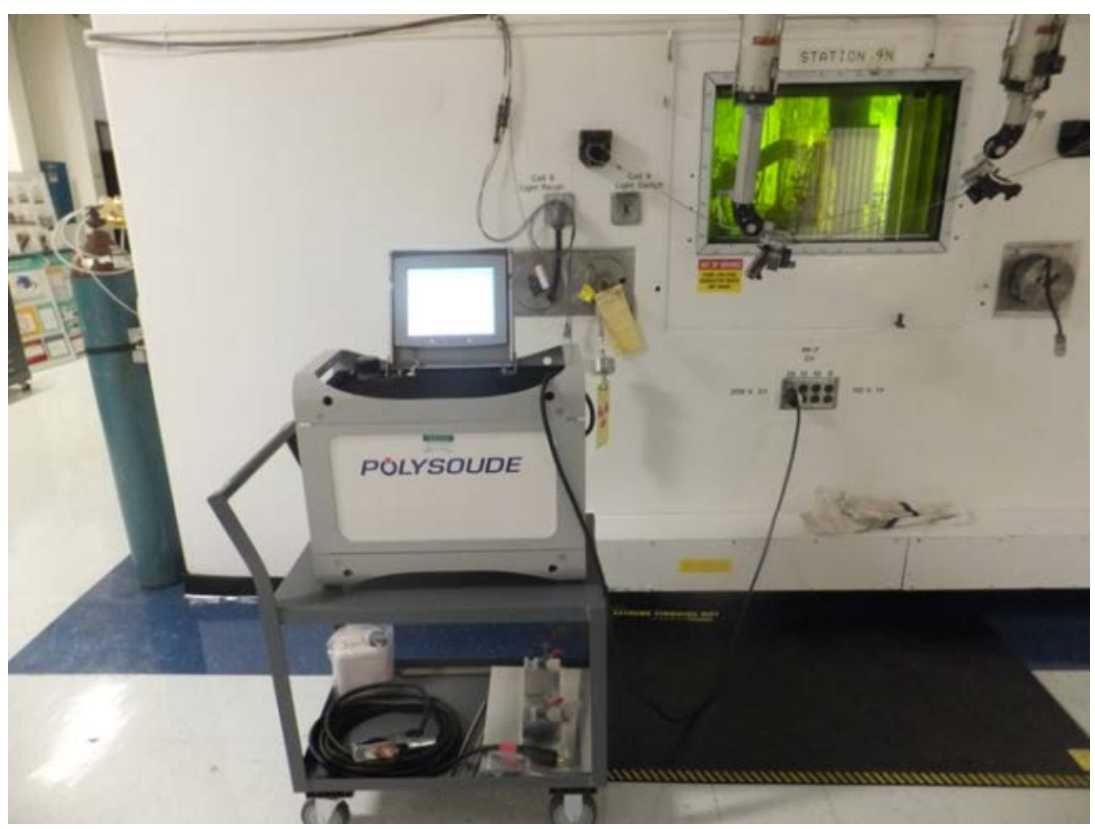

Fig. 4. An Astro Arc Polysoude tubing welder.

\subsection{Hydride Reorientation System}

The reorientation system consists of a high pressure piping system and test chamber within a programmable crucible furnace (see Fig. 5). The system was installed into the hot cell in FY16. Calibrations and benchmark tests were performed with unirradiated materials. For each experiment, a 6in.-long specimen was welded with two end plugs, with one end sealed and the other end connected to the high-pressure piping system within the test chamber. The test chamber was purged with pure argon gas in order to remove air and moisture contents, and then the sample was internally pressurized to cause a hoop stress ranging from 0 to $150 \mathrm{MPa}$ [5]. Pressurized samples were subjected to a preprogrammed temperature profile for up to five cycles, with each cycle being heated to $400^{\circ} \mathrm{C}$, held for 2 hours, and slow-cooled/heated $\left(1^{\circ} \mathrm{C} / \mathrm{min}\right)$ to $170^{\circ} \mathrm{C}$; the final cycle cooled from $170^{\circ} \mathrm{C}$ to room temperature (RT). Hoop stress was calculated using values $r=4.62 \mathrm{~mm}$ for inner radius and $t=0.76 \mathrm{~mm}$ for the wall thickness of the HBR Zircaloy-4 cladding. 


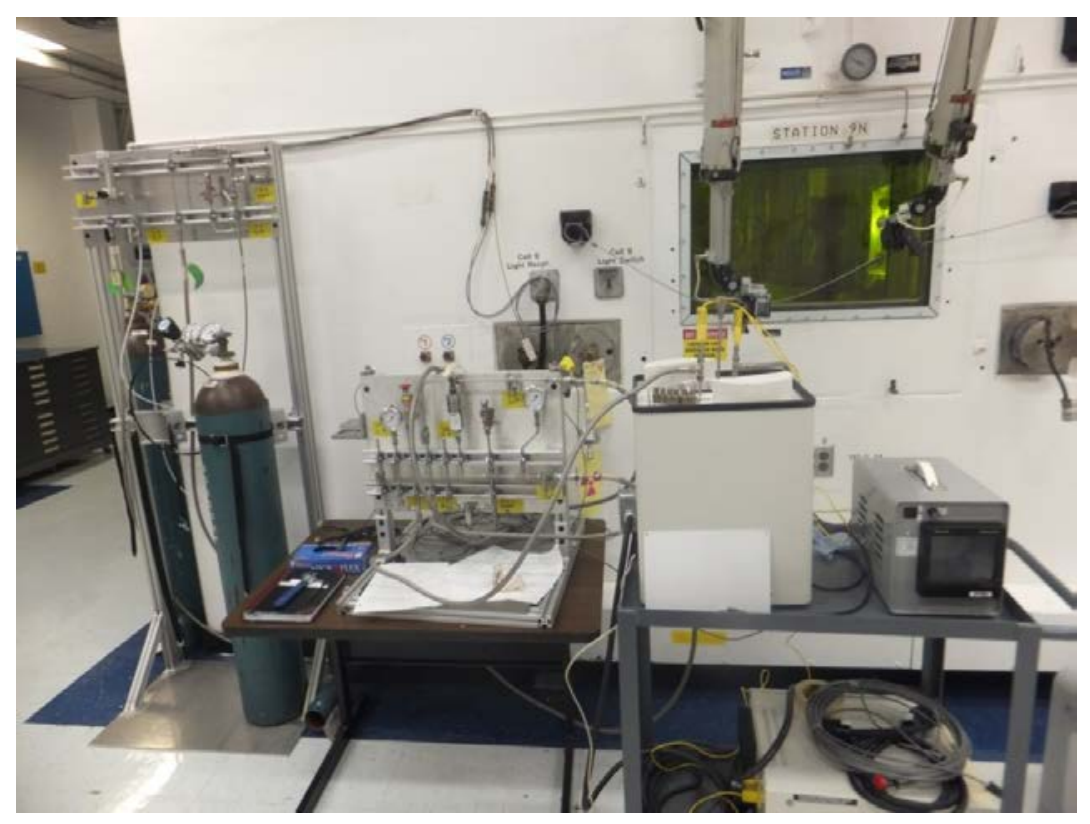

(a)

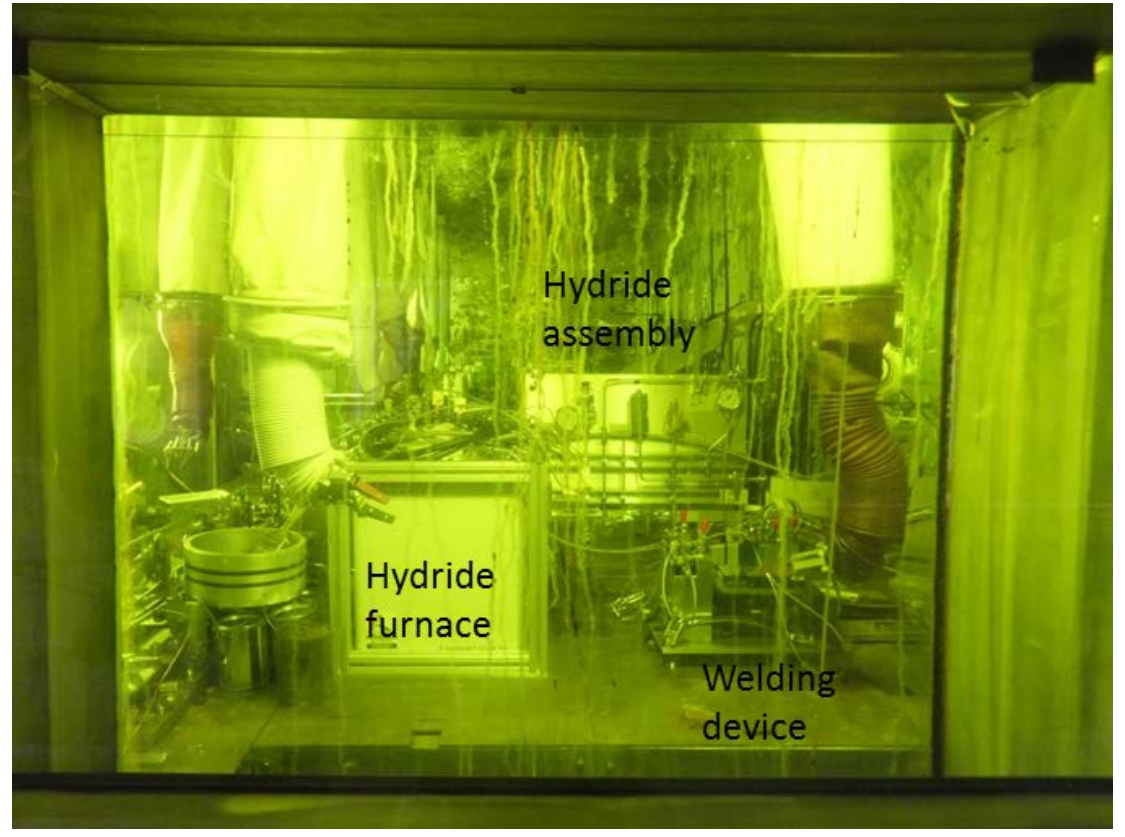

(b)

Fig. 5 The hydride reorientation system (a) before and (b) after installed into the hot cell. 


\section{MATERIALS HYDRIDING AND CHARACTERIZATION}

The Zircaloy-4 cladding samples were hydrogen charged by the gaseous method, as described in Sect. 2 . Gas charging was conducted under stress-free conditions. The target hydrogen concentrations can range from tens to a few thousand weight parts per million. The most important ranges for licensing and modeling real reactor fuel are usually less than 1,000 wppm. For this work, the Zircaloy-4 was hydrided to a target concentration of 300-400 wppm, which is similar to hydrogen content of HBR high burnup cladding to be tested in a hot cell.

Metallographic examinations were performed on hydrided Zircaloy-4 samples. As shown in Fig. 6, the hydride density increases as the hydrogen concentration in the sample increases. Hydrogen measurements indicated the hydrogen content of the specimens shown in Fig. 6 range from 70 to 320 wppm.

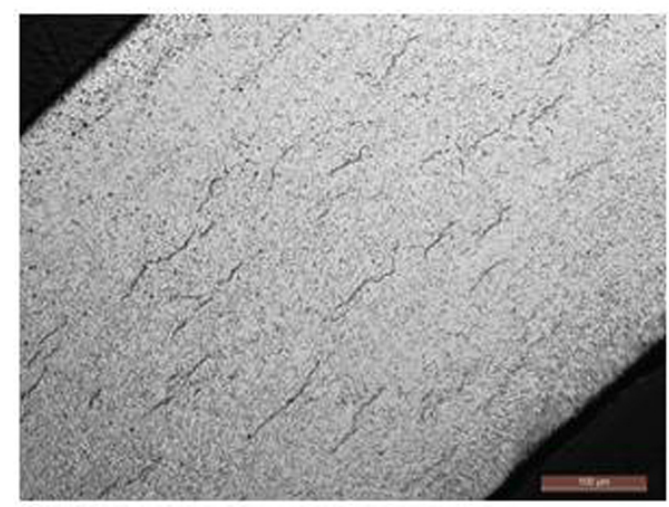

$\approx 70 \mathrm{wppm}$

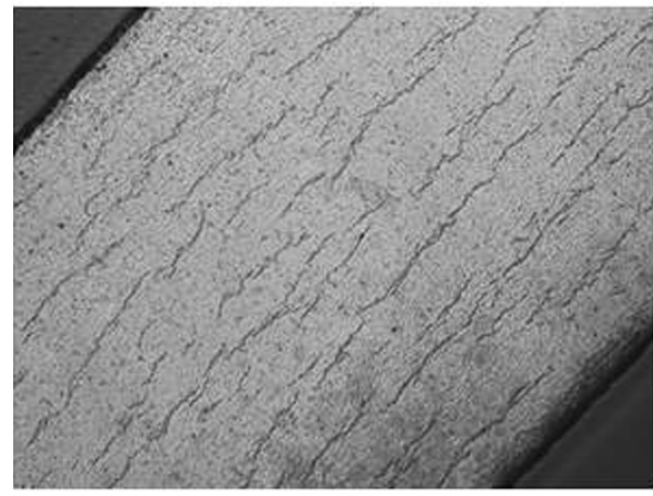

$\approx 240 \mathrm{wppm}$

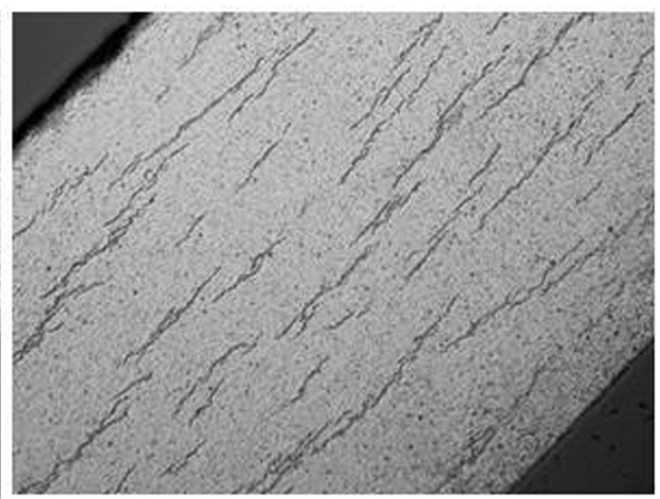

$\approx 150$ wppm

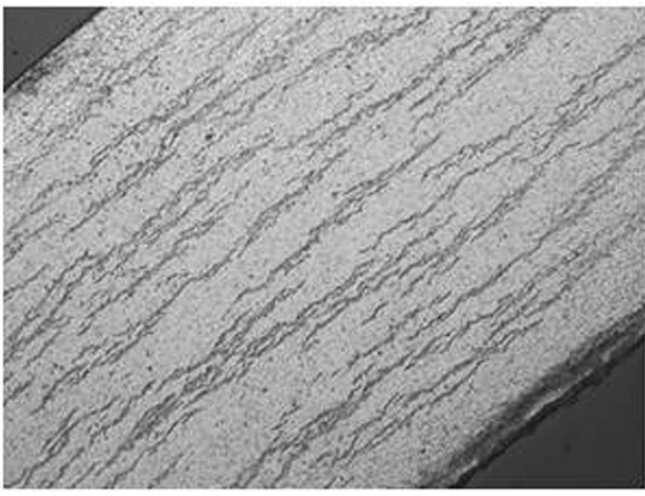

$\approx 320 \mathrm{wppm}$

Fig. 6. Micrographs showing typical, uniform circumferential hydride distributions in hydrogen charged Zircaloy-4. 


\section{OUT-OF-CELL HYDRIDE REORIENTATION TESTING}

To optimize the in-cell test condition, four out-of-cell hydride reorientation tests with hydrided HBR cladding were performed. The out-of-cell test results have provided a guideline to in-cell hydride reorientation procedures with high burnup HBR fuel segments.

\subsection{HR-HBR\#1, $145 \mathrm{MPa}$ at $400^{\circ} \mathrm{C}$, one cycle}

A hydride reorientation (HR) test HR-HBR\#1 on a hydrided $15 \times 15$ Zircaloy- 4 was conducted at the maximum hoop stress of $145 \mathrm{MPa}$ and the hold temperature $\mathrm{T}=400^{\circ} \mathrm{C}$. Total test time was over 72 hours. After fabrication, the specimen was assembled into a holder within the furnace for heating to $400^{\circ} \mathrm{C}$, held at $400^{\circ} \mathrm{C}$ for 2 hours, cooled at $5^{\circ} \mathrm{C} / \mathrm{h}$ to $170^{\circ} \mathrm{C}$, then cooled at a faster rate from $170^{\circ} \mathrm{C}$ to RT. The internal pressure was dynamically monitored with a digital pressure transducer.

Figure 7 shows the temperature and pressure history for a drying-storage simulation experiment conducted with a $2 \mathrm{~h}$ hold time and one-cycle cooling. The plotted temperature is a thermocouple reading near the specimen surface. The drying simulation also is referred to as radial hydride treatment in this work.

Figure 8 shows the hydride morphology of Sample HR-HBR\#1 with hydrogen content $\mathrm{H} \approx 274$ wppm. The specimen was sectioned at the midplane of a 6-in.-long sample. The radial hydrides can be observed clearly. The maximum length of radial hydrides is about 50-60 $\mu \mathrm{m}$, as they often are terminated when intersecting with circumferential hydrides. Figure 9 includes micrographs taken in eight areas in different circumferential directions of Sample HR-HBR\#1, which shows that hydrides are uniformly distributed in circumferential directions.

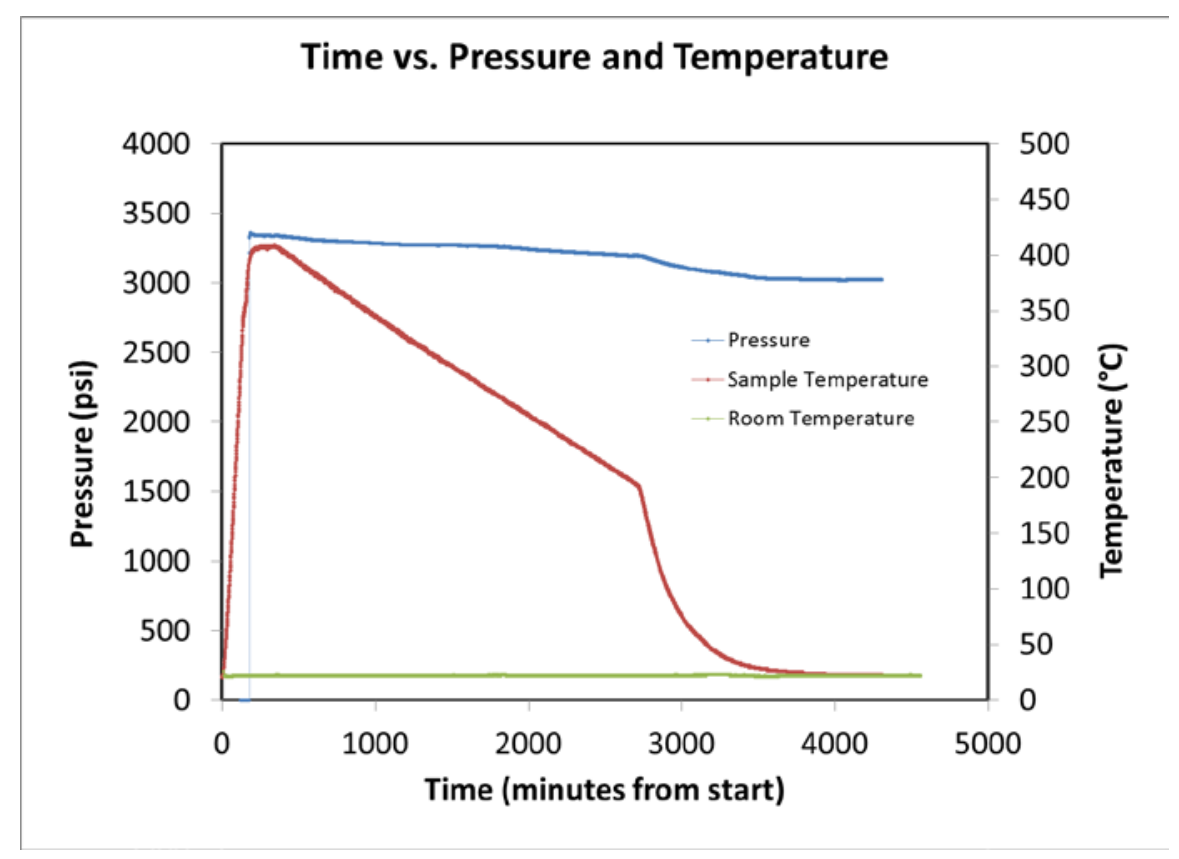

Fig. 7. Pressure and sample temperature as a function of time for Test HR-HBR\#1. 


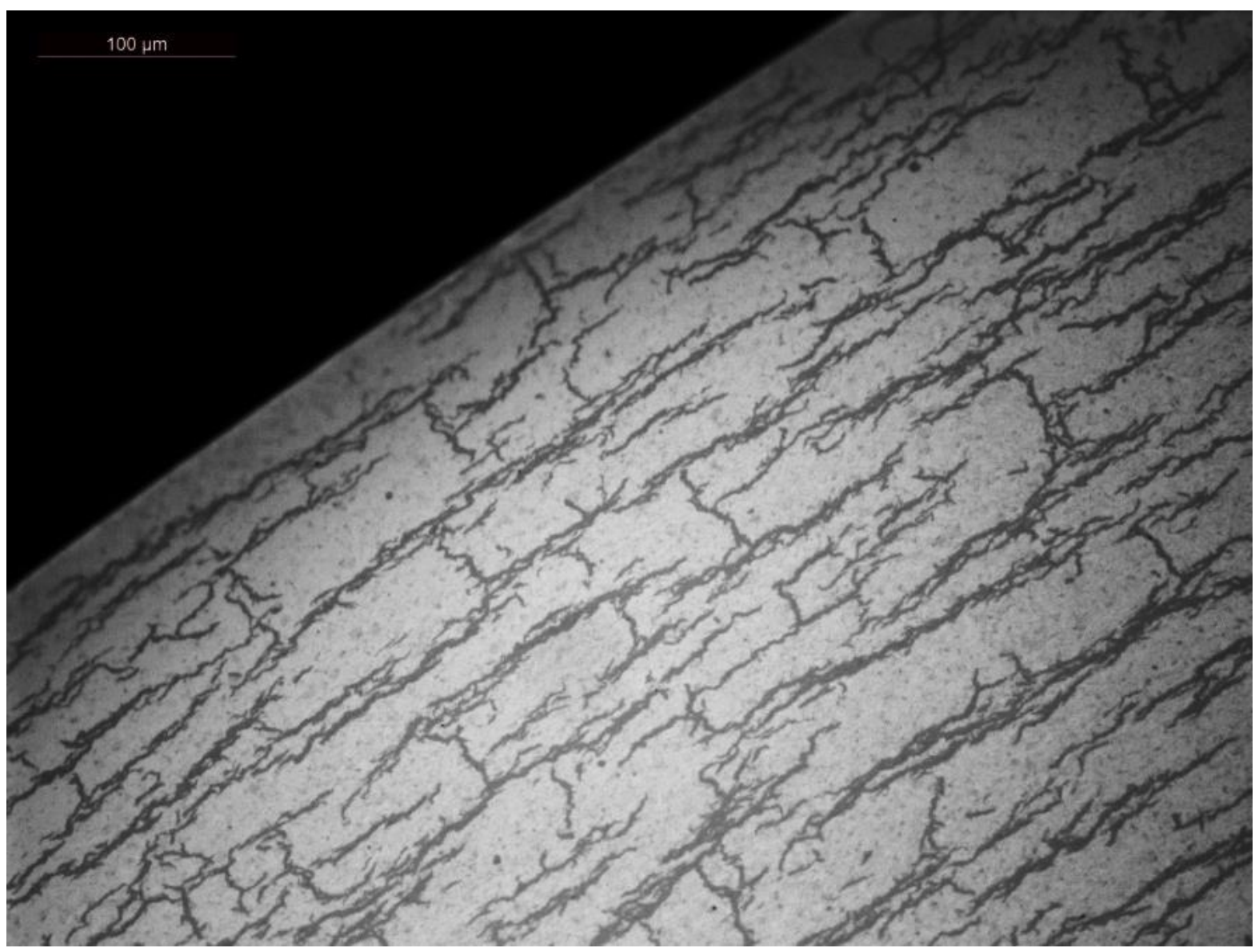

Fig. 8. High magnification micrograph showing radial hydrides of Sample HR-HBR\#1 with hydrogen content $H \approx 274$ wppm.

The specimen was sectioned at the midplane of a 6-in.-long sample. 

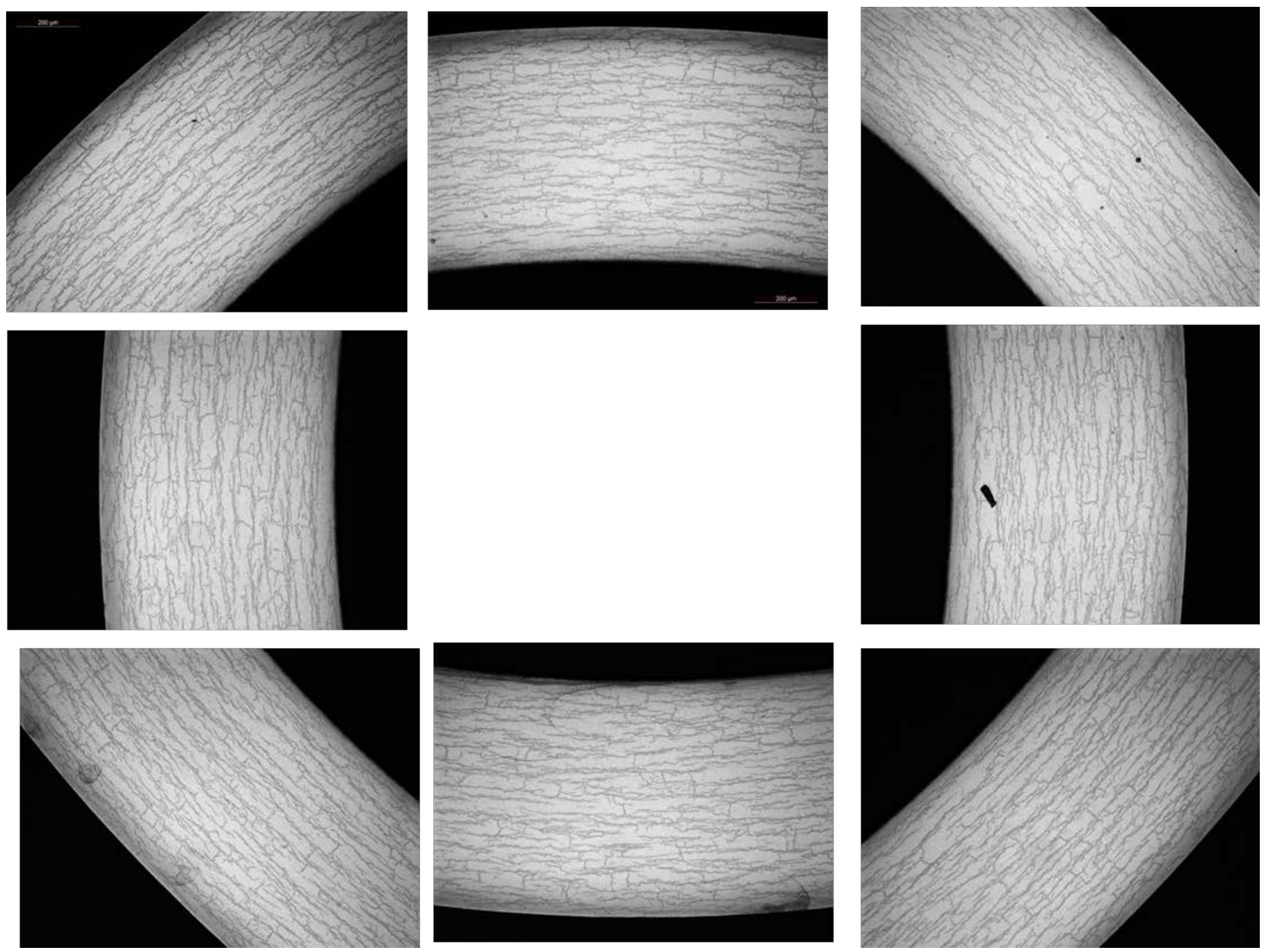

Fig. 9. Radial hydride distribution shown in eight areas in different circumferential directions of Sample HR-HBR\#1. The specimen was sectioned at the midplane of a 6-in.-long sample. 


\subsection{HR-HBR\#2, $145-150 \mathrm{MPa}$ at $400^{\circ} \mathrm{C}$, five cycles}

Test HR-HBR\#2 was conducted on a hydrided $15 \times 15$ Zircaloy- 4 at the maximum hoop stress of $145 \mathrm{MPa}$ and the target hold temperature $\mathrm{T}=400^{\circ} \mathrm{C}$. However, thermal cycling was performed to increase the radial hydrides. After fabrication, the specimen was assembled into a holder within the furnace for heating to target temperature $400^{\circ} \mathrm{C}$, held for 2 hours, cooled at $1^{\circ} \mathrm{C} / \mathrm{min}$ to $170^{\circ} \mathrm{C}$, and then heated at $1^{\circ} \mathrm{C} / \mathrm{min}$ to target hold temperature $400^{\circ} \mathrm{C}$ again for five cycles. The sample was furnace cooled from $170^{\circ} \mathrm{C}$ to RT for the last cycle. Figure 10 shows the temperature and pressure history for HR-HBR\#2. The plotted temperature is a thermocouple reading near the specimen surface.

Figure 11 shows the hydride morphology of Sample HR-HBR\#2 with hydrogen content $\mathrm{H} \approx 286$ wppm. The specimen was sectioned at the midplane of a 6-in.-long sample. The radial hydride can be observed clearly. The maximum length of the radial hydride is about 50-60 $\mu \mathrm{m}$, similar to HR-HBR\#1. However, the density of radial hydrides in HR-HBR\#2 is much higher than the density in HR-HBR\#1, mainly because of multithermal cycles. Figure 12 shows radial hydride distribution in eight areas in different circumferential directions of Sample HR-HBR\#2.

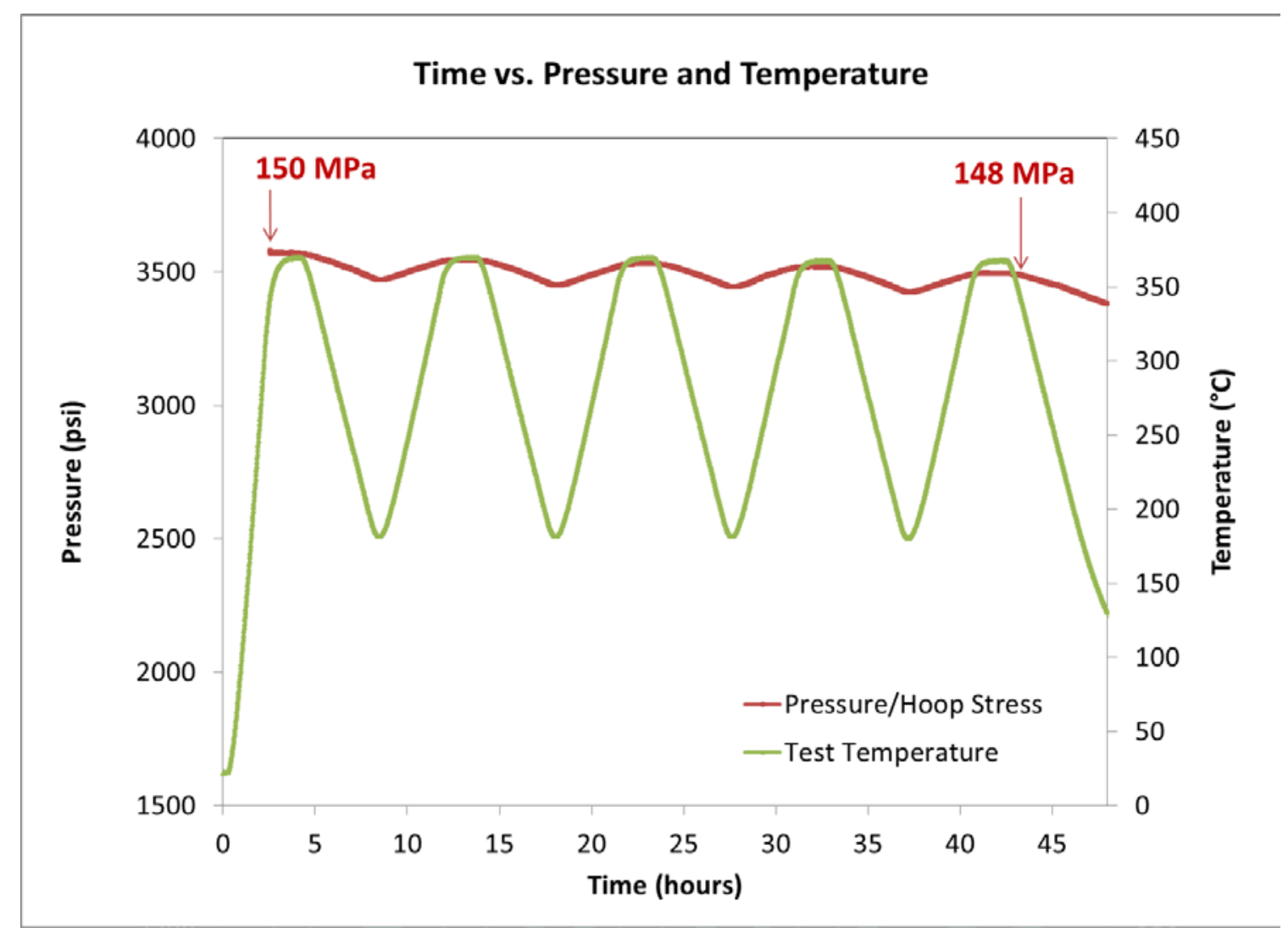

Fig. 10. Pressure and sample temperature as a function of time for Test HR-HBR\#2. 


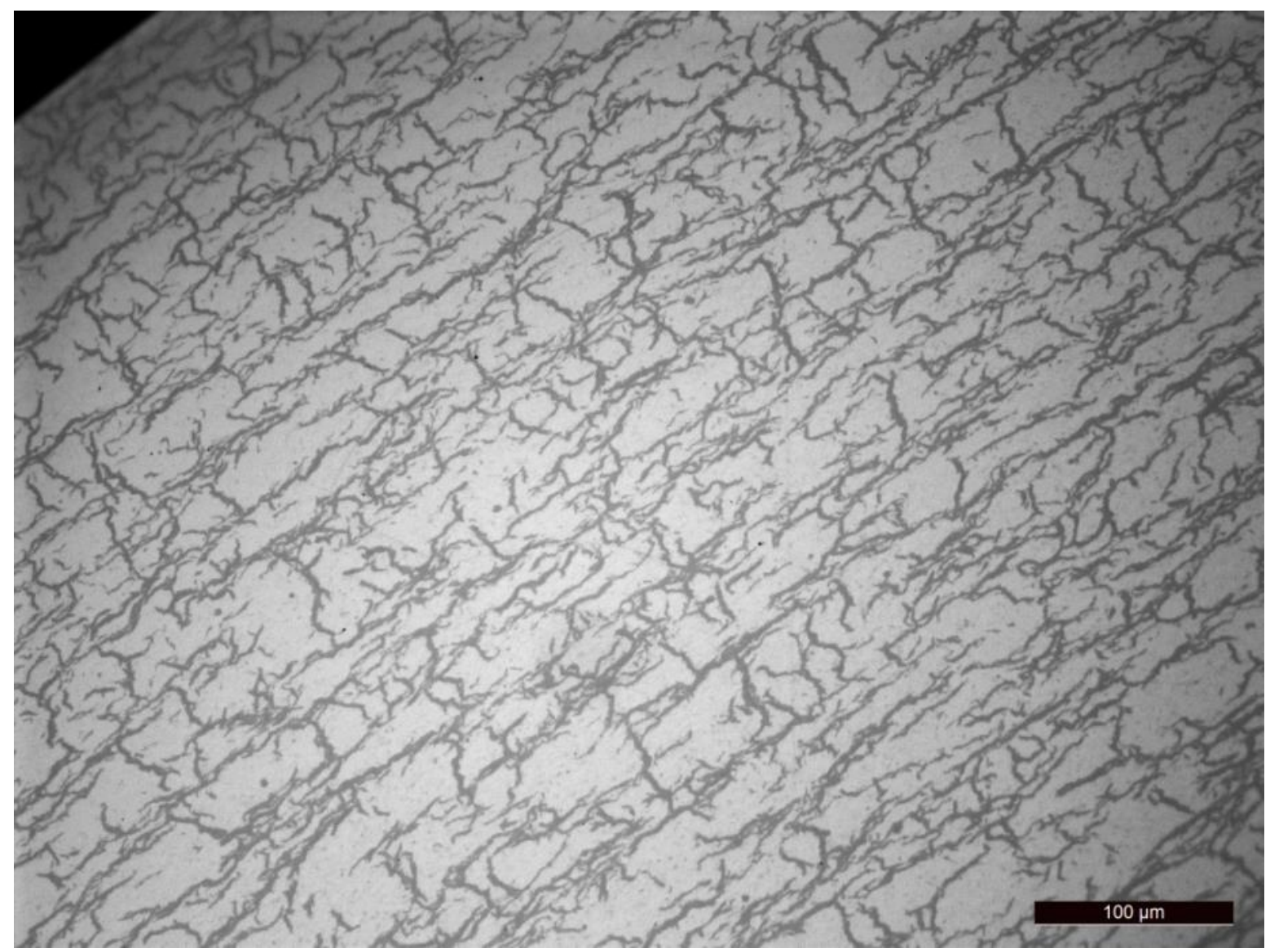

Fig. 11. High magnification micrograph showing radial hydrides of Sample HR-HBR\#2 with hydrogen content $\mathbf{H} \approx 286 \mathrm{ppm}$. The specimen was sectioned at the midplane of a 6-in.-long sample. 


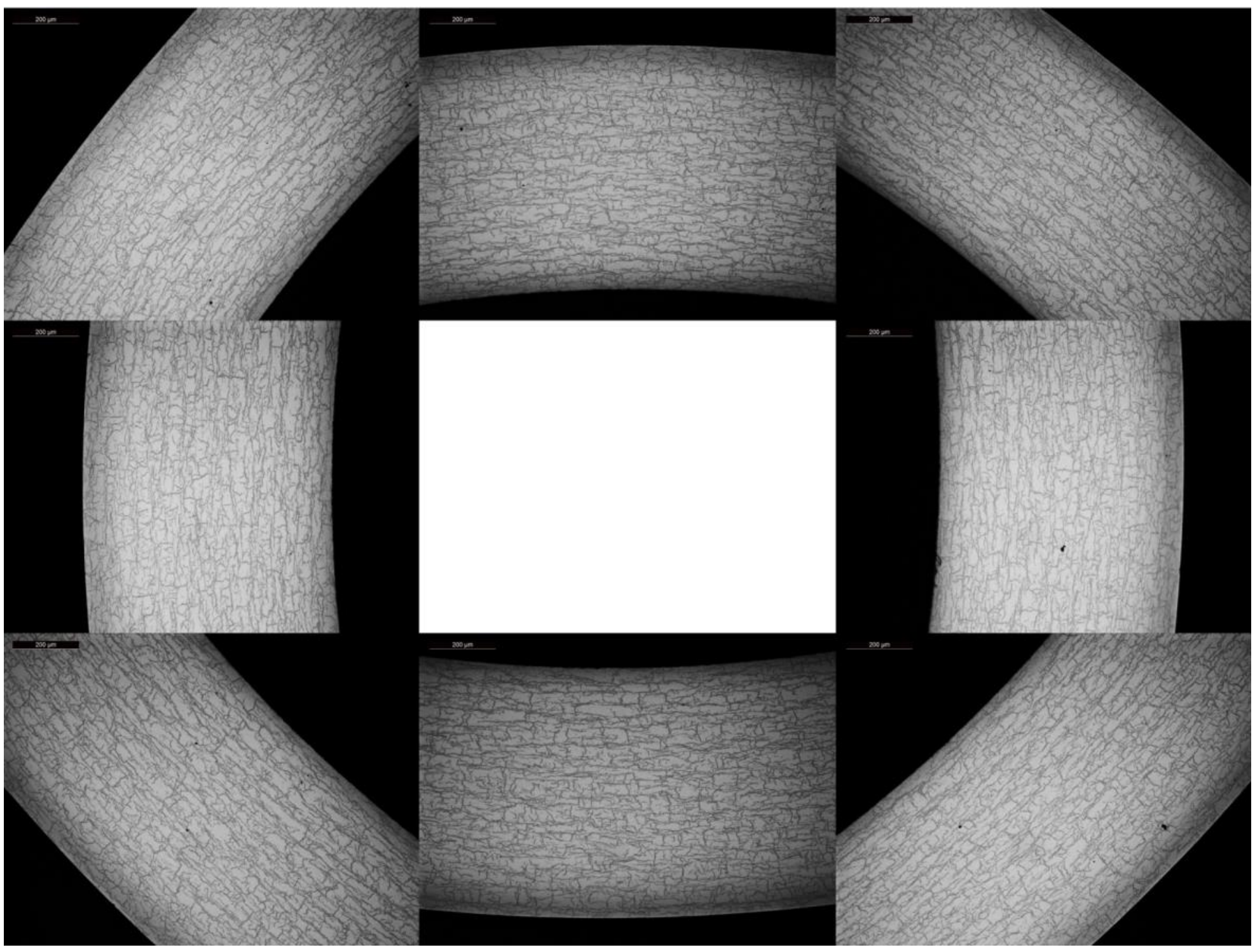

Fig. 12. Radial hydride distribution shown in eight areas in different circumferential directions of Sample HR-HBR\#2. The specimen was sectioned at the midplane of a 6-in.-long sample. 


\subsection{HR-HBR\#3, $100 \mathrm{MPa}$ at $400^{\circ} \mathrm{C}$, five cycles}

Test HR-HBR\#3 was conducted on a hydrided $15 \times 15$ Zircaloy- 4 at the maximum hoop stress of $100 \mathrm{MPa}$ and the hold temperature $\mathrm{T}=400^{\circ} \mathrm{C}$. After fabrication, the specimen was assembled into a holder within the furnace for heating to $400^{\circ} \mathrm{C}$, held at $400^{\circ} \mathrm{C}$ for 2 hours, cooled at $1^{\circ} \mathrm{C} / \mathrm{min}$ to $170^{\circ} \mathrm{C}$, and then heated at $1{ }^{\circ} \mathrm{C} / \mathrm{min}$ to $400^{\circ} \mathrm{C}$ again for five cycles. The sample was furnace cooled from $170^{\circ} \mathrm{C}$ to RT for the last cycle. Figure 13 shows the temperature and pressure history for HR-HBR\#3. The plotted temperature is a thermocouple reading near the specimen surface.

Figure 14 shows the hydride morphology of Sample HR-HBR\#3 with hydrogen content $\mathrm{H} \approx 310$ wppm. The specimen was sectioned at the midplane of a 6-in.-long sample. The radial hydrides can be observed clearly in Figure 14. The maximum length of the radial hydride is $<30 \mu \mathrm{m}$. The radial hydride ratio of HR-HBR\#3 also is lower than HR-HBR\#2. Figure 15 shows radial hydride distribution in eight areas in different circumferential directions of Sample HR-HBR\#3.

Time vs. Pressure and Temperature

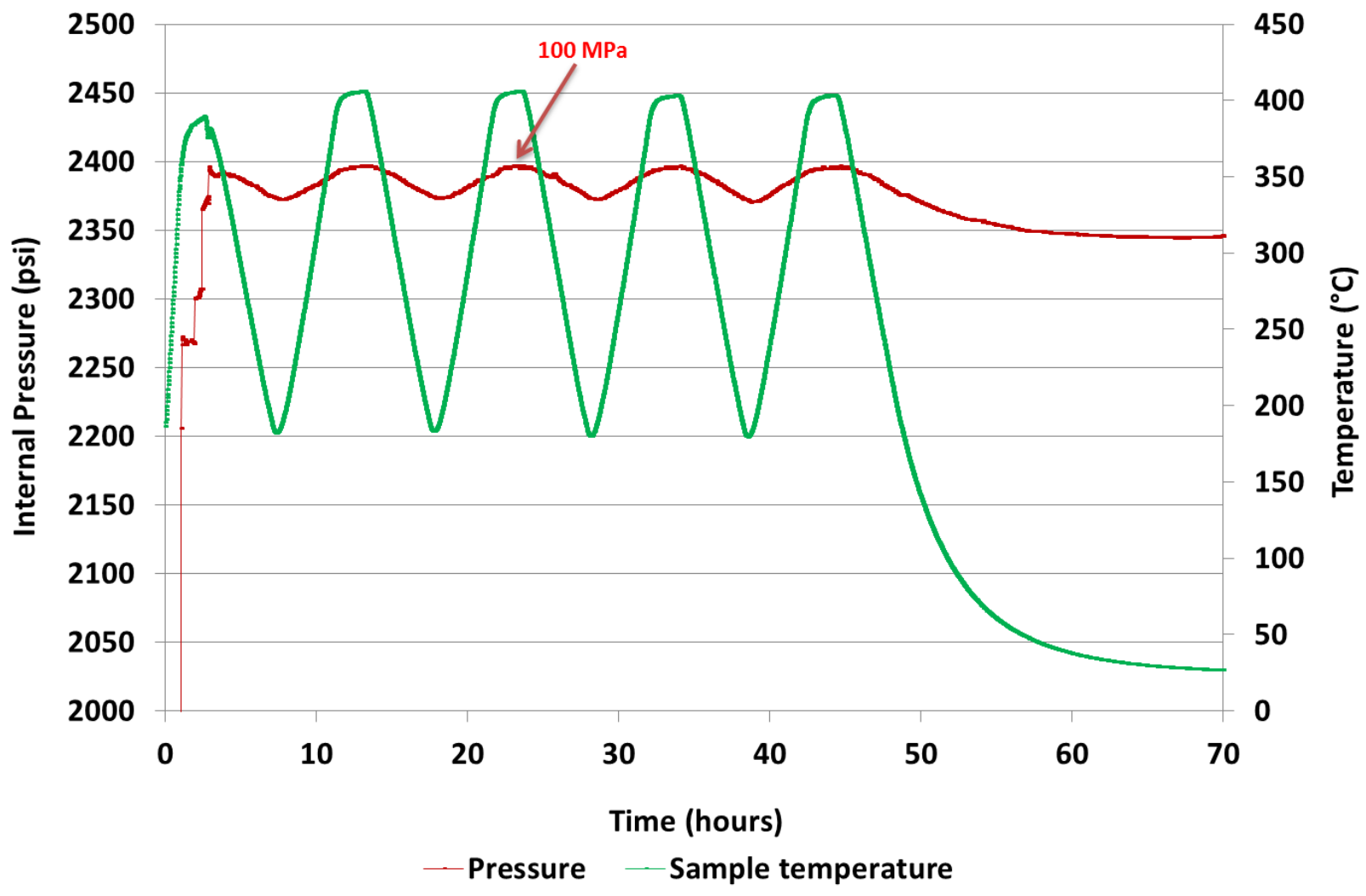

Fig. 13. Pressure and sample temperature as a function of time for Test HR-HBR\#3. 


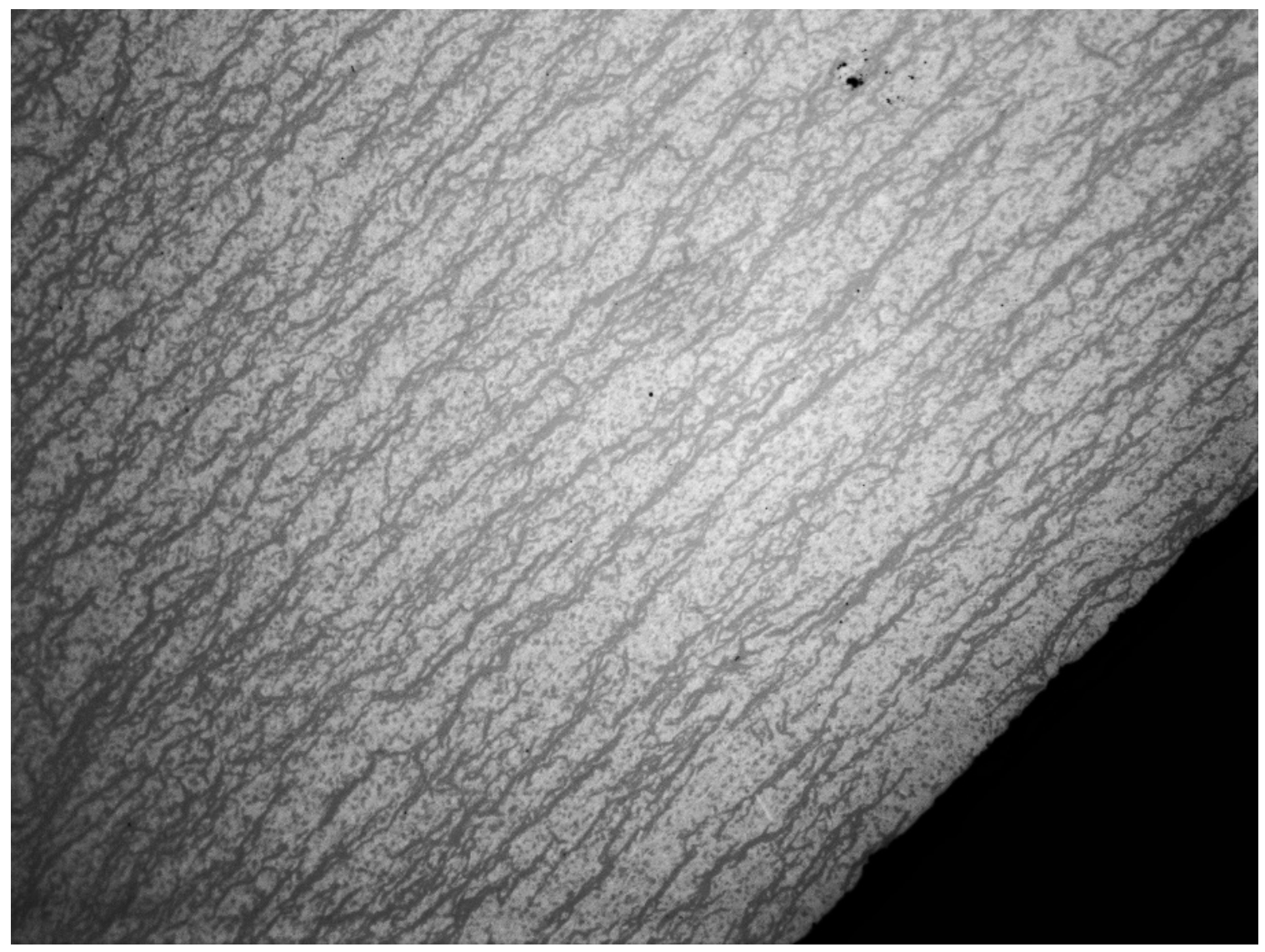

Fig. 14. High magnification micrograph showing radial hydrides of Sample HR-HBR\#3 with hydrogen content $H \approx 310$ ppm.

The specimen was sectioned at the midplane of a 6-in.-long sample. 


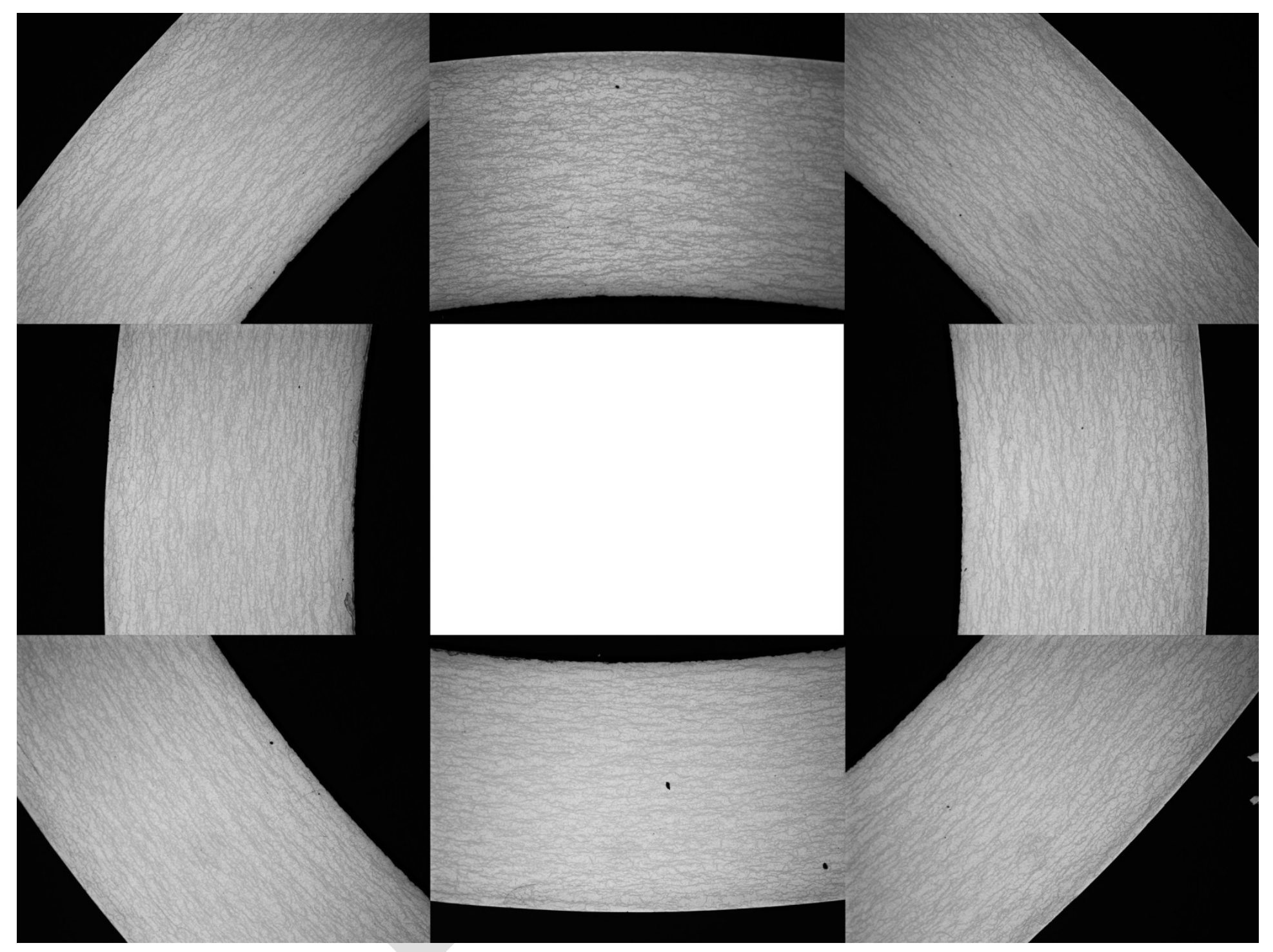

Fig. 15. Radial hydride distribution shown in eight areas in different circumferential directions of Sample HR-HBR\#3. The specimen was sectioned at the midplane of a 6-in.-long sample. 


\subsection{HR-HBR\#4, $120 \mathrm{MPa}$ at $400^{\circ} \mathrm{C}$, five cycles}

Test HR-HBR\#4 was conducted on a hydrided $15 \times 15$ Zircaloy- 4 at the maximum hoop stress of $120 \mathrm{MPa}$ and the hold temperature $\mathrm{T}=400^{\circ} \mathrm{C}$. After fabrication, the specimen was assembled into a holder within the furnace for heating to $400^{\circ} \mathrm{C}$, held at $400^{\circ} \mathrm{C}$ for 2 hours, cooled at $1^{\circ} \mathrm{C} / \mathrm{min}$ to $170^{\circ} \mathrm{C}$, and then heated at $1{ }^{\circ} \mathrm{C} / \mathrm{min}$ to $400^{\circ} \mathrm{C}$ again for five cycles. The sample was furnace cooled from $170^{\circ} \mathrm{C}$ to RT for the last cycle. Figure 16 shows the temperature and pressure history for HR-HBR\#4. The plotted temperature is a thermocouple reading near the specimen surface.

Figure 17 shows the hydride morphology of Sample HR-HBR\#4 with hydrogen content $\mathrm{H} \approx 312$ wppm. The specimen was sectioned at the midplane of a 6-in.-long sample. The radial hydride can be observed. The maximum length of the radial hydride is $<30 \mu \mathrm{m}$. The radial hydride ratio of HR-HBR\#4 also is lower than the ratio of HR-HBR\#2. However, the radial hydride ratio of HR-HRB\#4 is higher than that of HR-HRB\#3 because of the higher pressure. Figure 18 shows radial hydride distribution in eight areas in different circumferential directions of Sample HR-HBR\#4.

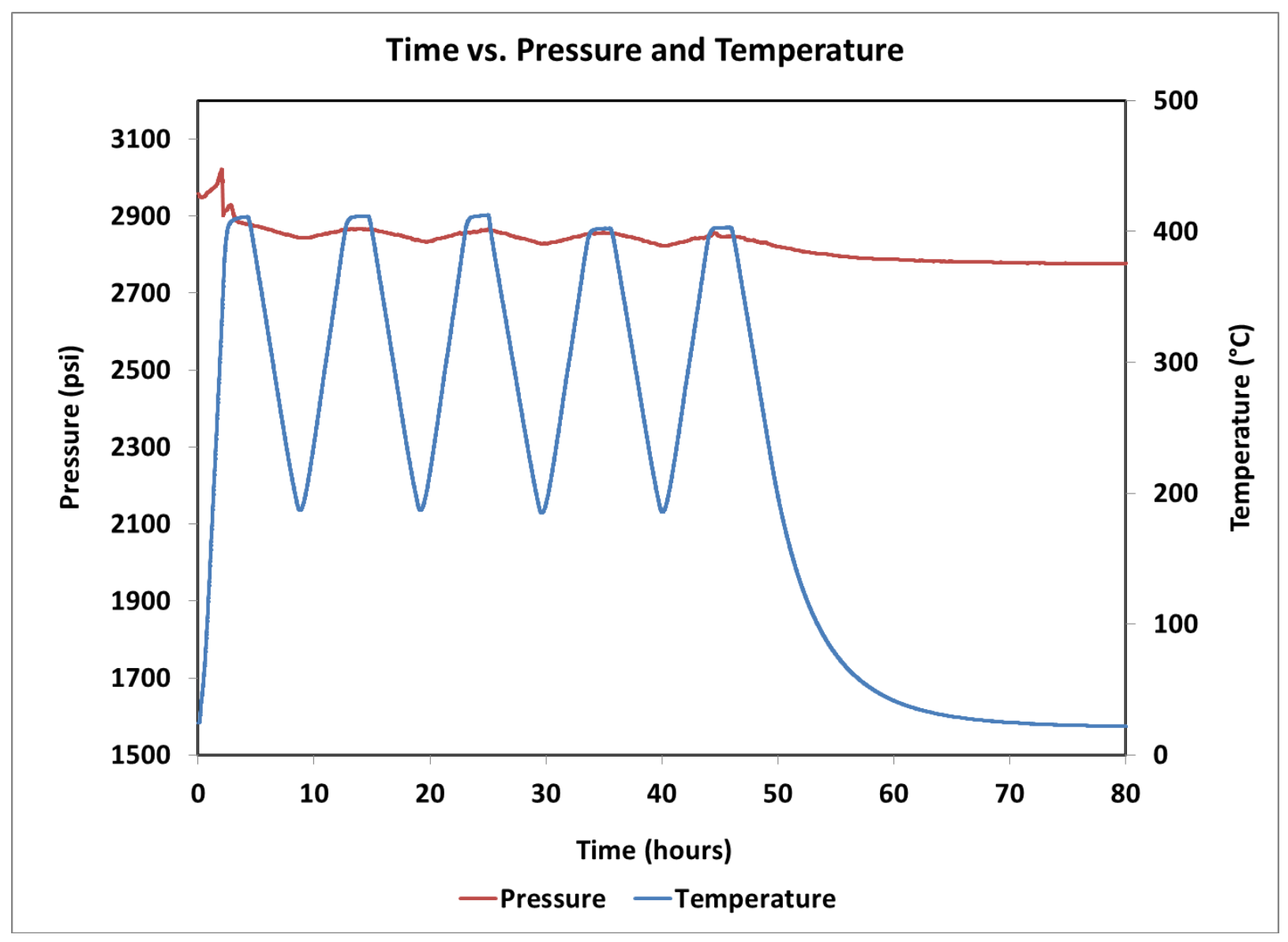

Fig. 16. Pressure and sample temperature as a function of time for Test HR-HBR\#4. 


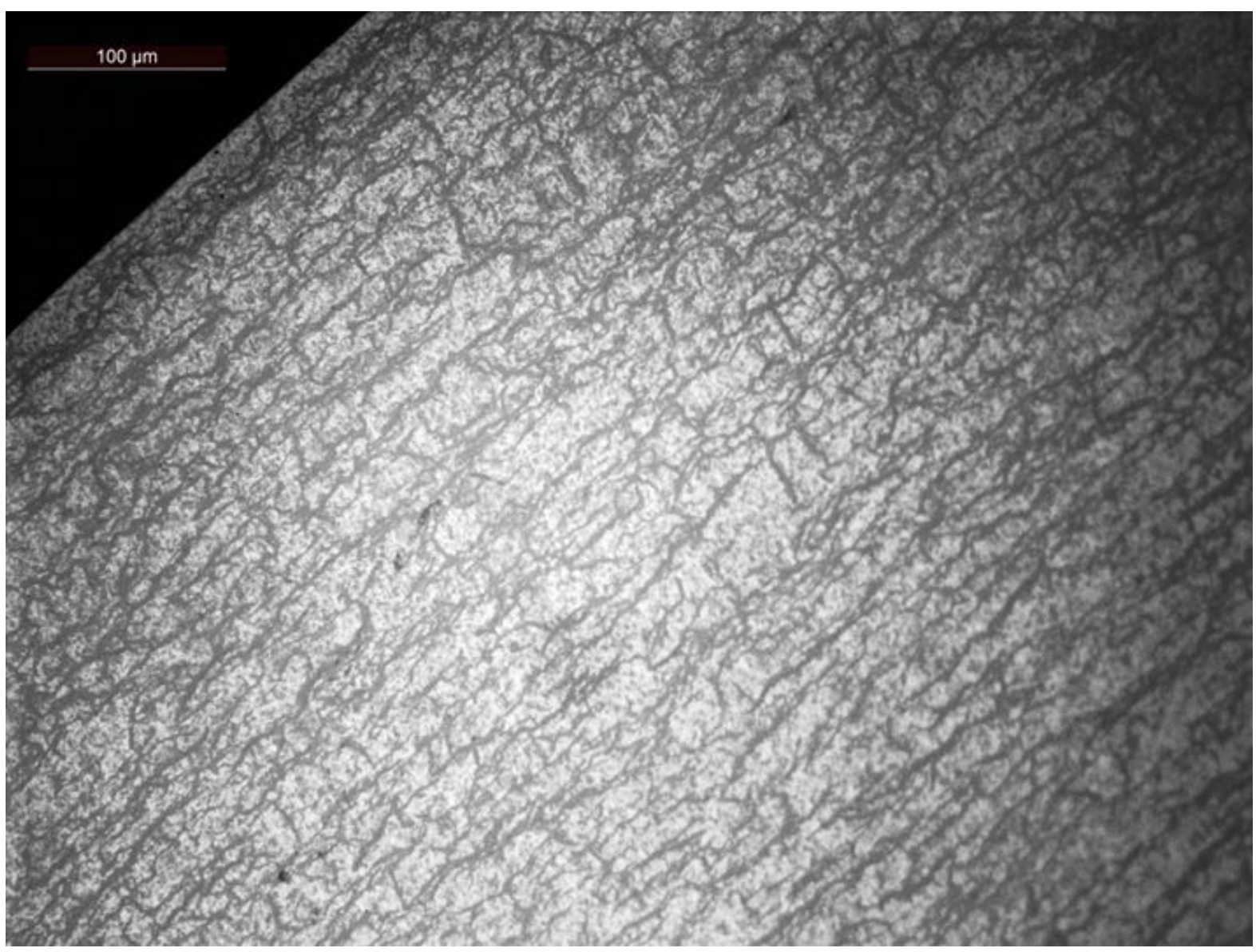

Fig. 17. High magnification micrograph showing radial hydrides of Sample HR-HBR\#4 with hydrogen content $\mathbf{H} \approx 312 \mathbf{p p m}$. The specimen was sectioned at the midplane of a 6-in.-long sample. 


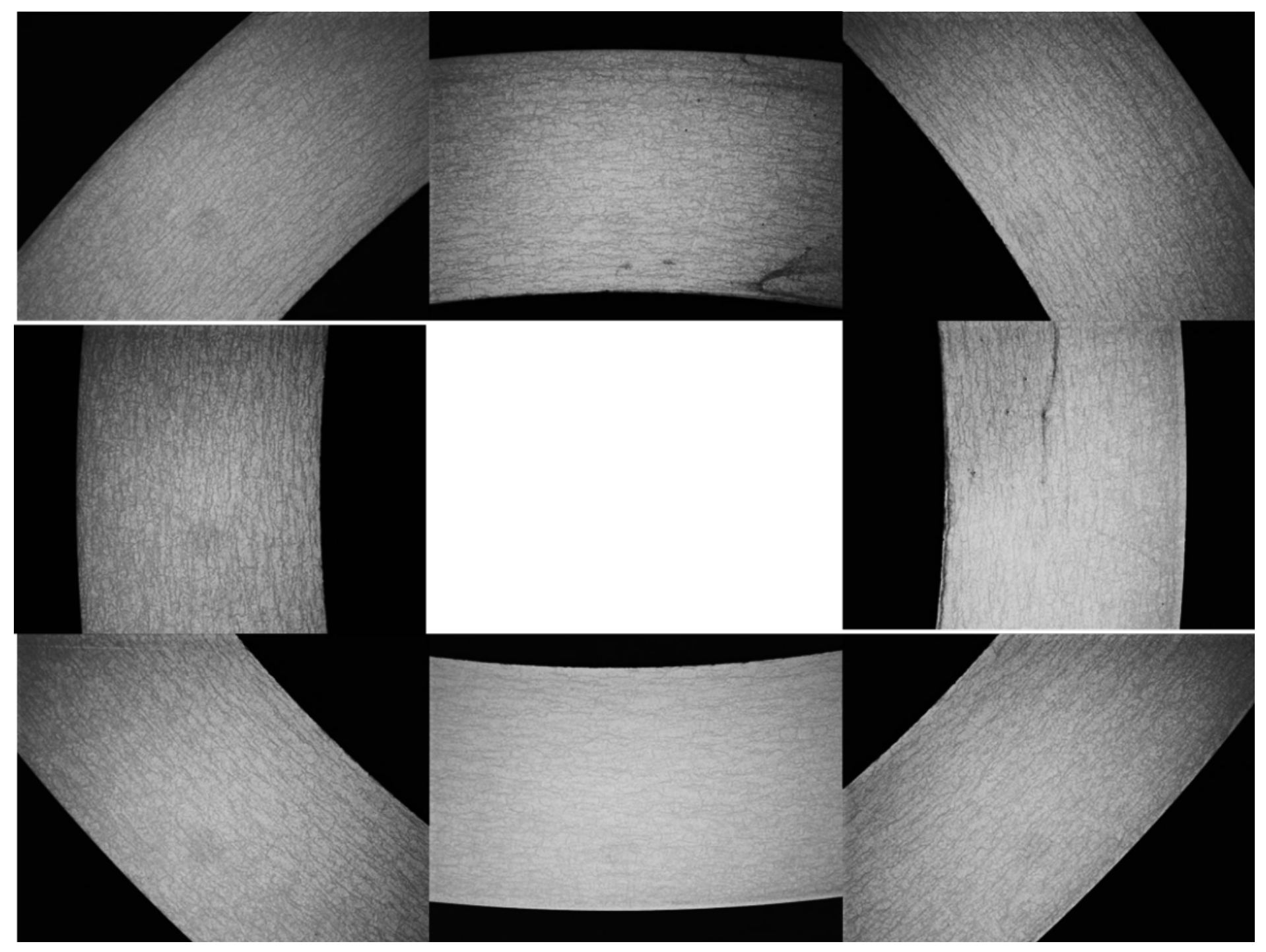

Fig. 18. Radial hydride distribution shown in eight areas in different circumferential directions of Sample HR-HBR\#4. The specimen was sectioned at the midplane of a 6-in.-long sample 


\section{DISCUSSION}

The terminal solid solubility (TSSd) of hydrogen in Zircaloy is shown in Fig. 19 [9-11]. The solubility limit is very low at room temperature ( $<10 \mathrm{wppm}$ is soluble), and $\approx 200 \mathrm{wppm}$ is soluble at $400^{\circ} \mathrm{C}$ according to the phase diagram for the zirconium-hydrogen binary system [12, 13]. Therefore, when the furnace is cooled from an elevated temperature to RT, the hydrogen precipitates as a hydride in hydrided cladding samples. In fact, the hydrided Zircaloy-4 is a composite material that consists of a ductile matrix, $\alpha$-Zr, and brittle second-phase hydrides. It was found that radial hydrides can be formed under a hoop tensile stress when the cladding sample is pressurized internally [3-6].

In this work, the hydrided tubing samples have been pressurized internally to produce a hoop stress up to $150 \mathrm{MPa}$ to form radial hydrides using the hydride reorientation system (see Sect. 4). Tests HR-HBR\#1 and HR-HBR\#2 indicate that multithermal cycling will increase the ratio of radial hydrides under the same maximum temperature and maximum internal pressure. In addition, our test results of Tests HR-HBR\#2 through HR-HBR\#4 reveal that the ratio of radial hydrides decreases as the internal pressure decreases when the temperature and pressure profiles remain the same.

Our goal is to investigate the impact of radial hydrides on high burnup fuel cladding ductility, for which we need to produce a reasonably high percentage of radial hydrides within the cladding by the hydride reorientation tests. The out-of-cell tests are very important to support planning of the in-cell hydride reorientation tests, as it establishes a test procedure and provides a guideline for in-cell test conditions. Based on the four out-of-cell tests, we decided to start our in-cell hydride reorientation test under the same test conditions of Test HR-HBR\#2 to maximize the radial hydride condition.

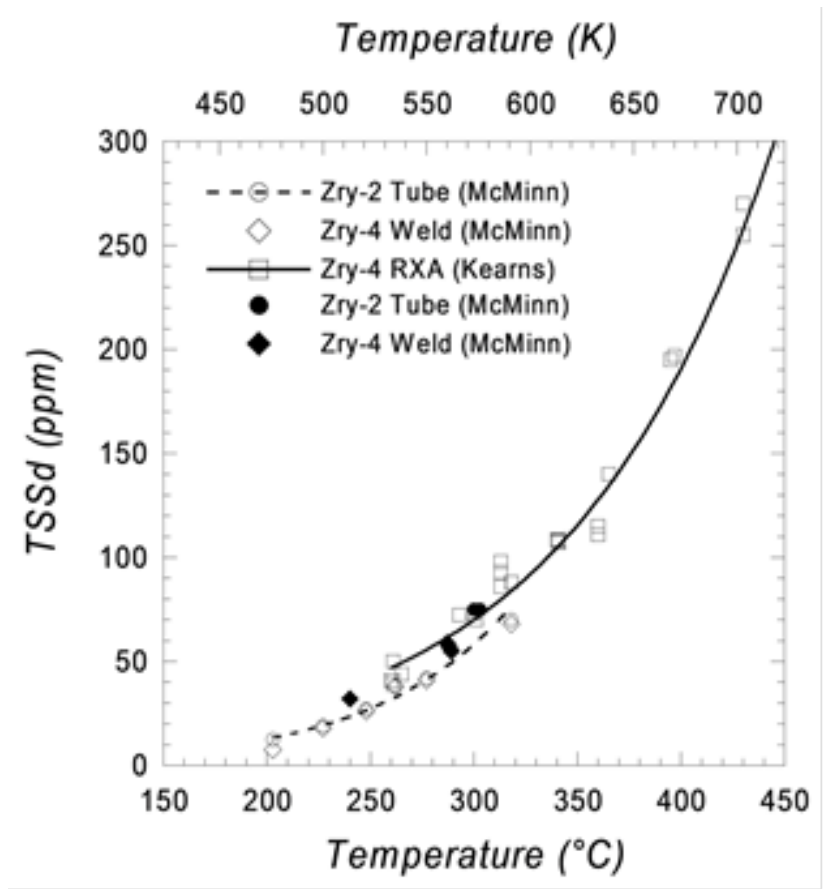

Fig. 19. Terminal solid solubility for dissolution (TSSd) of hydrogen in Zircaloy. (Sources: [1] J. J. Kearns, "Terminal Solubility and Partitioning of Hydrogen in the Alpha Phase of Zirconium, Zircaloy-2 and Zircaloy-4,” Journal of Nuclear Materials 22 [1967]: 292. [2] A. McMinn, E. C. Darby, and J. S. Schofield, "The Terminal Solid Solubility of Hydrogen in Zirconium Alloys," Zirconium in the Nuclear Industry: 12th International Symposium, ASTM STP 1354, p. 173-195 [2000].) 


\section{CIRFT EVALUATIONS OF HBR FUEL FOR HYDRIDE REORIENTATION STUDY}

\subsection{Overview of CIRFT Evaluations and Results for HBR Fuel Rods}

Rod segments, measuring 6 in. long, for CIRFT evaluations were prepared from five HBU HBR SNF rods. Specimen labels and corresponding segment IDs are given in Table 3.

ORNL completed 24 tests in FY 2013 and FY 2014. Fifteen tests were dedicated to dynamic testing conditions with amplitudes ranging between 5.08 and $35.56 \mathrm{Nm}$. Several tests were run at amplitudes below $8.89 \mathrm{Nm}$ over tens of millions of cycles, and the specimens did not show any sign of failure, so these tests were stopped.

Table 3. Specimen labels used for HBR SNF

\begin{tabular}{|c|c|c|c|c|c|}
\hline Spec ID & ORNL ID & Endcap A & Endcap B & Seg. ID & Note \\
\hline S1 & S1 & S1-A & S1-B & 606C3C & \\
\hline S2 & S2 & S2-A & S2-B & 605D1E & \\
\hline S3 & Dcal & Dcal-A & Dcal-B & 609C5 & \\
\hline S4 & Scal & Scal-A & Scal-B & 609C6 & \\
\hline D1 & DL1 & DL1-A & DL1-B & 607C4B & \\
\hline D2 & DL2 & DL2-A & DL2-B & 608C4B & \\
\hline D3 & DL3 & DL3-A & DL3-B & $605 \mathrm{C} 10 \mathrm{~A}$ & \\
\hline D5 & DM2 & DM2-A & DM2-B & 605D1B & \\
\hline D4 & DM1 & DM1-A & DM1-B & 605D1C & \\
\hline D6 & DH1 & DH1-A & DH1-B & $609 C 4$ & \\
\hline D7 & DH2 & DH2-A & DH2-B & 609C3 & \\
\hline D8 & DM3 & DM3-A & DM3-B & 606C3E & \\
\hline D9 & DH3 & DH3-A & DH3-B & $609 C 7$ & \\
\hline D10 & S5 & S5-A & S5-B & 606C3A & \\
\hline D11 & $\mathrm{R} 1$ & R1-A & R1-B & 607C4A & \\
\hline D12 & $\mathrm{R} 2$ & R2-A & R2-B & 608C4A & \\
\hline D13 & R3 & R3-A & R3-B & 606B3E & \\
\hline D14 & $\mathrm{R} 4$ & R4-A & R4-B & 606B3D & \\
\hline D15 & R5 & R5-A & R5-B & 606B3С & \\
\hline D16 & S3 & S3-A & S3-B & $605 \mathrm{D} 1 \mathrm{~F}$ & \\
\hline Demo1 & Demo1 & Demo1-A & Demo1-B & 606B2 & \\
\hline HR1 & HR1 & HR1-A & HR1-B & 607D4C & FY 2016 \\
\hline HR2 & HR2 & HR2-A & HR2-B & 607D4A & FY 2016 \\
\hline HR3 & HR3 & HR3-A & HR3-B & 608D4A & FY 2016 \\
\hline HR4 & HR4 & HR4-A & HR4-B & 608D4C & FY 2016 \\
\hline
\end{tabular}




\subsection{FY 2016 PHASE II CIRFT HR Test Results (Appendix A)}

\subsubsection{Hydride Reorientation Test Samples Preparation}

Four CIRFT evaluations were completed on the HBR specimens with hydride reoriented treatment (HRT), $145 \mathrm{MPa}$ hoop stress, 170 to $400^{\circ} \mathrm{C}$, five cycles in FY 2016. Bending amplitudes ranging from 10.16 and 16.26 Nm were tested. One of the HBR HRT specimens (HR2) was tested under static conditions, however the specimen survived the static loading without failure and was then tested under dynamic loading, as will be discussed. Due to a welded endcap leak, only thermal heat treatment was applied to the HR4 sample.

The sample preparation for the hydride reorientation (HR) project is detailed below.

- The HBU HBR fuels under simulated drying operation conditions of the SNF were used for the HR testing study. Based on out-of-cell benchmark HR tests with hydrided HBR Zircaloy-4 cladding, four in-cell tests were conducted with HBU HBR fuel samples subjected to hydride reorientation at approximately $145 \mathrm{MPa}$ at $400^{\circ} \mathrm{C}$.

- The HBR fuel samples for HR tests were prepared in the irradiation fuel examination laboratory. After the samples were sectioned into 6 in.-long pieces, the surface oxide layer and fuel material were removed from both ends to a depth of approximately $0.5 \mathrm{in}$. Endcaps were welded at both ends, and the HBR fuel specimens were then pressurized with argon gas at a maximum hoop stress level of $145 \mathrm{MPa}$ and a target hold temperature $\left(\mathrm{T}=400^{\circ} \mathrm{C}\right)$. Thermal cycling was performed to increase the radial hydrides. All in-cell tests had the same temperature profiles. Fig. 20 shows the temperature history of the first in-cell HR test, HR1, with a HBU HBR sample.

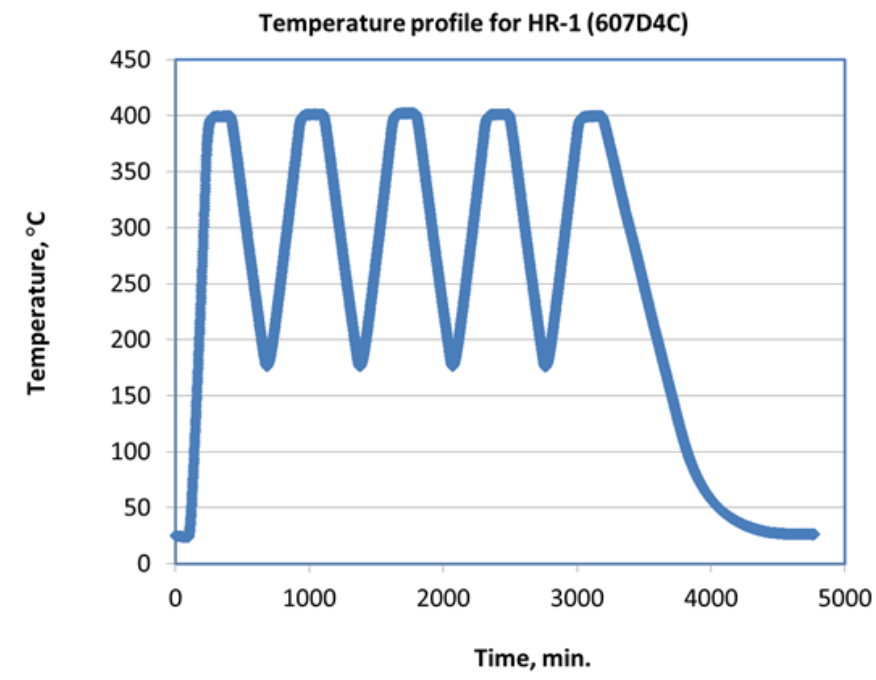

Fig. 20. Sample temperature as a function of time for in-cell HR test HR-1.

- The hydride-reoriented samples were subjected to CIRFT testing at room temperature to evaluate the materials performance after hydride reorientation. After the tests were completed in the CIRFT, the specimens were examined to verify the radial hydrides had been generated. Fig. 21 shows the hydride morphology of hydride-reoriented sample HR1. The hydrogen concentration of this sample was about 360-400 wppm. The MET mount specimen was sectioned at the midplane of a 6 in.-long sample. Although the in-cell HR test conditions were the same as the out-of-cell test HR-HBR\#2 and the hydrogen concentration of these two samples were compatible, the morphology of HBU sample HR1 was different from hydrided sample HR-HBR\#2. For the 
unirradiated sample, the circumferential hydrides were uniformly distributed across the wall, and the maximum length of its radial hydrides was about 50-60 $\mu \mathrm{m}$. For HBU samples, the radial hydrides were mainly distributed near the inner surface, and the circumferential hydrides are mostly seen near the outer surface. The length of the radial hydride of the HBU sample, Fig. 21(a), was also much longer than the unirradiated sample, Fig. 21(b).

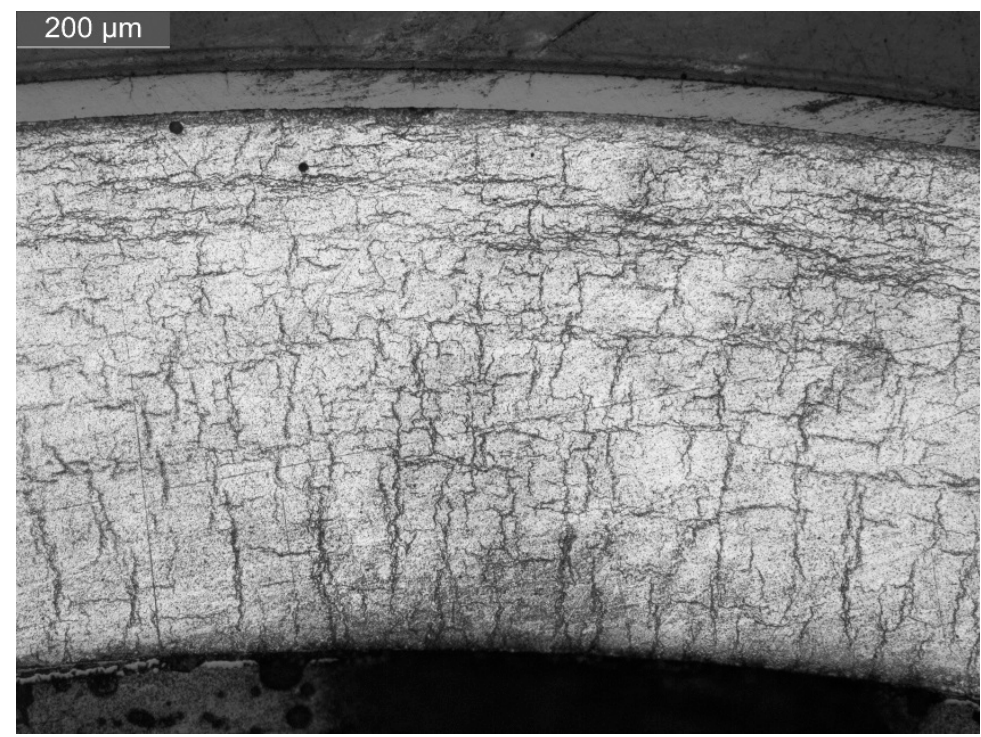

(a)

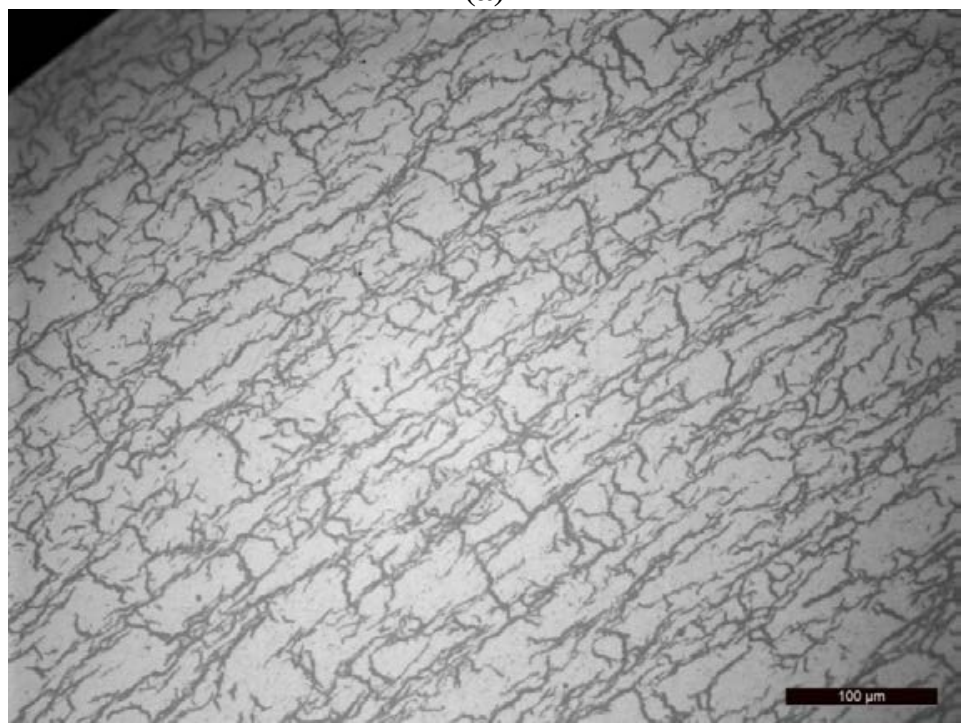

(b)

Fig. 21. (a) High magnification micrograph showing radial hydrides of Sample HR-1 (H $\approx 360-400 \mathrm{ppm})$. The HBU HBR specimen was pressurized to $145 \mathrm{MPa}$ at $400^{\circ} \mathrm{C}$ with five thermal cycles. (b) High magnification micrograph showing radial hydrides of Sample HR-HBR\#2 (H $\approx 286 \mathrm{ppm})$. The specimen was sectioned at the midplane of a 6 in.-long sample.

\subsubsection{Measurements and Monitoring Data}

The results for each test are given in Appendix A.

The flexural rigidity of the rod specimens treated by hydride reorientation was shown to be much lower than as-received specimens under equivalent amplitude. For example, under the same amplitude of $100 \mathrm{~N}$, 
the rigidity of the HRT specimen (HR3) was only about 57\% of the as-received specimen (DL3). The variation of rigidity during a cyclic test was continuous. In HR3, a sudden drop was observed before failure.

\subsubsection{Fatigue Life}

The results for the dynamic tests of HBR fuel in FY 2016 are summarized in Table 4. Again, definitions of the column heads are same as those for LMK fuels in Table 10.

The plots based on the mean values of quantities are given in Fig. 22(a)-(d), where HBR1 represents the as-received specimen, and HBR2 represents the specimen after radial hydride treatment (RHT). Note the data of as-received HBR specimens were based on the original analysis method; (i.e., no correction was applied). It has been shown that the HRT reduces the fatigue life of SNF rods, which can be seen from the tests around $15 \mathrm{Nm}$. It was further observed for HR2, as indicated by the arrow, there was an additional fatigue life reduction. Such reduction obviously resulted from the large-deformation static loading before the dynamic cyclic loading.

Several images of the failed specimens that were subjected to the reorientation procedure are provided in Fig. 23. The failures of these specimens were in the gauge section, and in two of them, the failure was taking place at a pellet-to-pellet interface.

Table 4a. Dynamic test results for HBR SNF rods, FY 2016

\begin{tabular}{lcccccccccc}
\hline TN & Spec & $\begin{array}{c}\text { Load } \\
\text { in. }\end{array}$ & $\begin{array}{c}\text { cycles } \\
\text { cy }\end{array}$ & Fail & $\begin{array}{c}\text { ma } \\
\mathbf{N m}\end{array}$ & $\begin{array}{c}\text { ma_std } \\
\mathbf{N m}\end{array}$ & $\begin{array}{c}\text { ka } \\
\mathbf{m}^{\wedge} \mathbf{1}\end{array}$ & $\begin{array}{c}\text { ka_std } \\
\mathbf{m}^{\wedge}-\mathbf{1}\end{array}$ & $\begin{array}{c}\mathbf{k m} \\
\mathbf{m}^{\wedge}-\mathbf{1}\end{array}$ & $\begin{array}{c}\mathbf{k m \_ s t d} \\
\mathbf{m}^{\wedge}-\mathbf{1}\end{array}$ \\
\hline 25 & HR1 & 150 & $4.19 \mathrm{E}+04$ & 1 & 15.152 & 0.549 & 0.517 & 0.016 & 0.527 & 0.019 \\
26 & HR2 & 160 & $9.47 \mathrm{E}+03$ & 1 & 14.702 & 0.806 & 0.478 & 0.121 & 0.511 & 0.205 \\
27 & HR3 & 100 & $2.44 \mathrm{E}+05$ & 1 & 8.982 & 0.066 & 0.267 & 0.005 & 0.291 & 0.009 \\
28 & HR4 & 160 & $5.47 \mathrm{E}+04$ & 1 & 14.759 & 0.089 & 0.394 & 0.008 & 0.421 & 0.009 \\
\hline
\end{tabular}

Table 4b. Dynamic test results for HBR SNF rods, FY 2016

\begin{tabular}{|c|c|c|c|c|c|c|c|c|c|c|c|c|c|}
\hline $\mathbf{T N}$ & Spec & $\begin{array}{c}\mathrm{R} \\
\mathrm{Nm}^{\wedge} 2 \\
\end{array}$ & $\begin{array}{l}\text { R_std } \\
\mathbf{N m} \wedge 2\end{array}$ & $\begin{array}{c}\text { Sa } \\
\text { MPa }\end{array}$ & $\begin{array}{c}\text { sa_std } \\
\text { MPa }\end{array}$ & $\begin{array}{l}\text { ea } \\
\%\end{array}$ & $\begin{array}{c}\text { ea_std } \\
\%\end{array}$ & $\begin{array}{c}\text { em } \\
\%\end{array}$ & $\begin{array}{c}\text { em_std } \\
\%\end{array}$ & $\begin{array}{l}\text { Lg2 } \\
\text { mm }\end{array}$ & $\begin{array}{c}\text { Lg2_std } \\
\text { mm }\end{array}$ & $\begin{array}{c}\text { dh } \\
\text { mm }\end{array}$ & $\begin{array}{c}\text { dh_std } \\
\text { mm }\end{array}$ \\
\hline 25 & HR1 & 29.329 & 0.775 & 128.788 & 4.666 & 0.278 & 0.009 & 0.284 & 0.010 & 44.733 & 0.565 & 1.329 & 0.197 \\
\hline 26 & HR2 & 31.567 & 3.256 & 124.964 & 6.848 & 0.257 & 0.065 & 0.275 & 0.110 & 50.657 & 1.593 & -0.174 & 0.372 \\
\hline 27 & HR3 & 33.659 & 0.602 & 76.342 & 0.560 & 0.144 & 0.003 & 0.157 & 0.005 & 43.368 & 0.643 & -1.649 & 0.252 \\
\hline 28 & HR4 & 37.497 & 0.593 & 125.449 & 0.755 & 0.212 & 0.004 & 0.227 & 0.005 & 45.977 & 0.578 & 1.206 & 0.201 \\
\hline
\end{tabular}




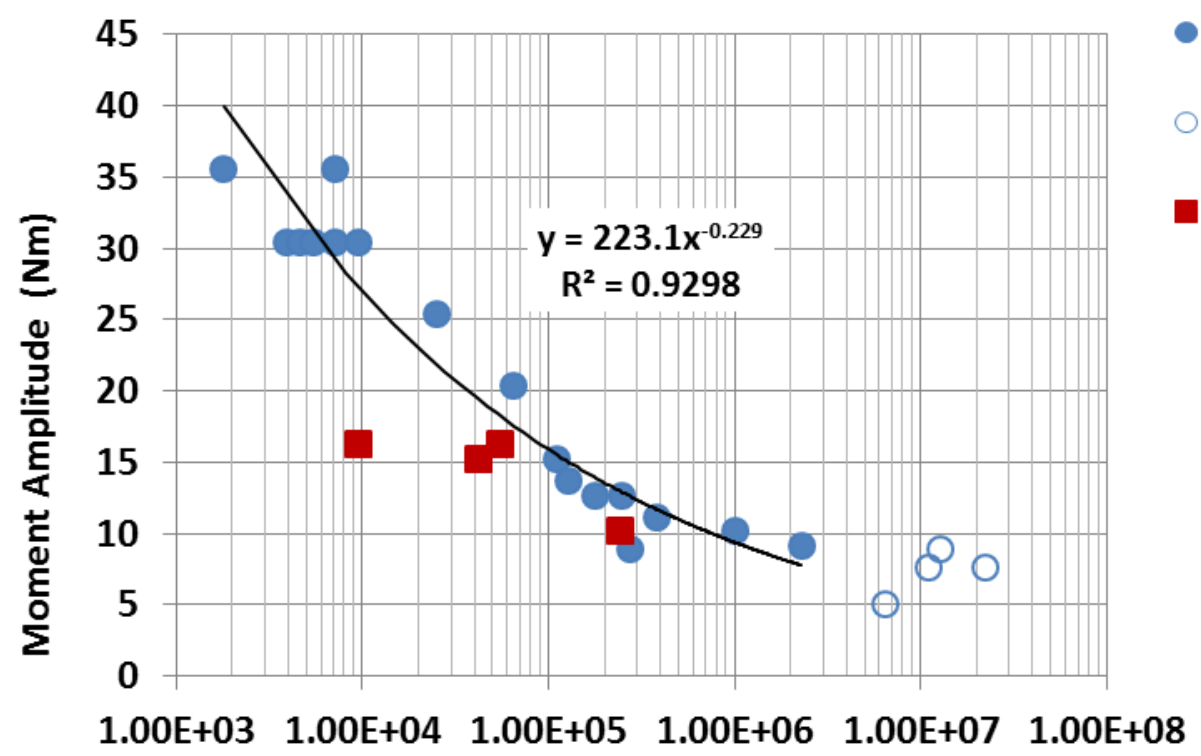

HBR1 failure

HBR1 No failure

HBR2 Failure

Number of Cycles or Cycles to Failure

(a)

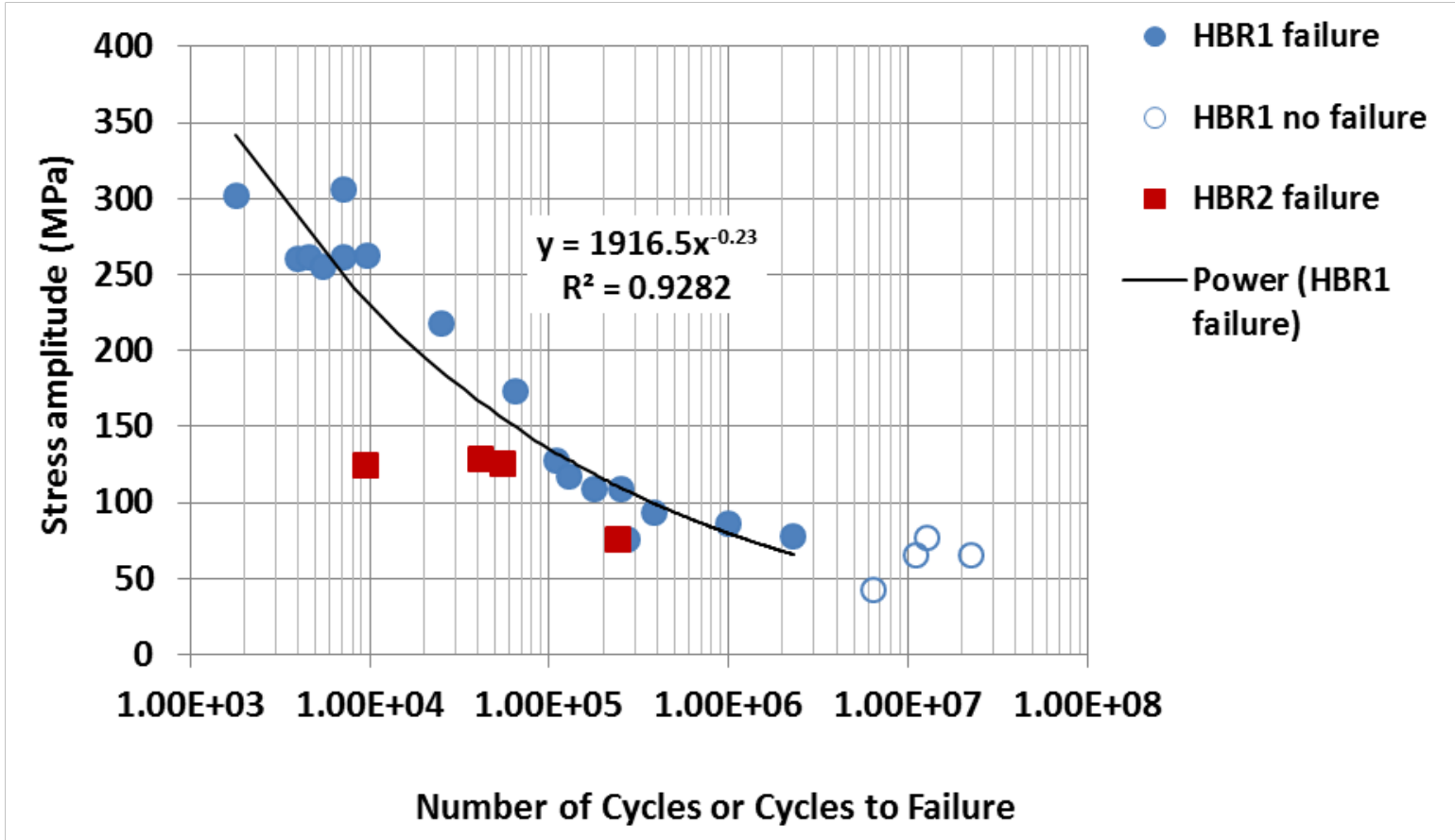

(b) 


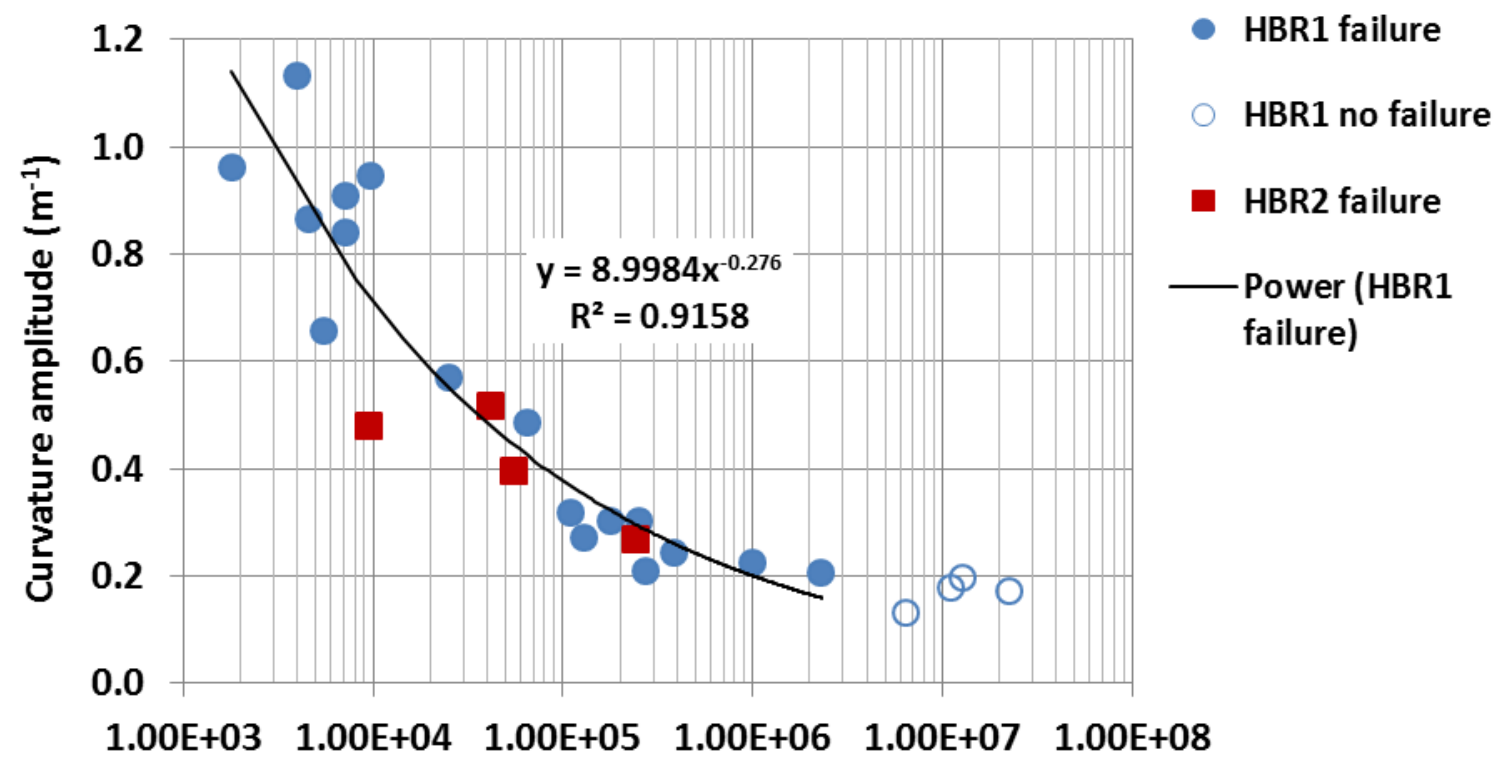

Number of Cycles or Cycles to Failure

(c)

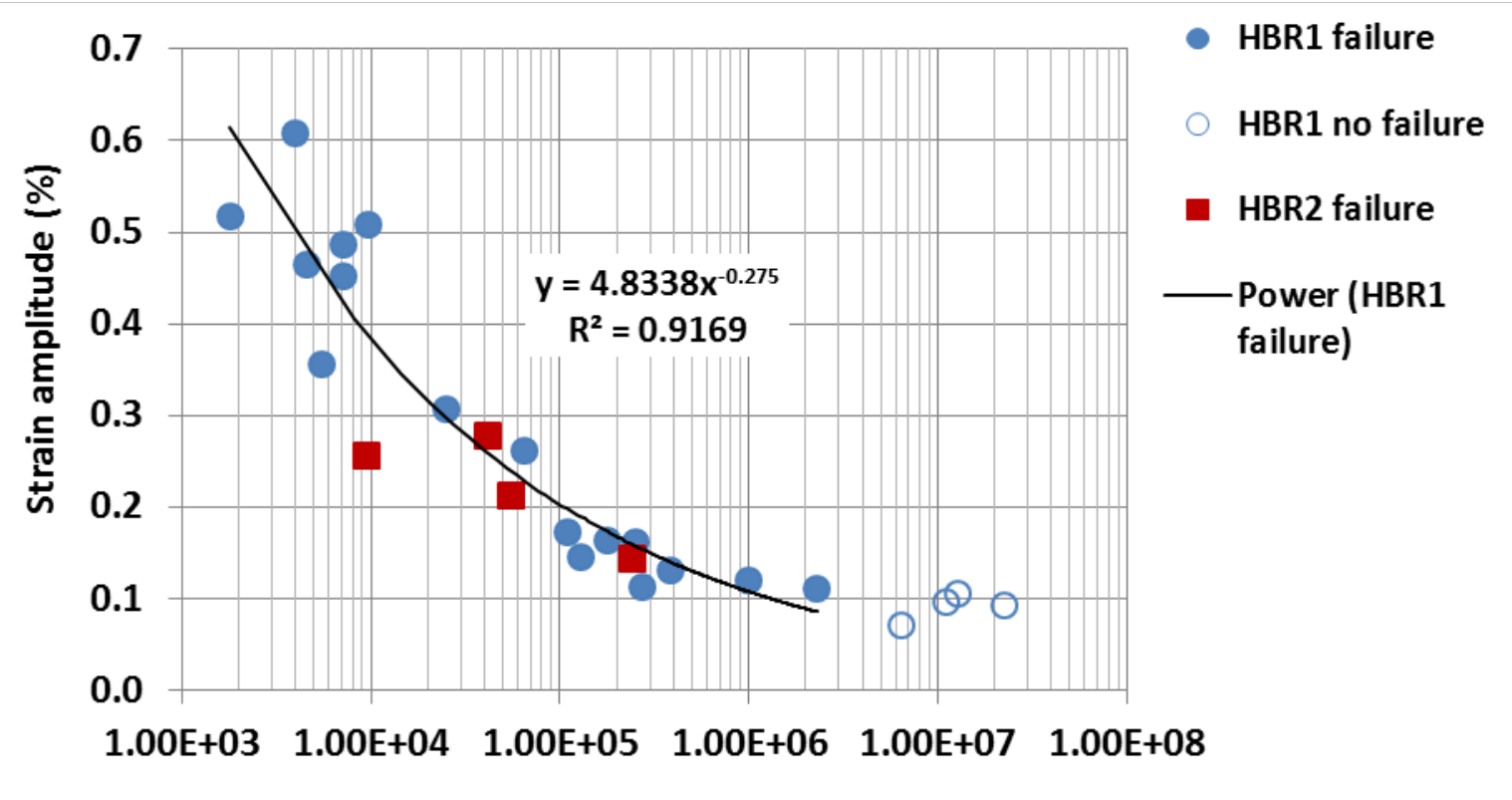

Number of Cycles or Cycles to Failure

(d)

Fig. 22. (a) Moment amplitude, (b) stress amplitude, (c) curvature amplitude, and (d) strain amplitude rigidity as a function of cycles or cycles to failure. 


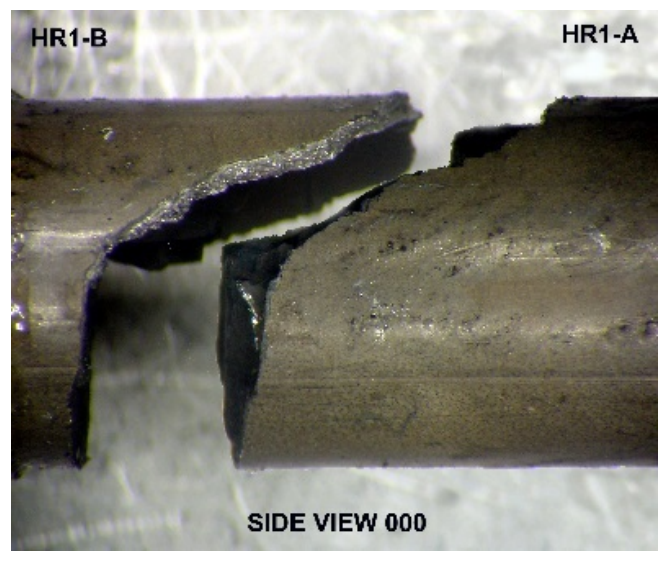

(a)

\section{HR1-A}

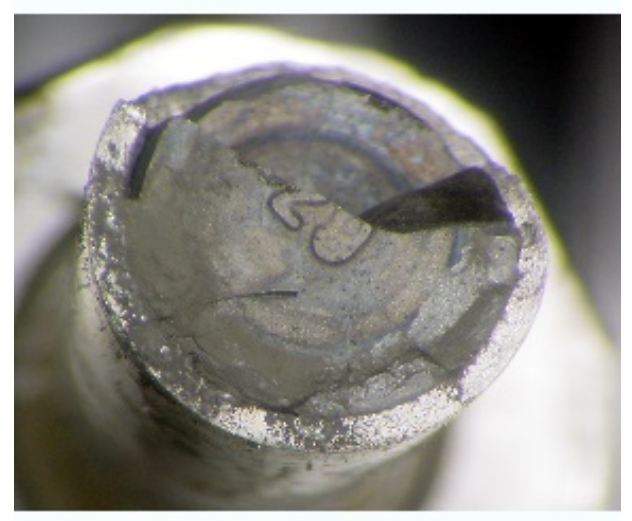

END VIEW

(c)

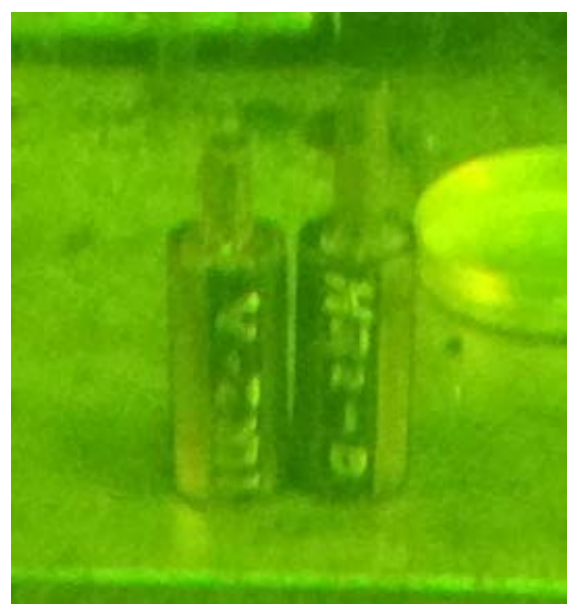

(e)

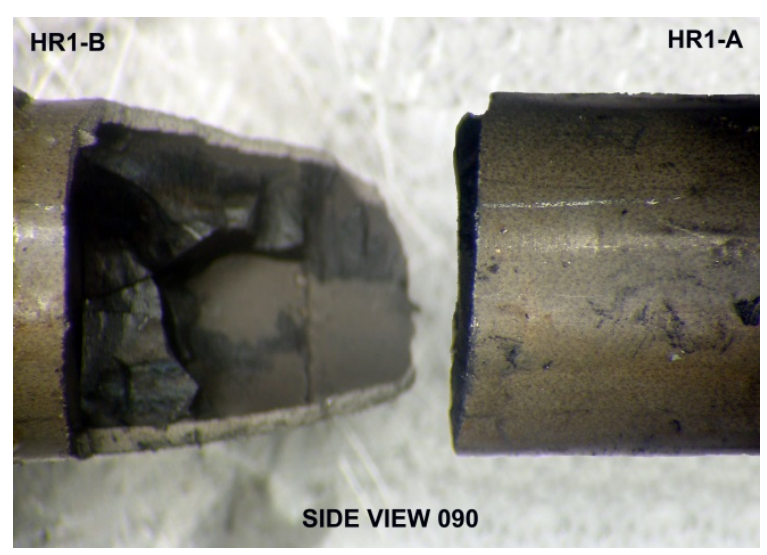

(b)

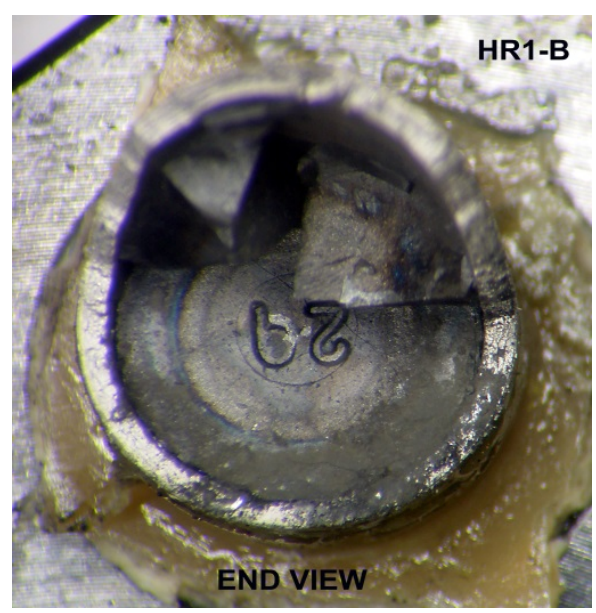

(d)

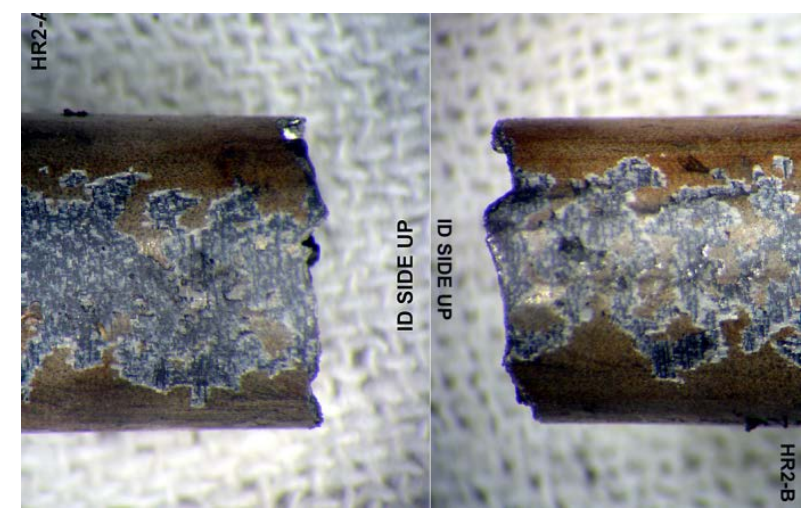

(f) 


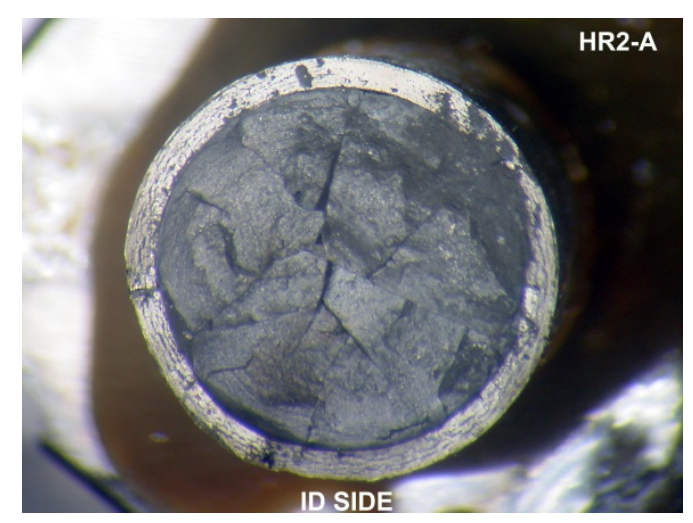

(g)

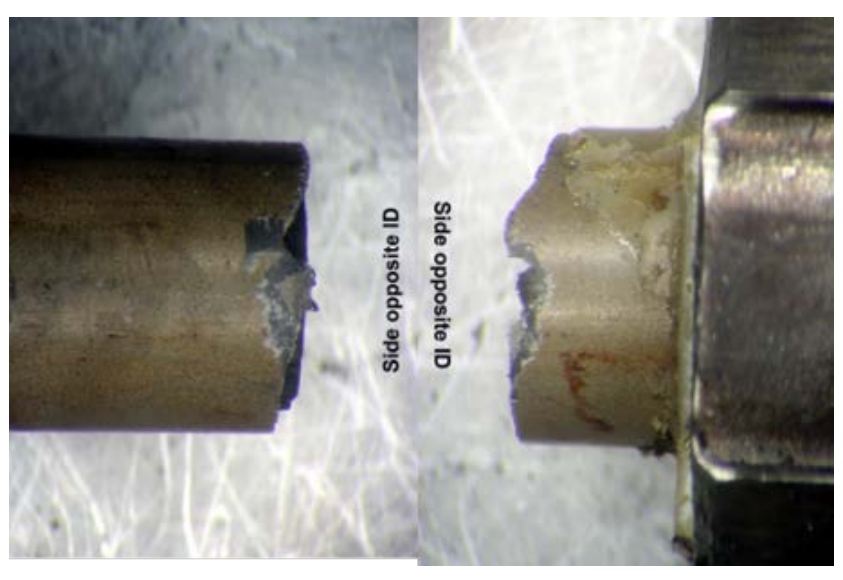

(i)

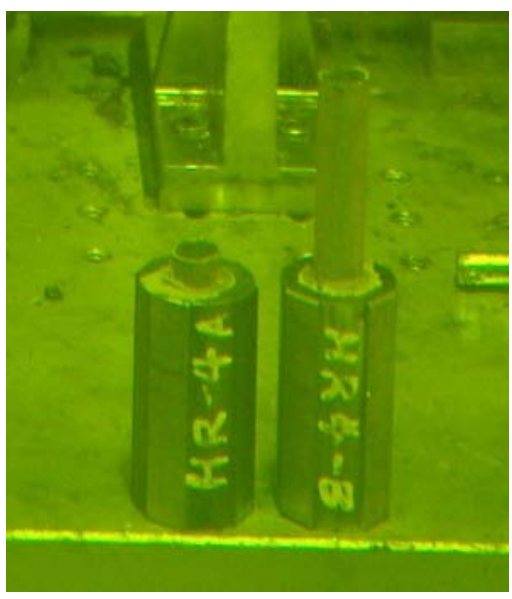

(k)

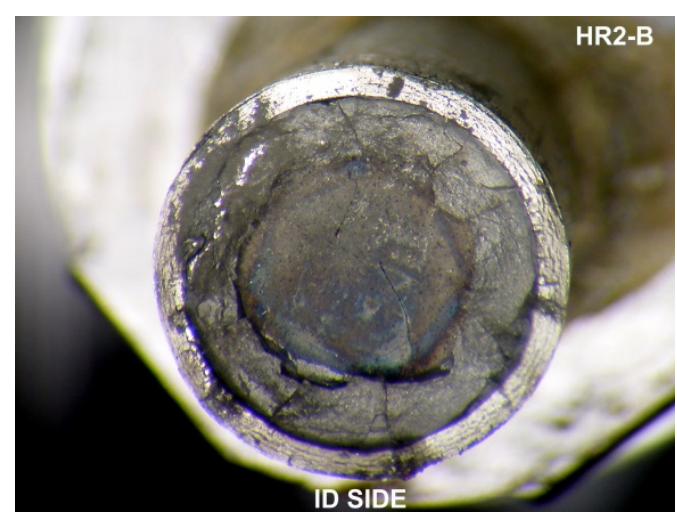

(h)

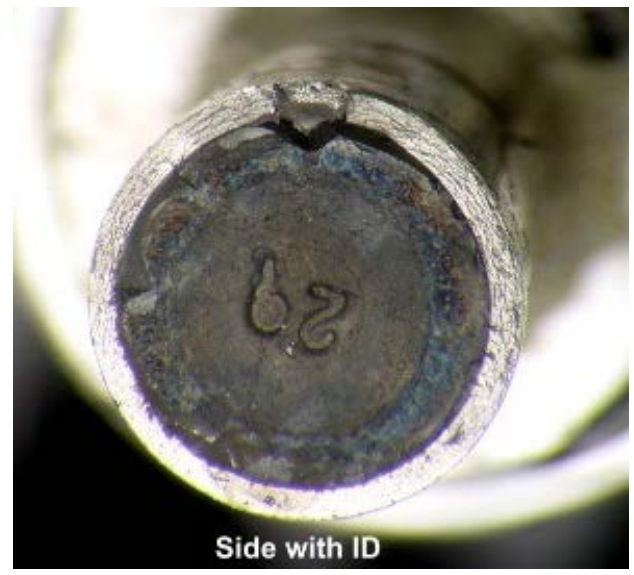

(j)

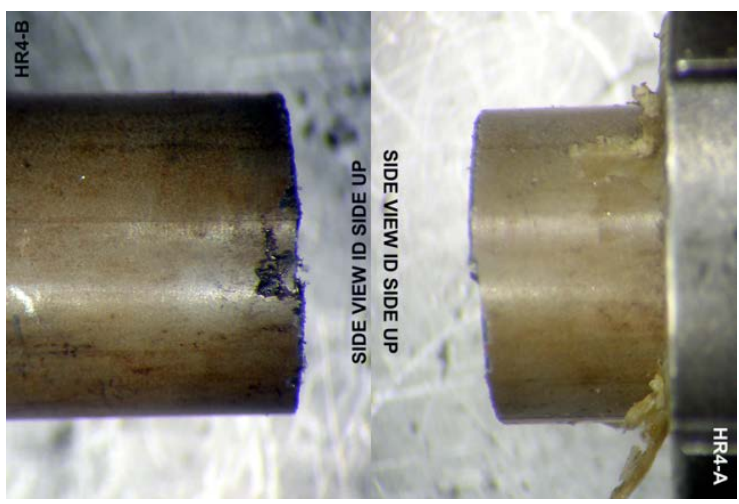

(l) 


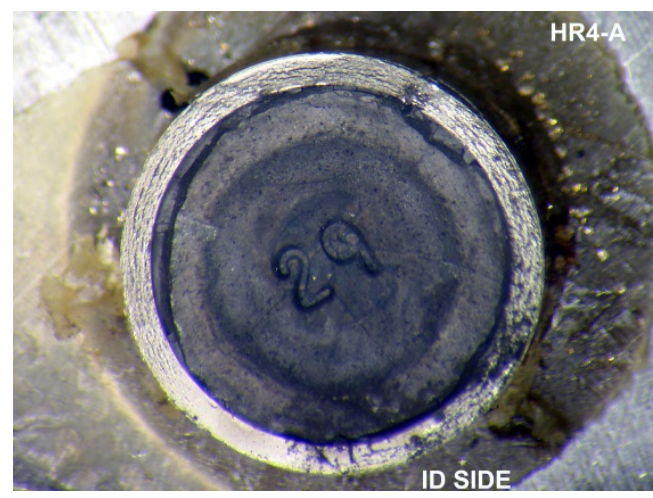

(m)

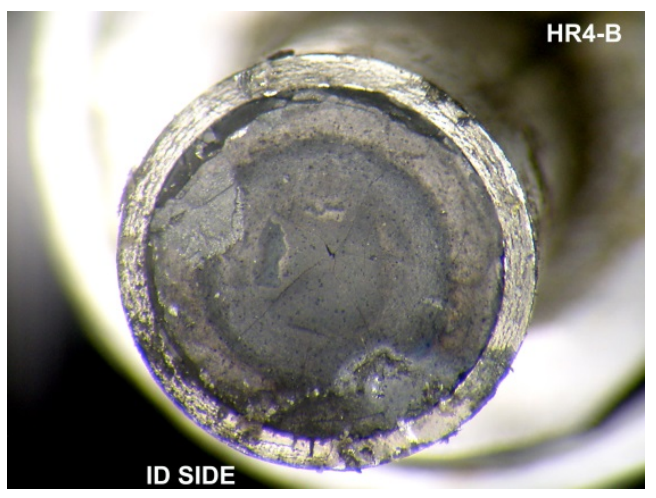

(n)

Fig. 23. Images showing the failure modes for (a) (b) (c) (d) HR1, (e) (f) (g) (h) HR2, (i) (j) HR3, and (k) (l) (m) (n) HR4. 


\section{CONCLUSION}

Four CIRFT data evaluations were completed on the high burnup Zircaloy-4 HBR SNF rods with radial hydride treatment (145 MPa hoop stress, 170 to $400^{\circ} \mathrm{C}$, five cycles) in FY 2016. Amplitudes ranging from 10.16 and $16.26 \mathrm{Nm}$ were tested. One of the specimens (HR2) was tested under static loading initally. This specimen survived the static loading without failure and was then tested under dynamic loading. Due to a welded endcap leak, only thermal heat treatment was applied to the HR4 sample.

General observations from Phase II CIRFT test data evaluations are:

1) Comparing reoriented CIRFT test results to results from non-reoriented CIRFT tests on the same high burnup Zircaloy-4 material, it appears that radial hydrides and HRT could have a negative impact on the fatigue life of CIRFT specimens.

2) Comparing the CIRFT testing result on a sample subjected to temperature cycling without rod pressurization (HR4) to the baseline CIRFT test results, it appears that the thermal heating along may have a negative impact on the fatigue life of the HBR rod. 


\section{ACKNOWLEDGMENTS}

This research was sponsored jointly by the Nuclear Regulatory Research of US Nuclear Regulatory Commission and US Department of Energy (DOE) Used Fuel Disposition Campaign under DOE contract DE-AC05-00OR22725 with UT-Battelle, LLC. The authors thank ORNL program managers Michelle Bales and Bruce Bevard for their support and guidance, Chuck Baldwin for post-irradiation examination, Dale Caquelin and Bob Morris for providing logistic hot cell support, Josh Schmidlin for fuel rod cutting and dimension measurement, Bryan Woody and Scott Thurman for hot cell operation support, Brian Sparks and Randy Parten for drawing and machining support. 


\section{REFERENCES}

1. Y. Yan, T. A. Burtseva, and M. C. Billone, Post-Quench Ductility Results for North Anna High Burnup $17 \times 17$ ZIRLO Cladding with Intermediate Hydrogen Content, Argonne National Laboratory letter report to the Nuclear Regulatory Commission, April 17, 2009. Available online as ML091200702 at http://www.nrc.gov/reading-rm/adams.html.

2. M. C. Billone, Y. Yan, T. Burtseva, and R. Daum, Cladding Embrittlement during Postulated Lossof-Coolant Accidents, NUREG/CR-6967, ANL-07/04, Argonne National Laboratory, Argonne, IL, 2008.

3. M. C. Billone, T. Burtseva, and Y. Yan. "Overview of Spent Nuclear Fuel Program: Test Plan and High Burnup Cladding at ANL,” NRC Program Review Meeting, Argonne National Laboratory, Argonne, IL, July 7, 2010.

4. R. Daum, H. Tsai, Y. Liu, and M. Billone, "High-Burnup Cladding Mechanical Performance during Cask Storage and Post-Storage Handling and Transportation," Nuclear Safety Research Conference, Washington, DC, October 25-27, 2004.

5. Y. Yan, et al., "Observation and Mechanism of Hydride in Zircaloy-4 and Local Radial Hydride Induced by High Pressure at High Temperatures,” 2013 International High-Level Radioactive Waste Management, Albuquerque, NM, April 28-May 2, 2013.

6. Y. Yan, L. K. Plummer, H. Ray, T. Cool, and H. Z. Bilheux, "Ductility Evaluation of As-Hydrided and Hydride Reoriented Zircaloy-4 Cladding under Simulated Dry-Storage Condition,” 2013 MRS Fall Meeting Proceeding, Boston, MA, December 1-6, 2013.

7. M. C. Billone, T. A. Burtseva, and Y. Yan, Ductile-to-Brittle Transition Temperature for HighBurnup Zircaloy-4 and ZIRLO ${ }^{\mathrm{TM}}$ Cladding Alloys Exposed to Simulated Drying-Storage Conditions, Argonne National Laboratory letter report to the Nuclear Regulatory Commission, ANL-13/13, September 28, 2013. Available online as ML12181A238 at http://www.nrc.gov/readingrm/adams.html.

8. E. J. Ruzauska and K. N. Fardell, "Design, Operation, and Performance Data for High Burnup PWR Fuel from the H. B. Robinson Plant for Use in the NRC Experimental Program at Argonne National Laboratory,” Electric Power Research Institute report 1001558, May 2001.

9. M. Griffiths, J. F. Mecke, and J. E. Winegar, "Evolution of Microstructure in Zirconium Alloys During Irradiation,” Zirconium in the Nuclear Industry: 11th International Symposium, ASTM STP 1295, pp. 580-602 (1996).

10. J. J. Kearns, "Terminal Solubility and Partitioning of Hydrogen in the Alpha Phase of Zirconium, Zircaloy-2, and Zircaloy-4,” Journal of Nuclear Materials 22 (1967): 292.

11. A. McMinn, E. C. Darby, and J. S. Schofield, "The Terminal Solid Solubility of Hydrogen in Zirconium Alloys," Zirconium in the Nuclear Industry: 12th International Symposium, ASTM STP 1354, p. 173-195 (2000).

12. D. O. Northwood and U. Kosasih, "Hydrides and Delayed Hydrogen Cracking in Zirconium and its Alloys,” International Metals Review 28, no. 2 (1983): 92.

13. S. Mishra, K. S. Sivaramakrishnan, and M. K. Asundi, "Formation of the Gamma Phase by a Peritectoid Reaction in the Zirconium-Hydrogen System,” Journal of Nuclear Materials 45 (1972): 235. 


\section{APPENDIX A CIRFT TESTING RESULTS OF HBR SNF- Phase II}




\section{Table of Contents}

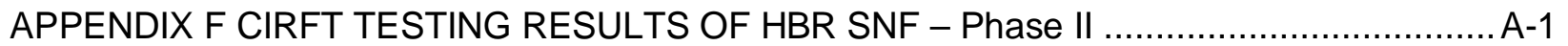

Measurement and monitoring rigidity curves of HBR HR data .................................. A-3 
Measurement and monitoring rigidity curves of HBR HR data 


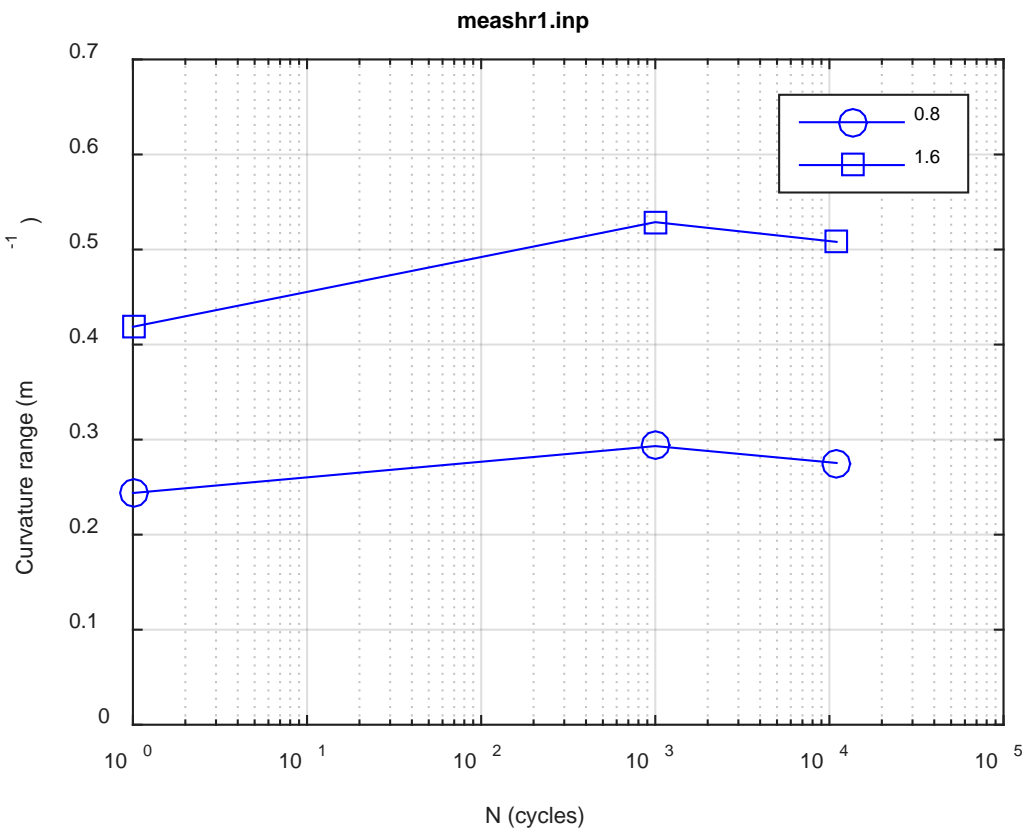

(a)

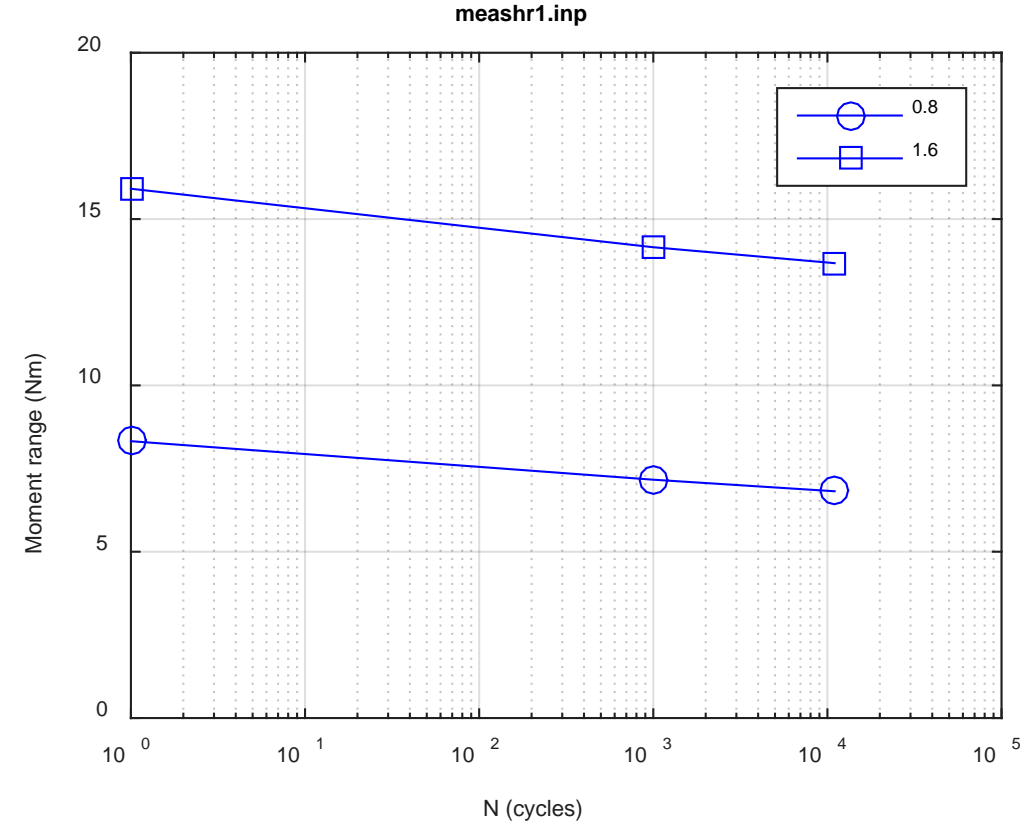

(b) 


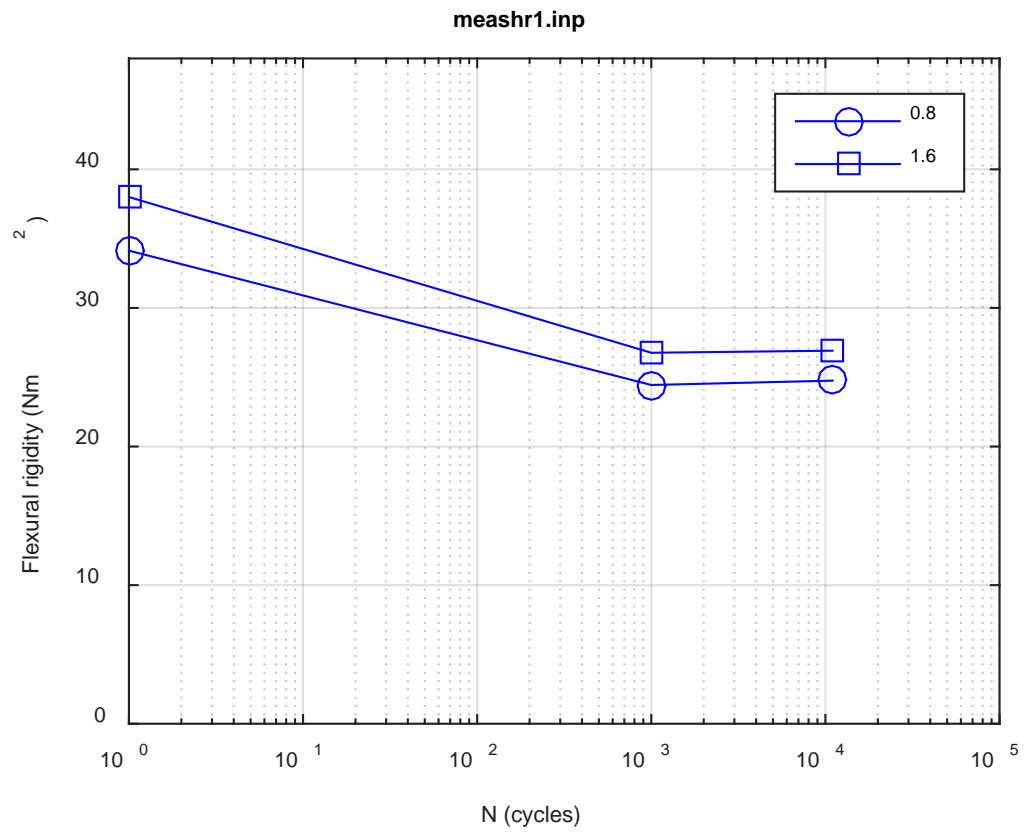

(c)

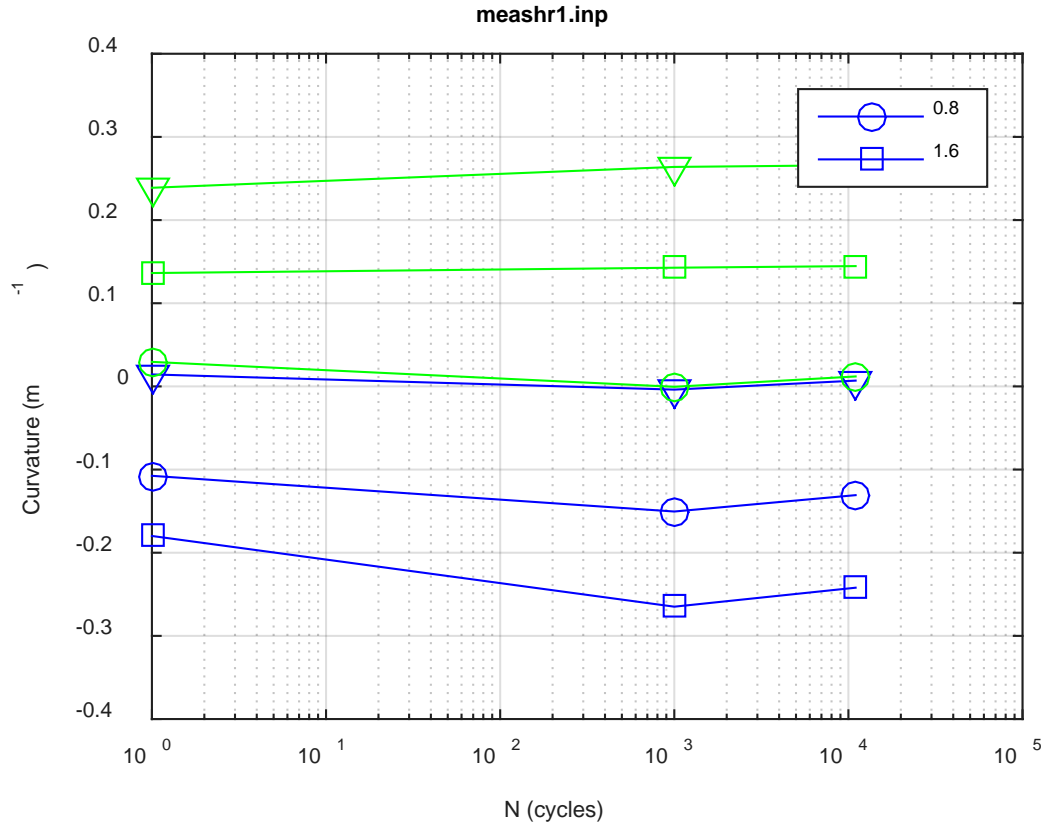

(d) 


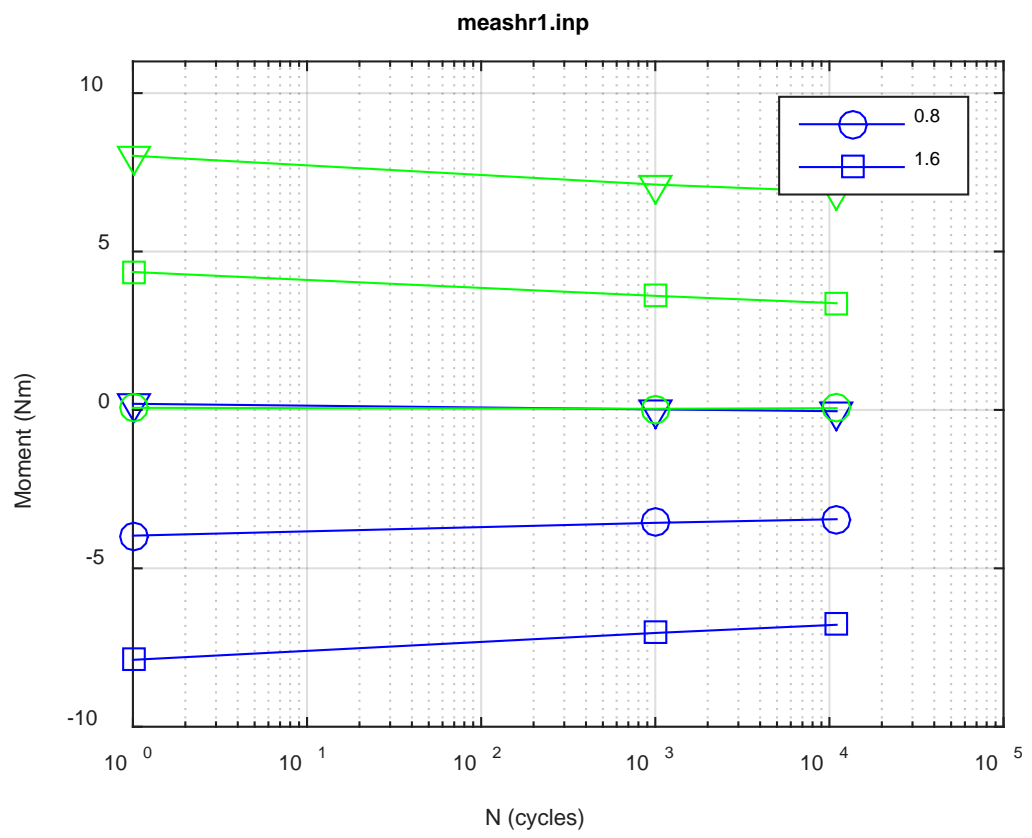

(e)

Fig. F.1 Measurement-based responses: (a) curvature range, (b) moment range, (c) rigidity, (d) curvature peak/valley, (e) moment peak/valley, HR1, $15.24 \mathrm{Nm}$. 


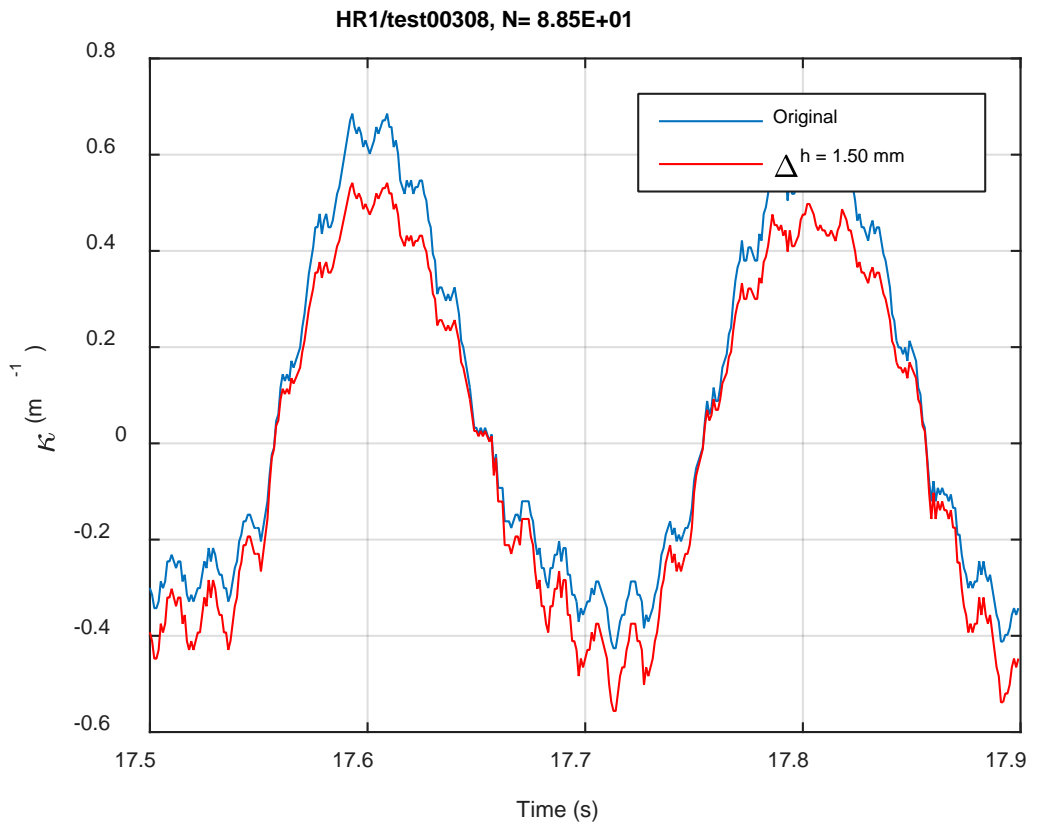

(a)

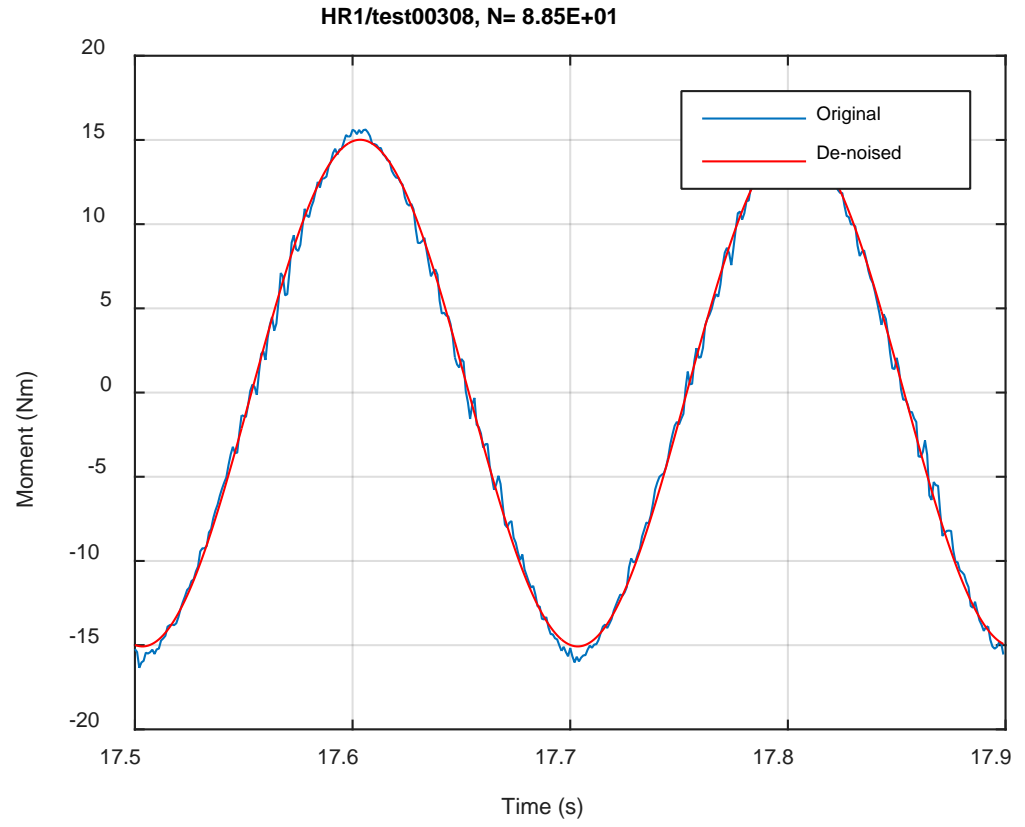

(b) 


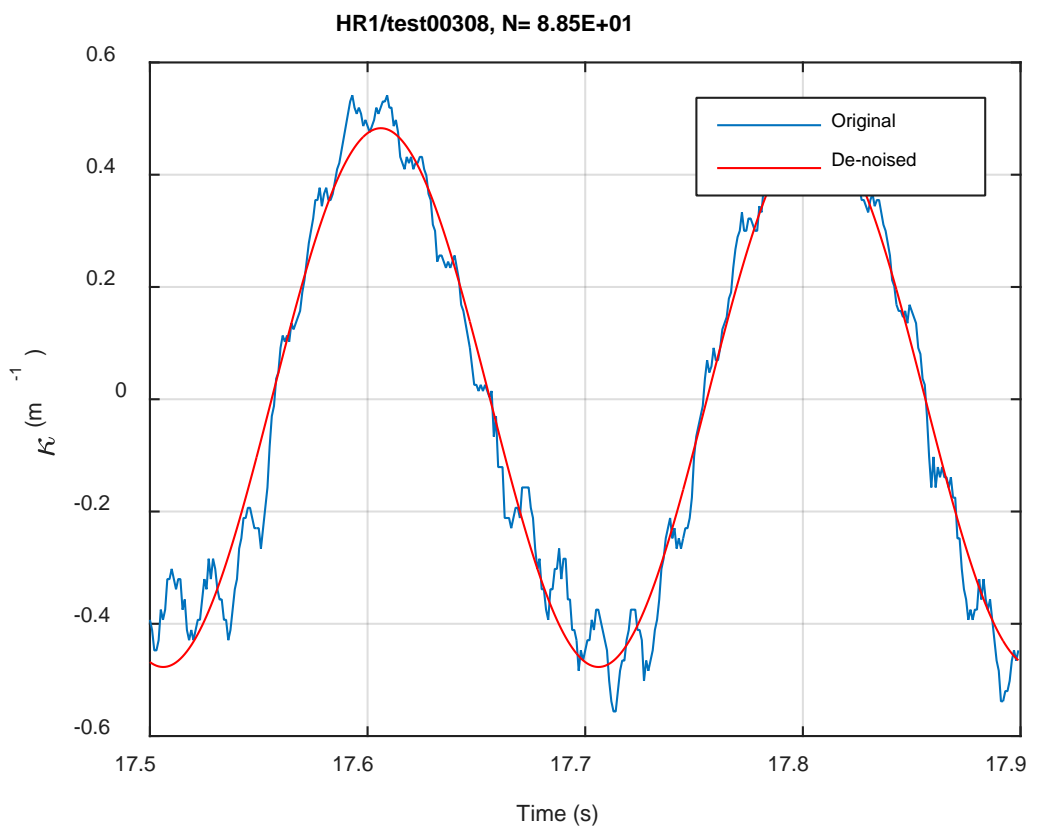

(c)

Fig. F.2 Monitoring-based responses: (a) curvature, (b) moment, (c) curvature, HR1, 15.24 Nm, Ns $=8.85 \mathrm{E}+01$ cycles. 


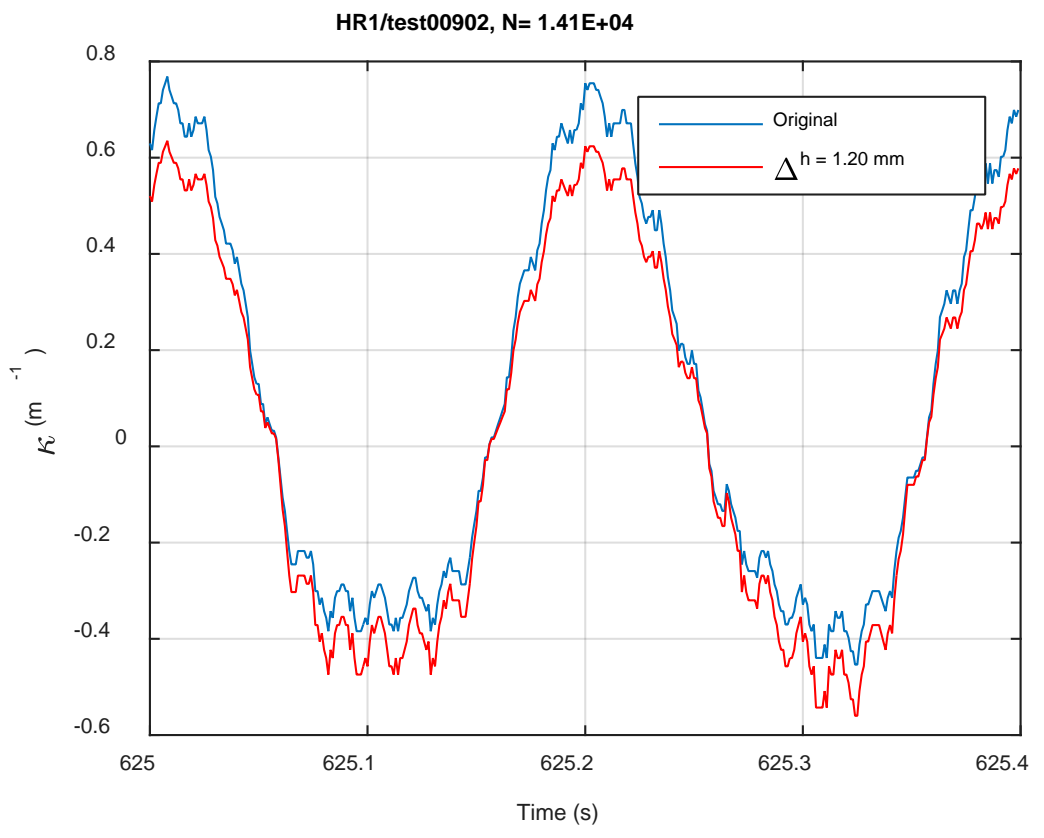

(a)

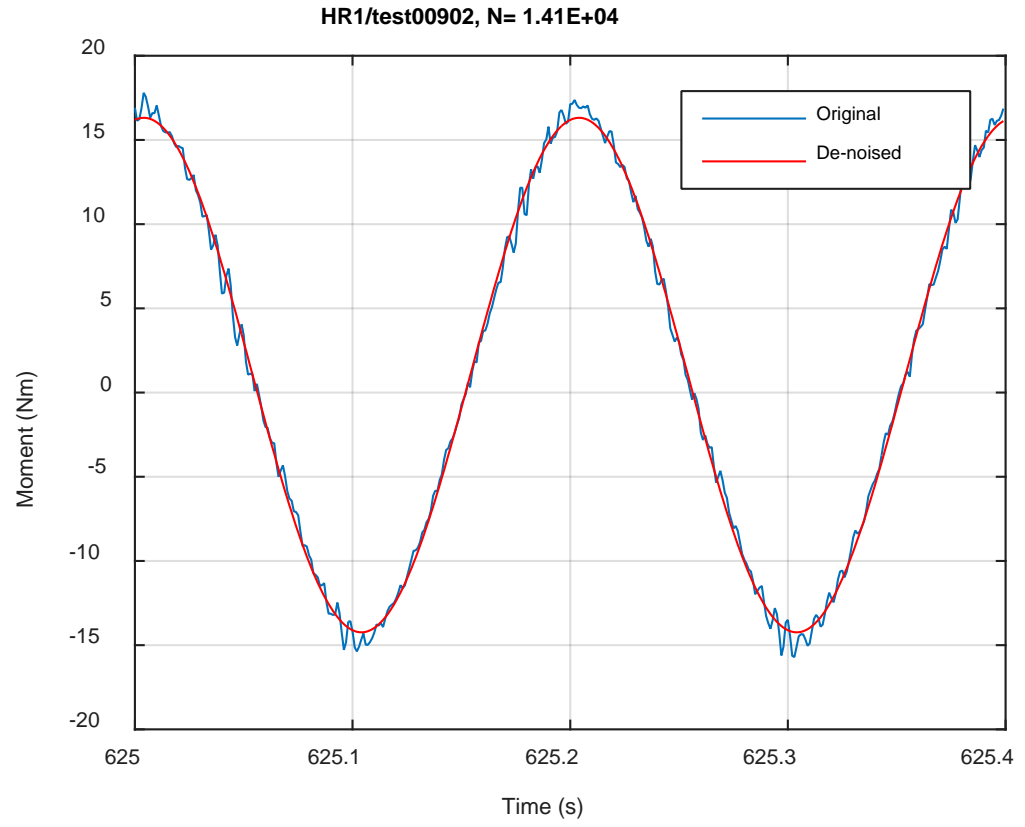

(b) 


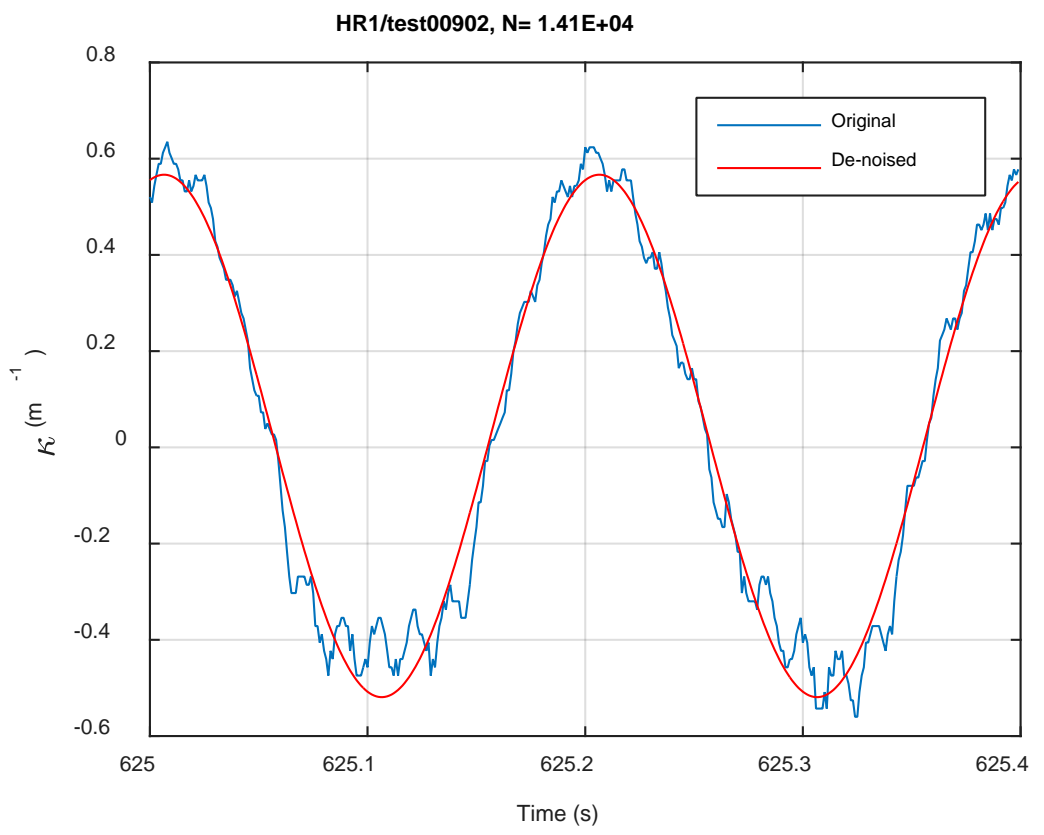

(c)

Fig. F.3 Monitoring-based responses: (a) curvature, (b) moment, (c) curvature, HR1, 15.24 Nm, Ns $=1.41 \mathrm{E}+04$ cycles. 


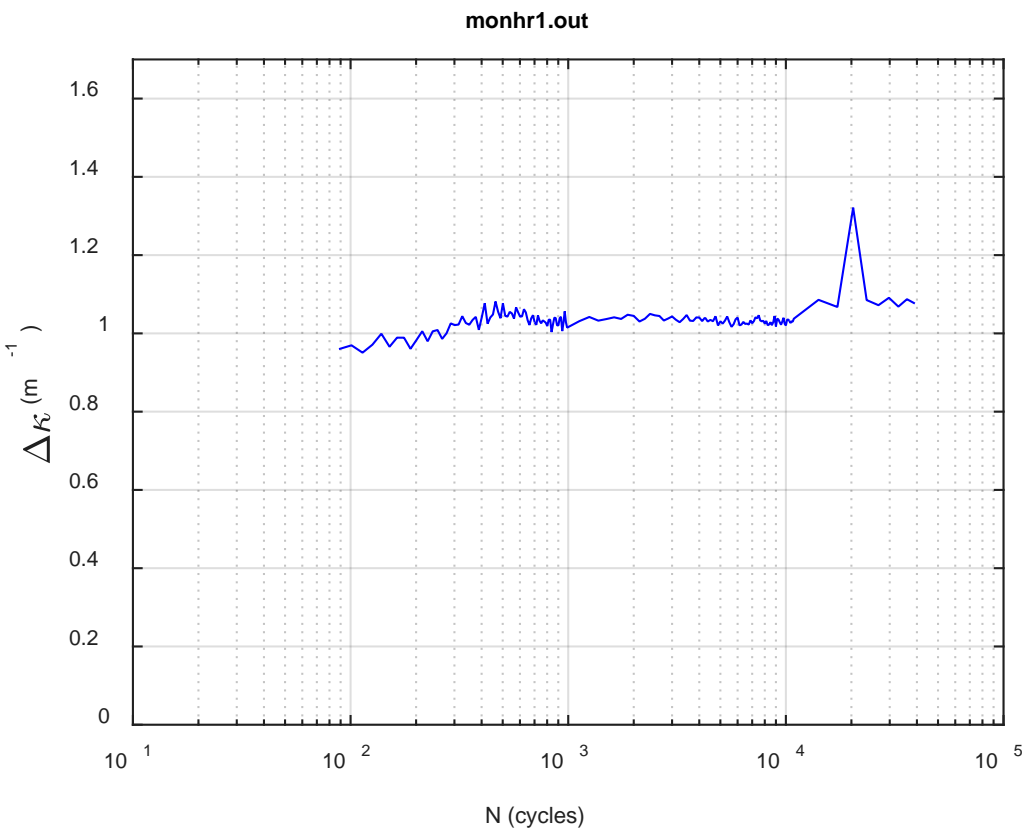

(a)

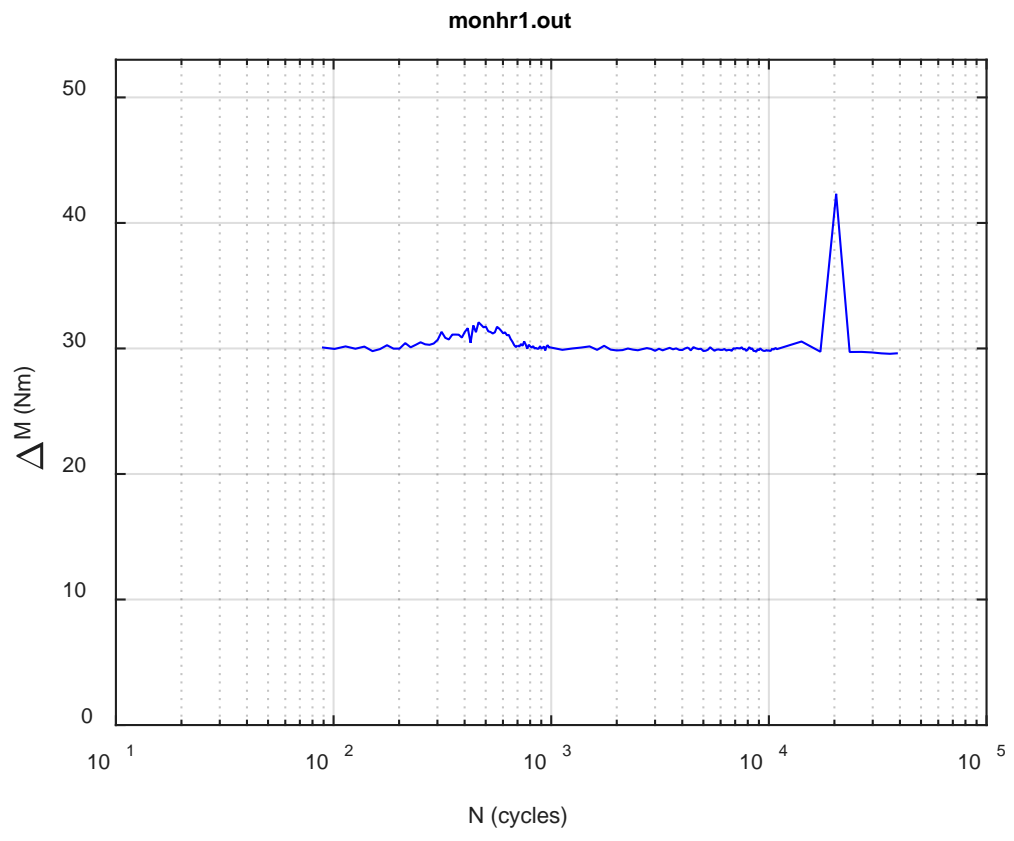

(b)

A-11 


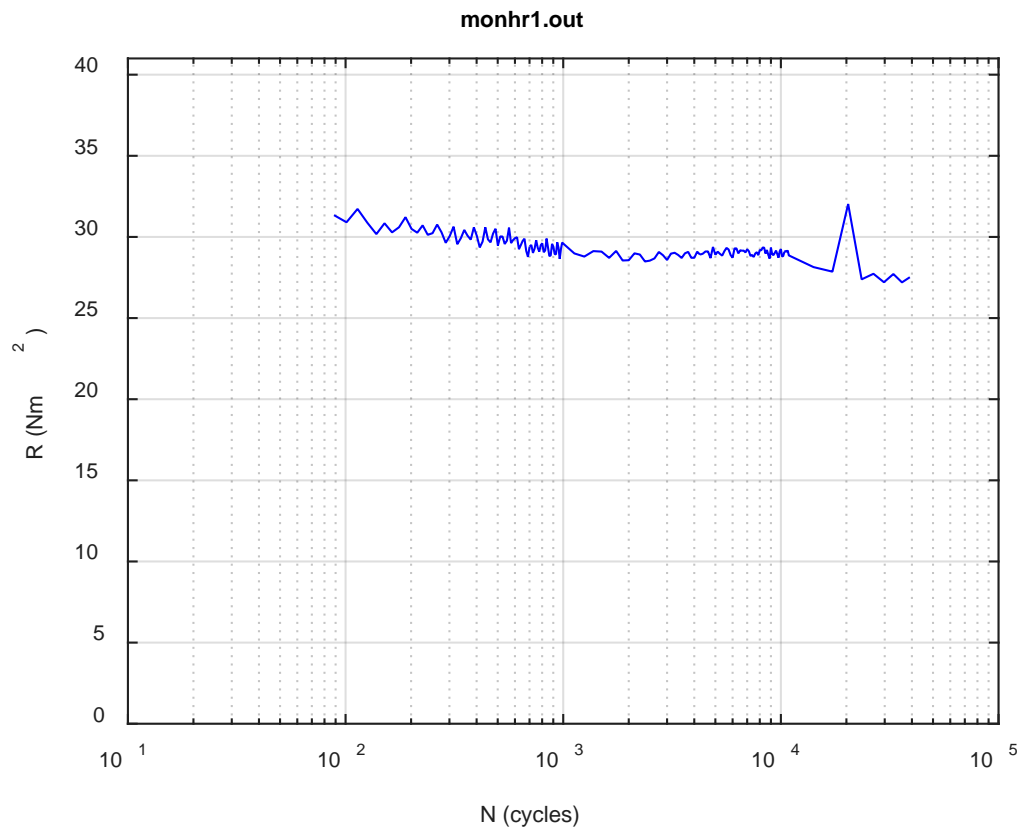

(c)

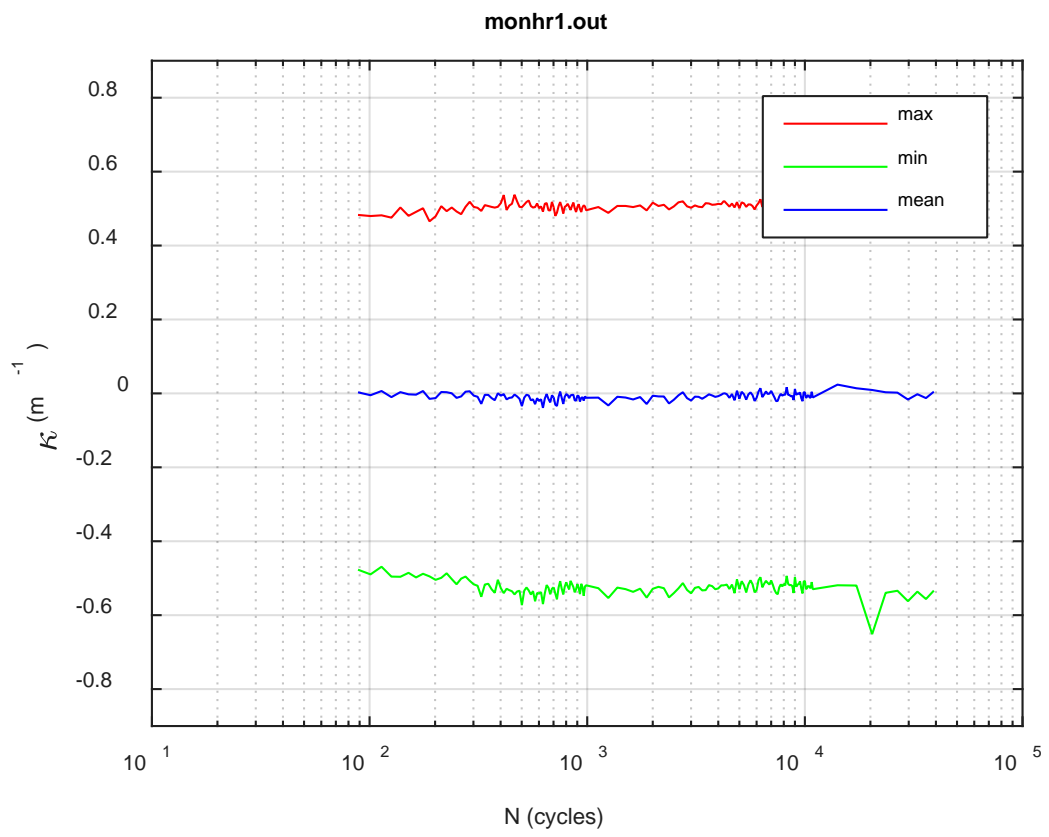

(d) 


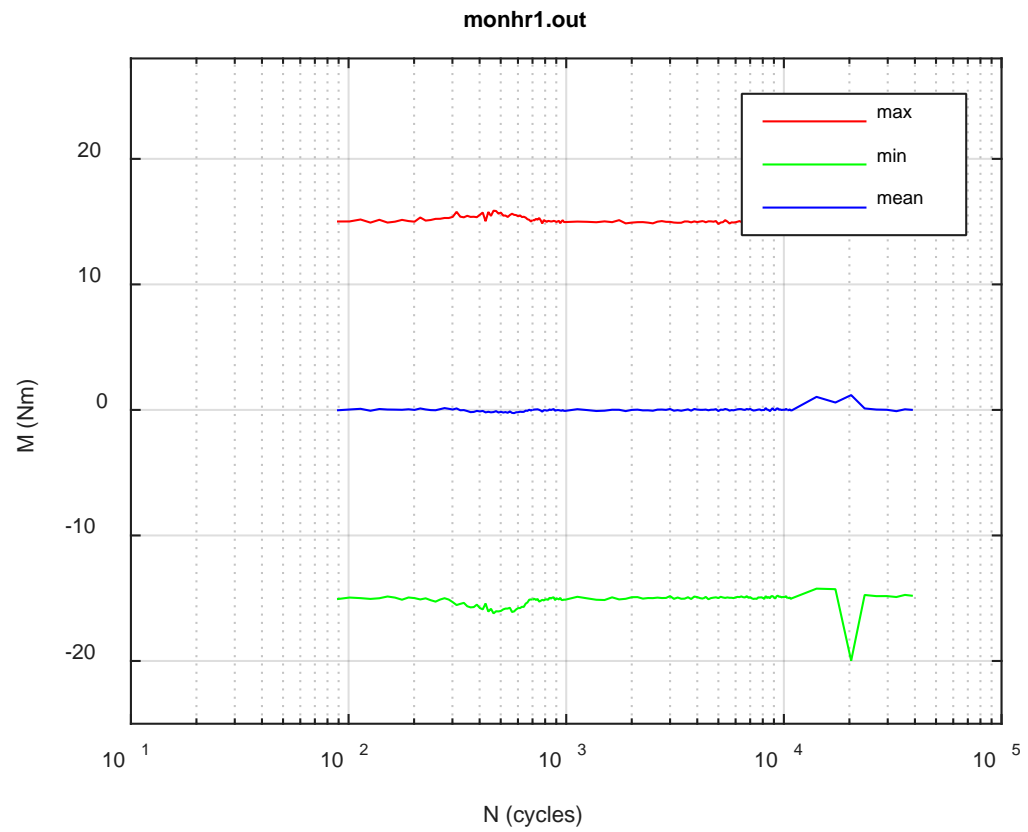

(e)

Fig. F.4 Monitoring-based responses: (a) curvature range, (b) moment range, (c) rigidity, (d) curvature peak/valley, (e) moment peak/valley, HR1, $15.24 \mathrm{Nm}, \mathrm{Nf}=4.19 \mathrm{E}+04$ cycles. 


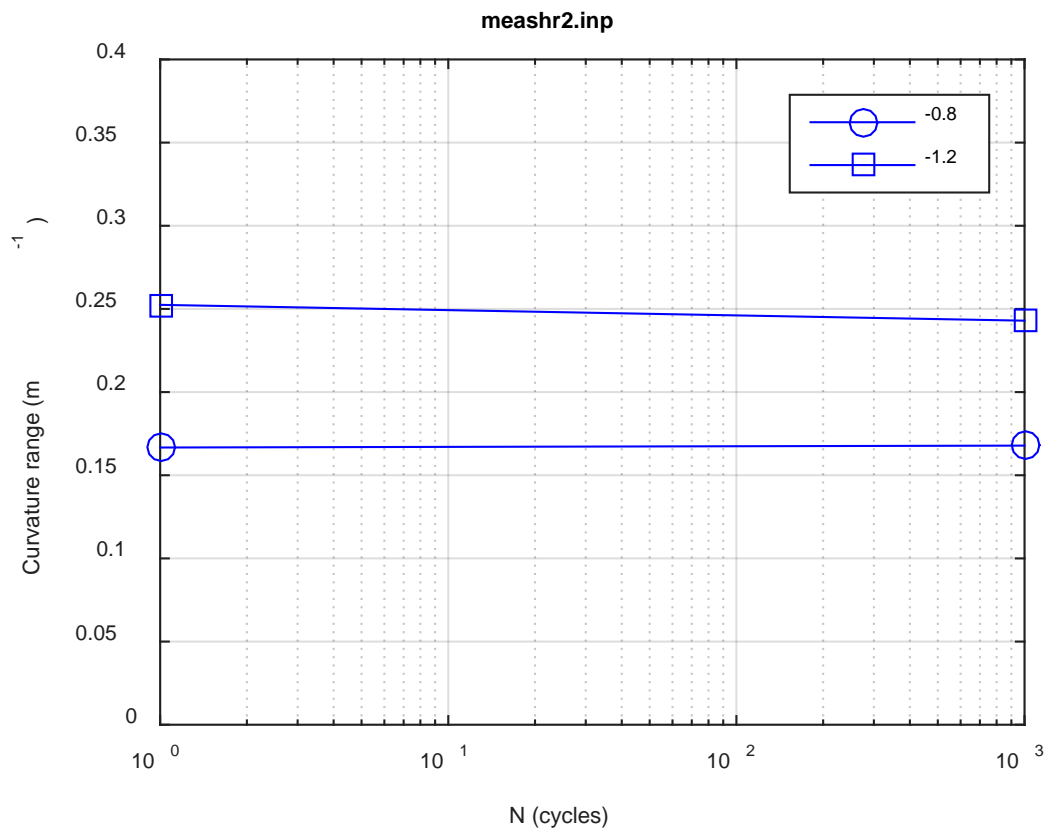

(a)

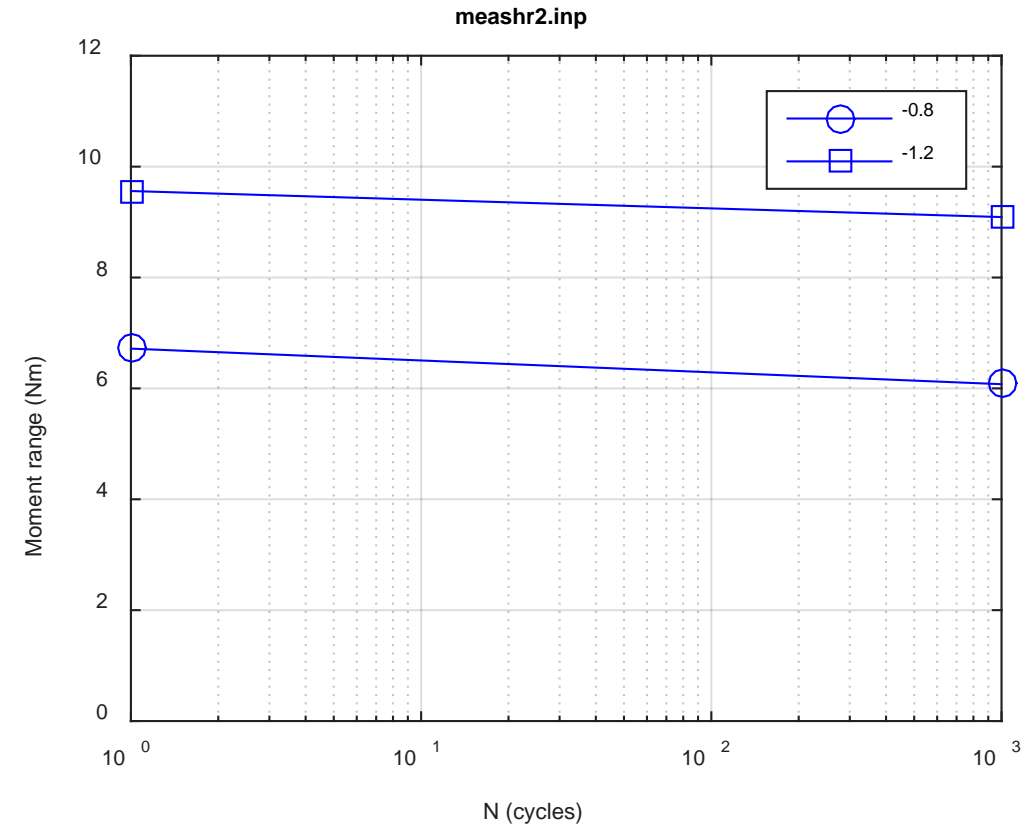

(b) 


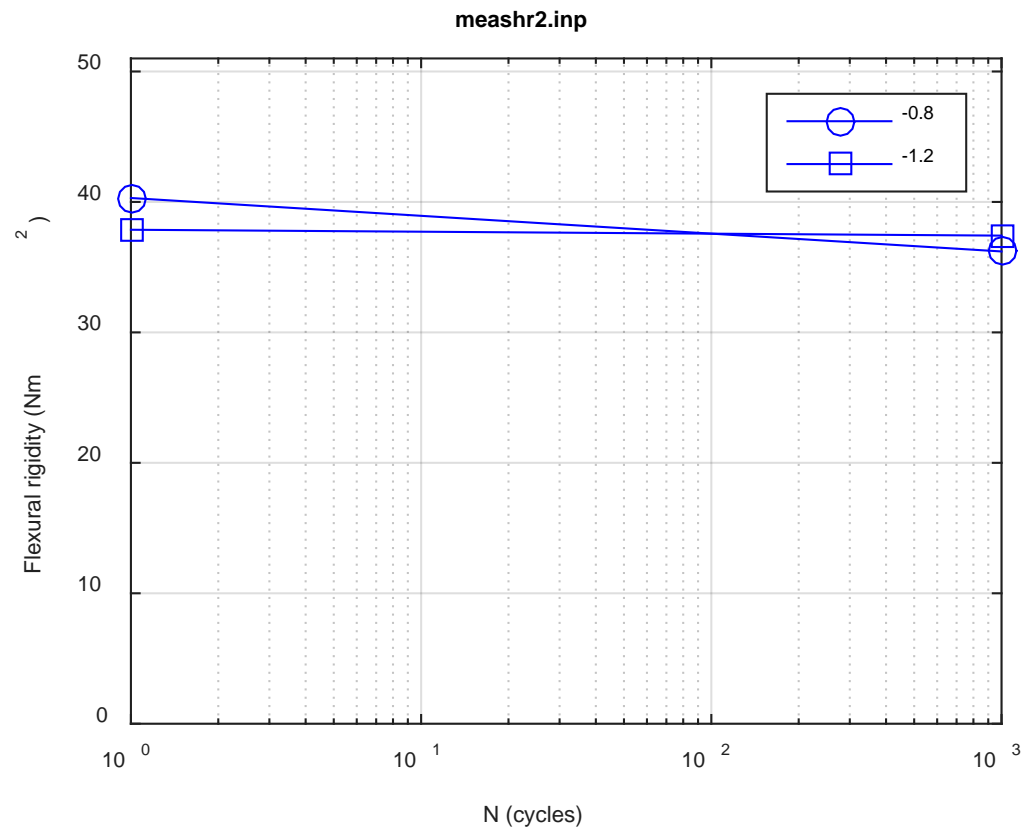

(c)

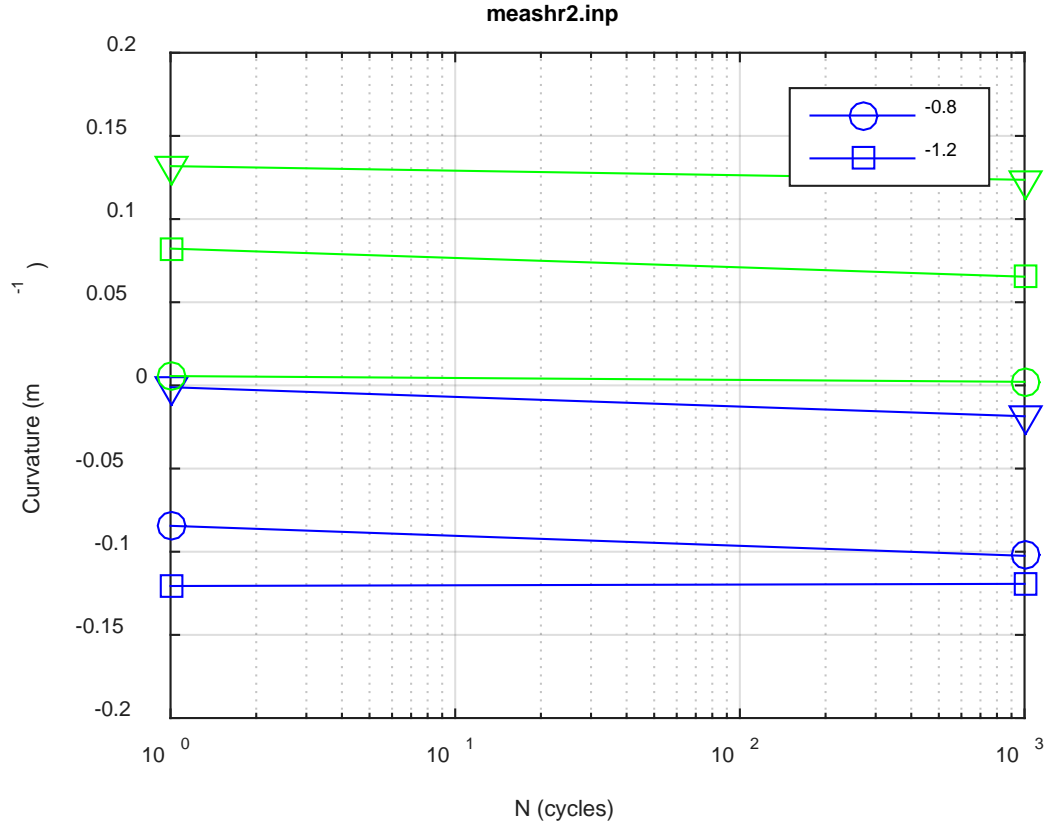

(d) 


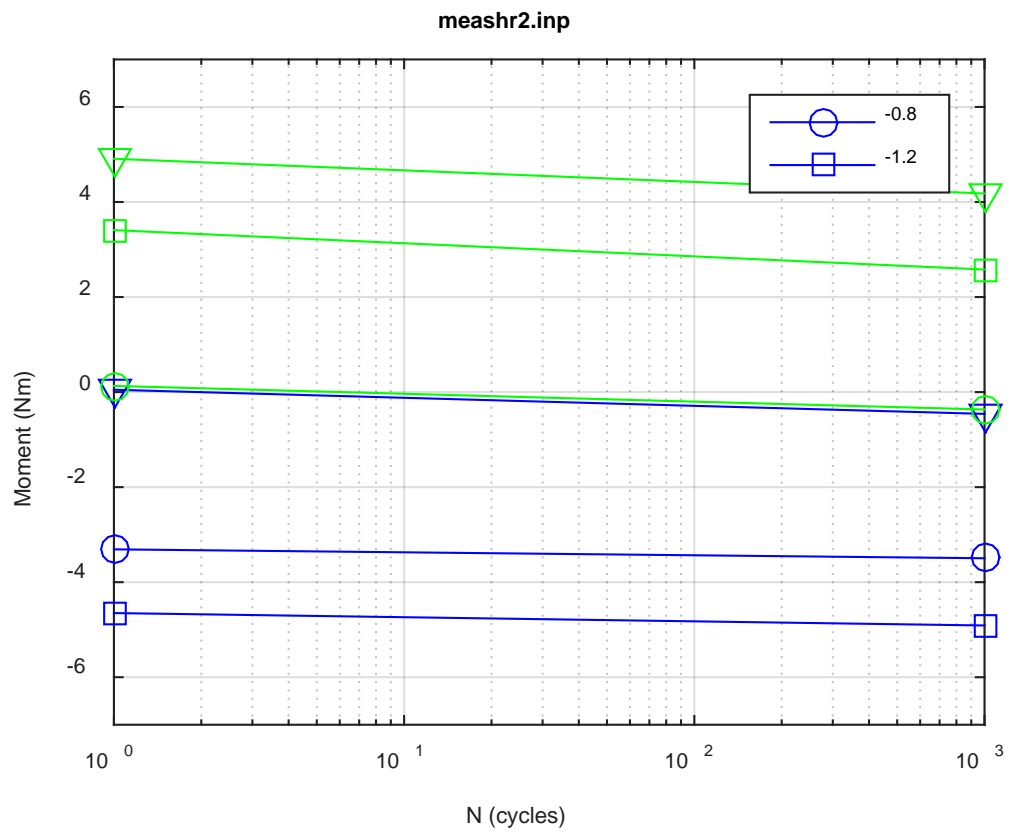

(e)

Fig. F.5 Measurement-based responses: (a) curvature range, (b) moment range, (c) rigidity, (d) curvature peak/valley, (e) moment peak/valley, HR2, 16.26 Nm. 


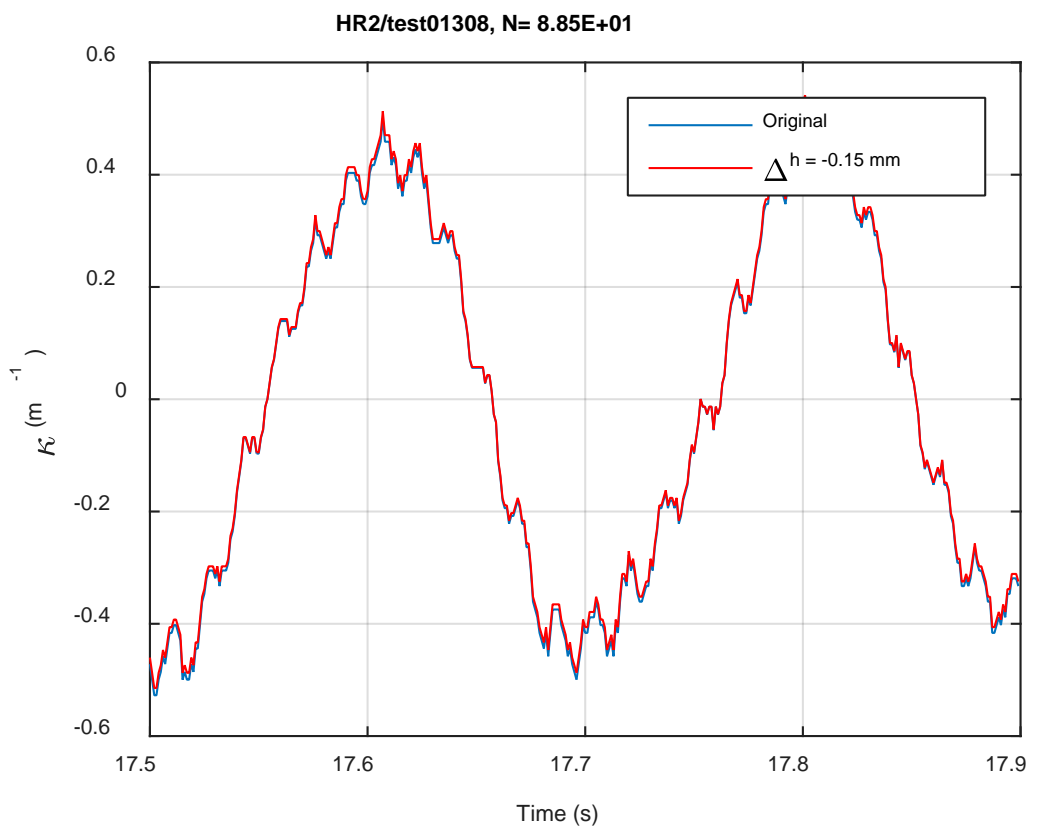

(a)

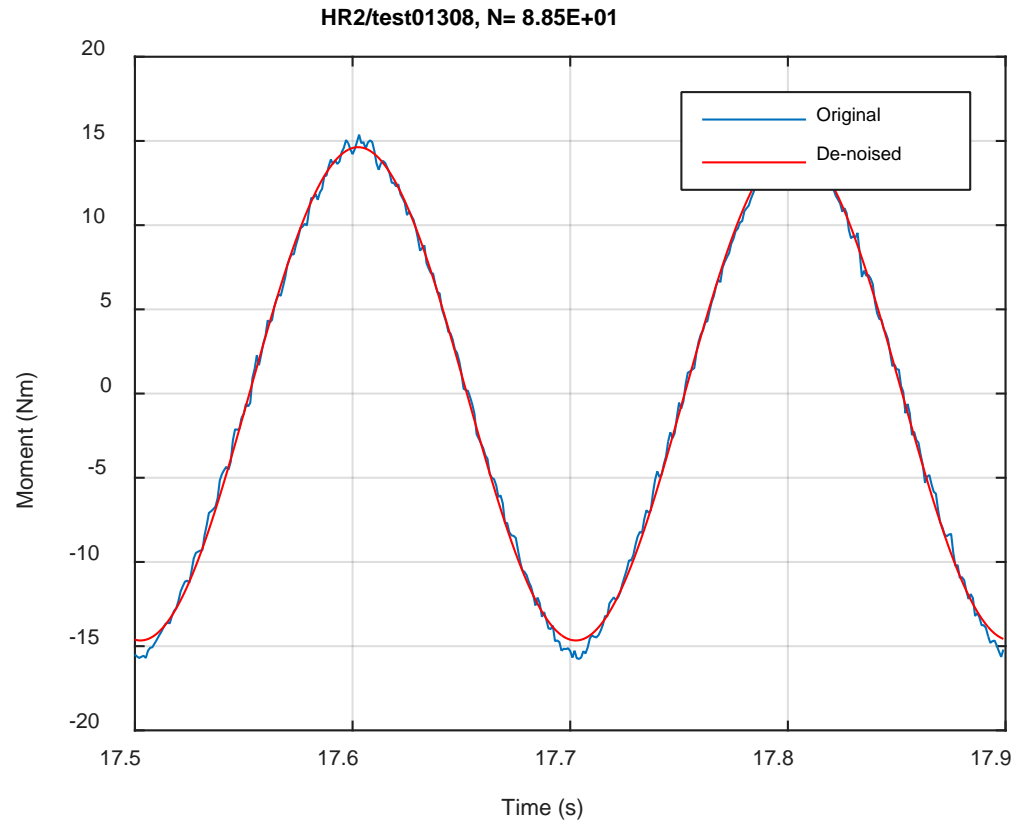

(b) 


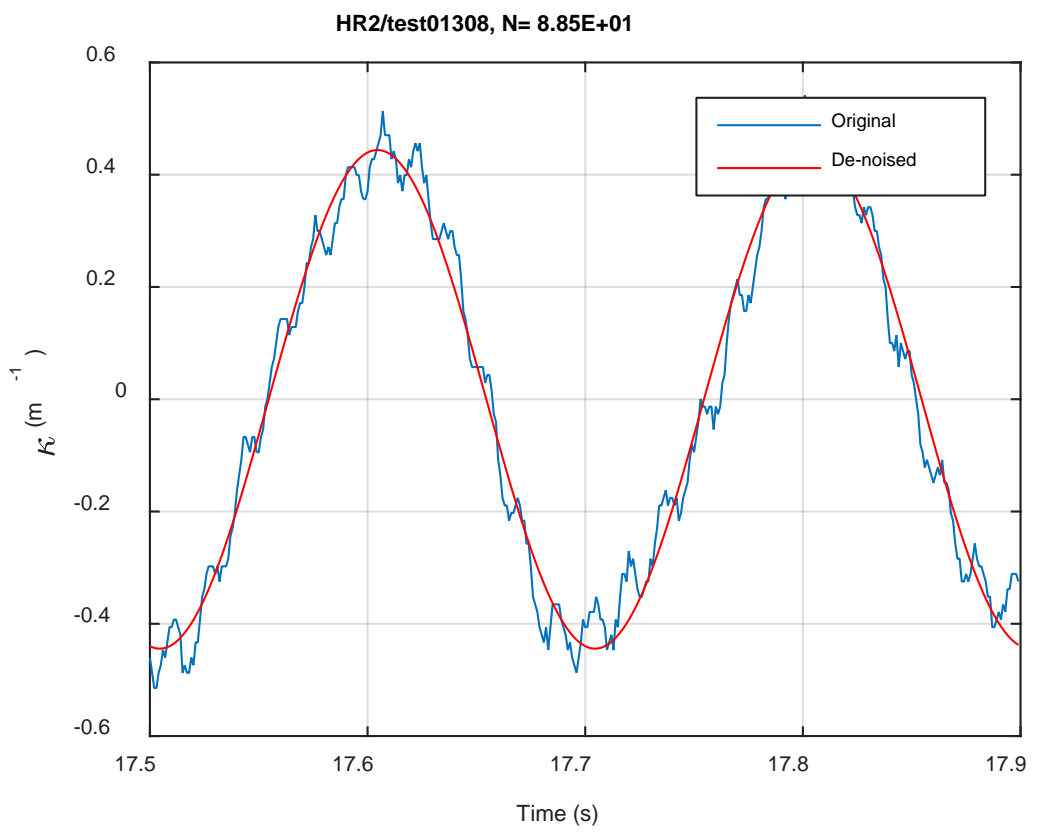

(c)

Fig. F.6 Monitoring-based responses: (a) curvature, (b) moment, (c) curvature, HR2, 16.26 Nm, Ns $=8.85 \mathrm{E}+01$ cycles. 


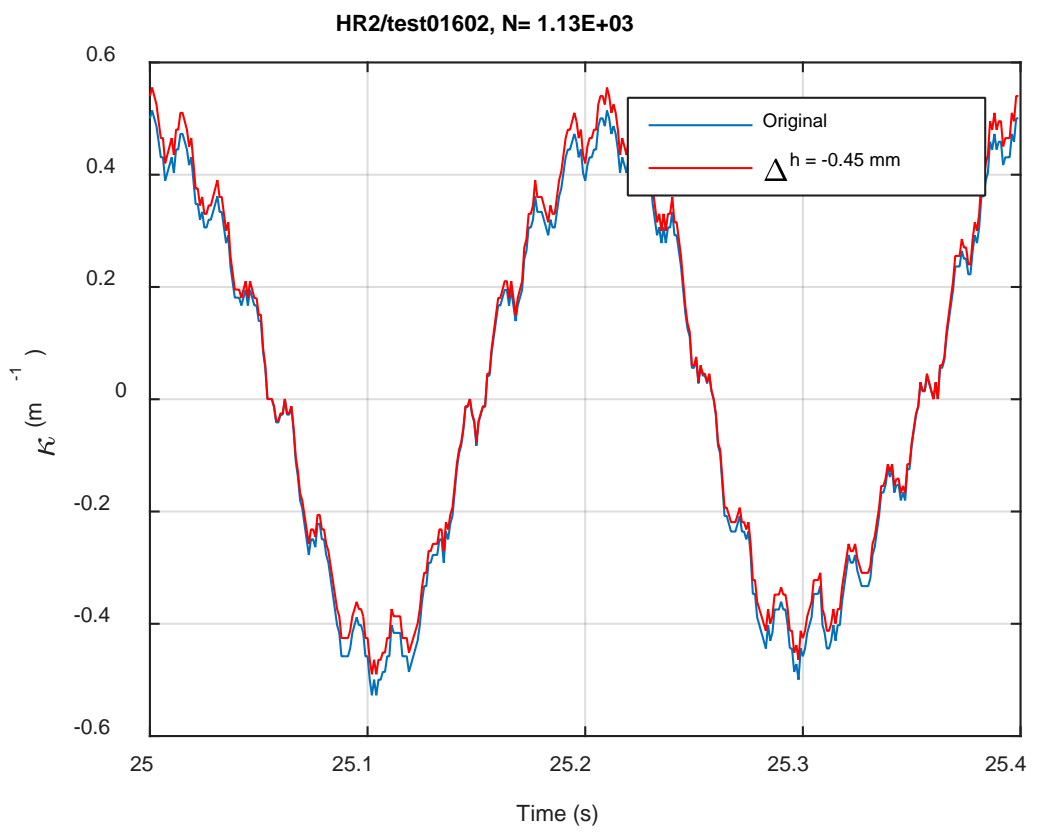

(a)

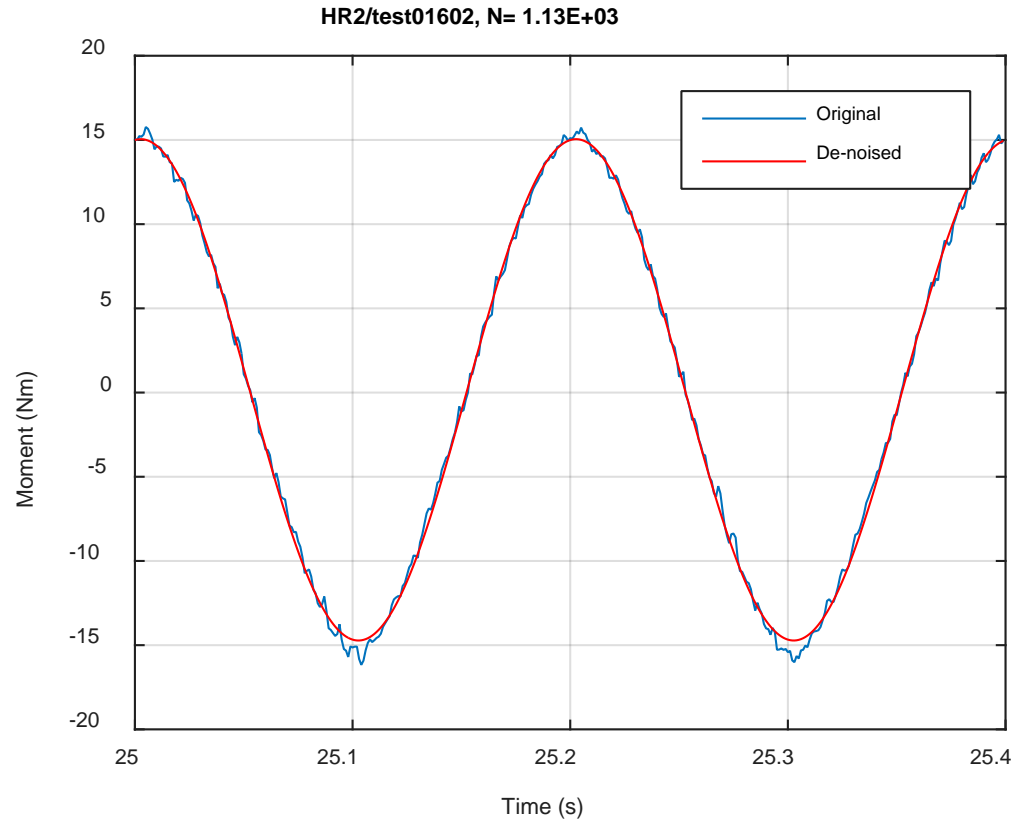

(b) 


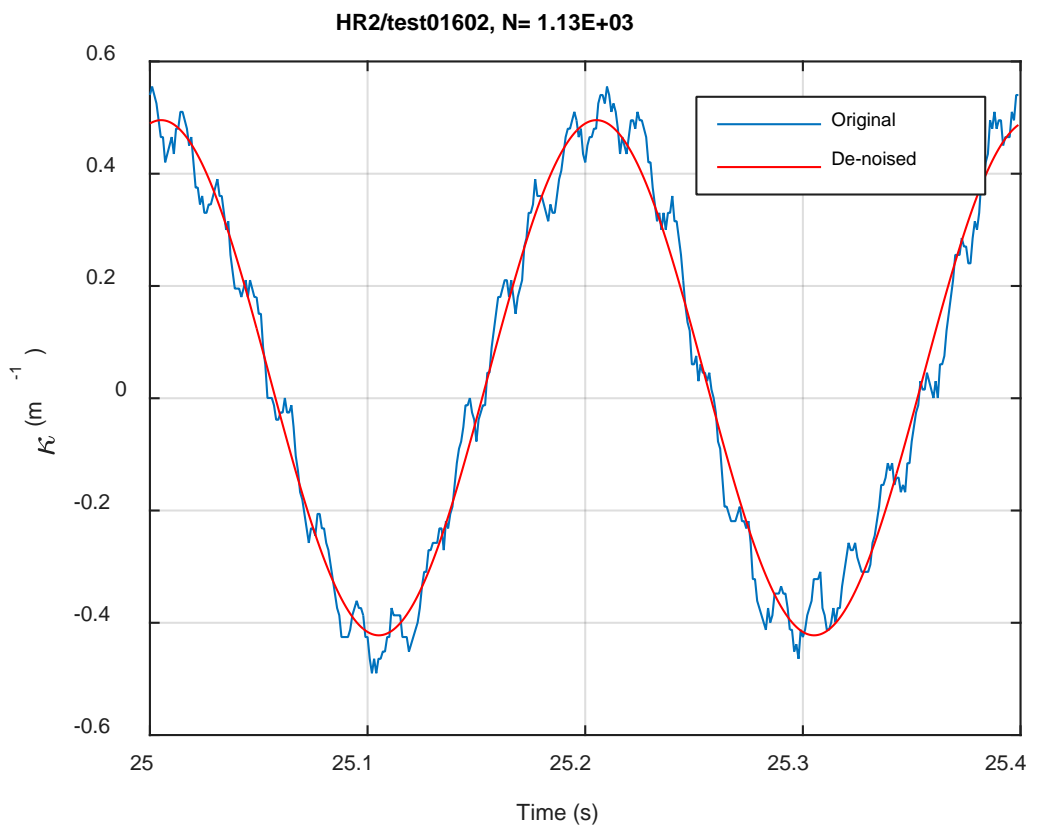

(c)

Fig. F.7 Monitoring-based responses: (a) curvature, (b) moment, (c) curvature, HR2, 16.26 Nm, Ns $=1.13 E+03$ cycles. 


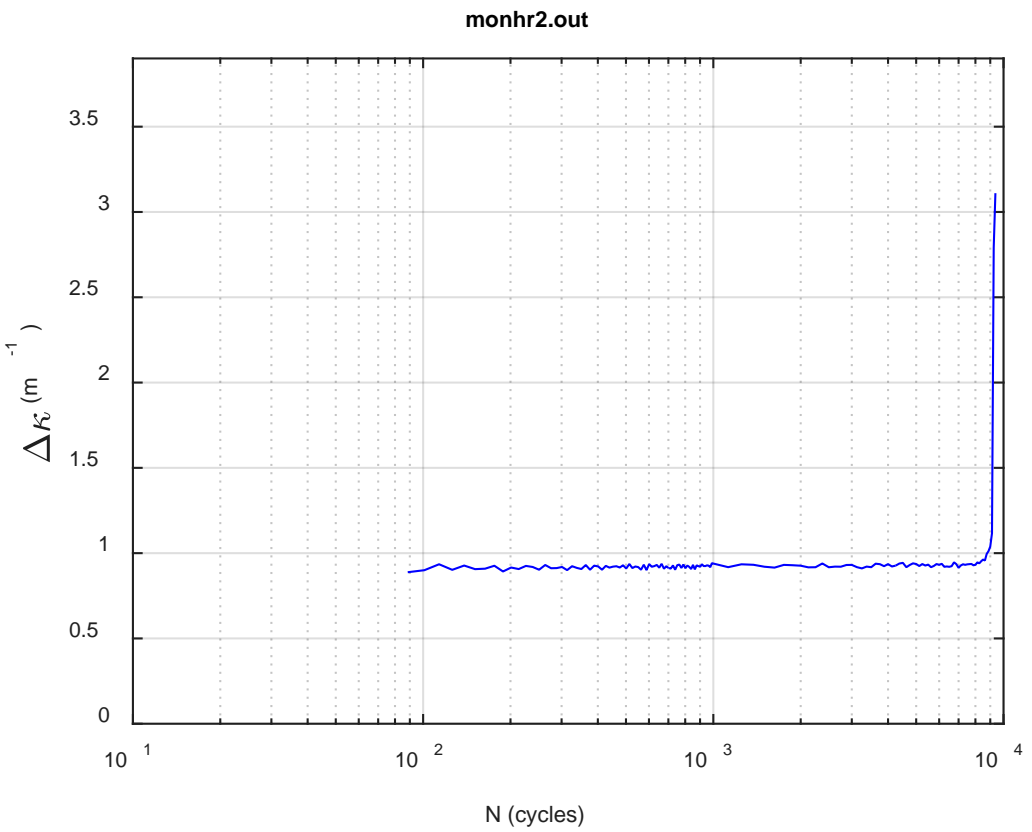

(a)

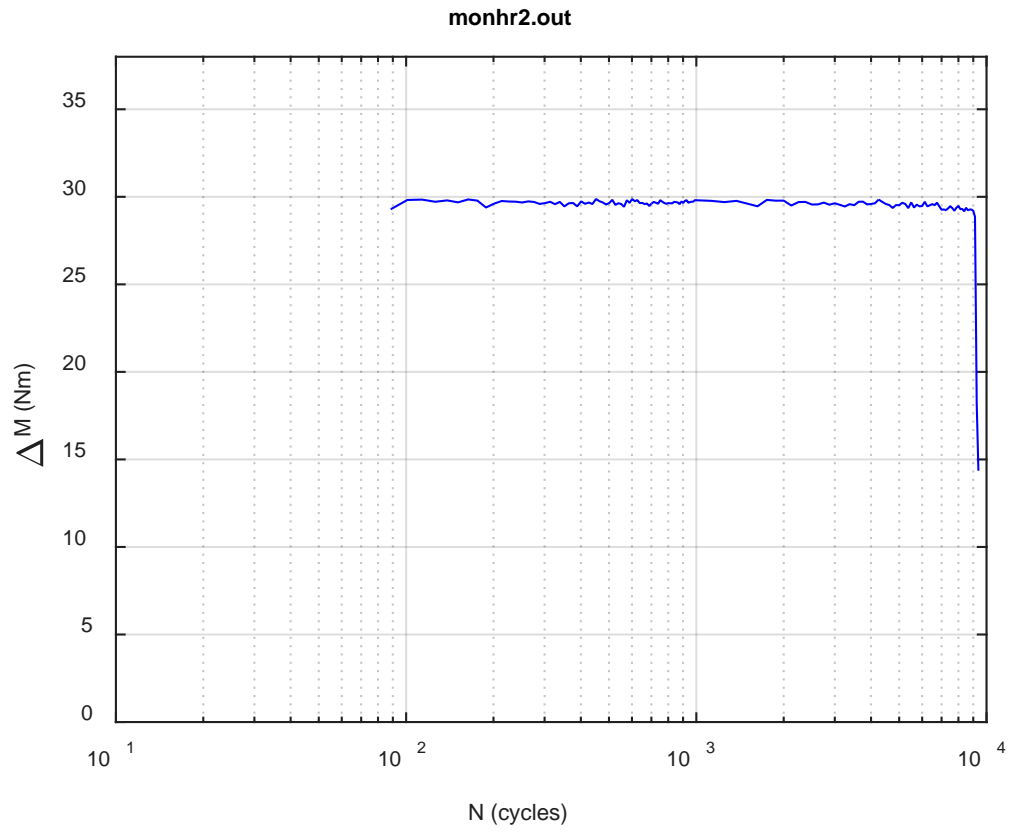

(b)

A-21 


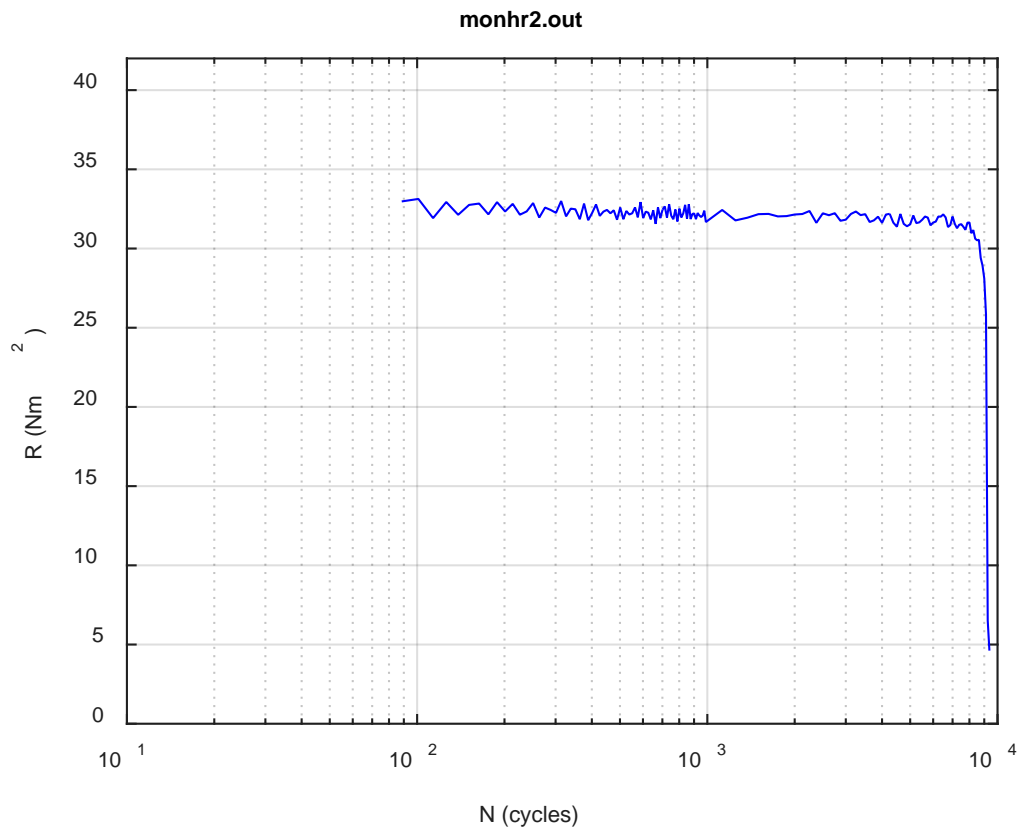

(c)

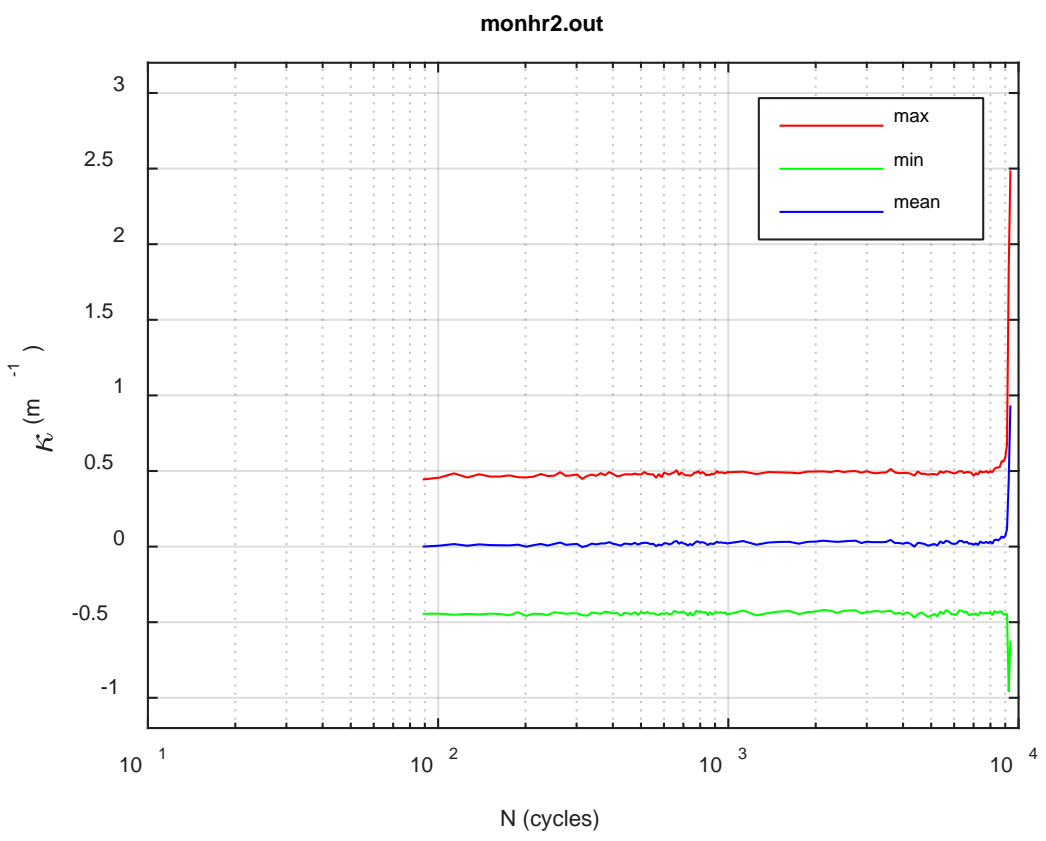

(d) 


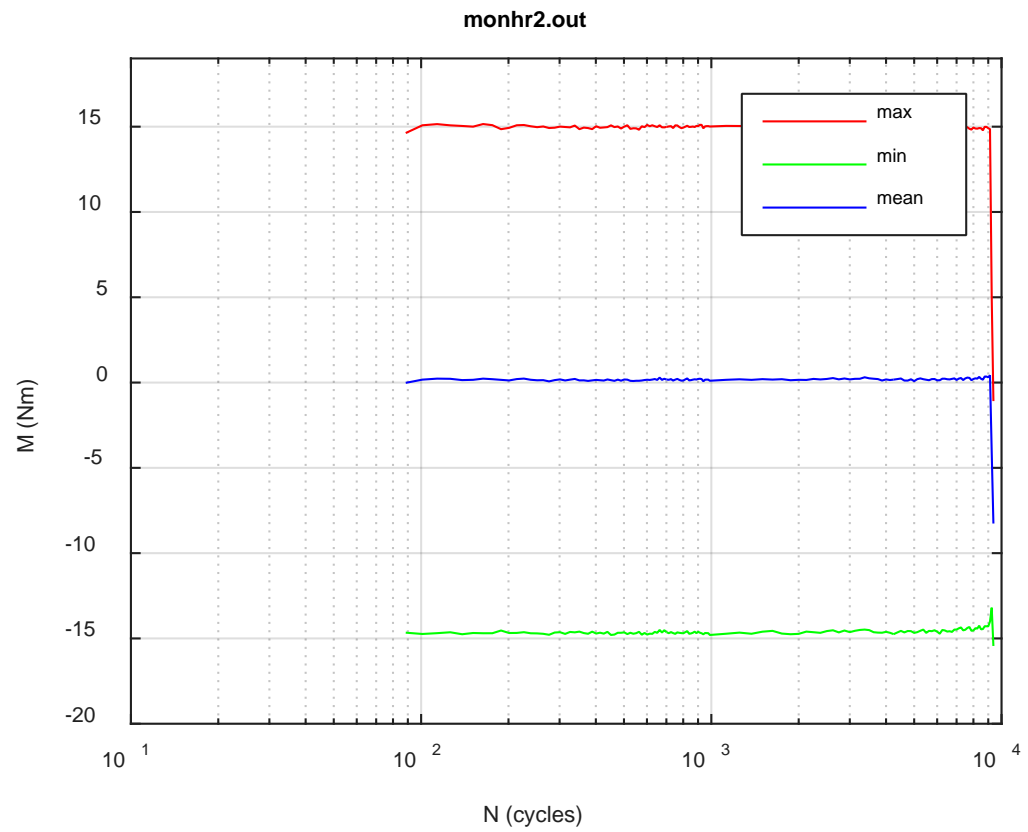

(e)

Fig. F.8 Monitoring-based responses: (a) curvature range, (b) moment range, (c) rigidity, (d) curvature peak/valley, (e) moment peak/valley, HR2, $16.26 \mathrm{Nm}, \mathrm{Nf}=9.47 \mathrm{E}+03$ cycles. 


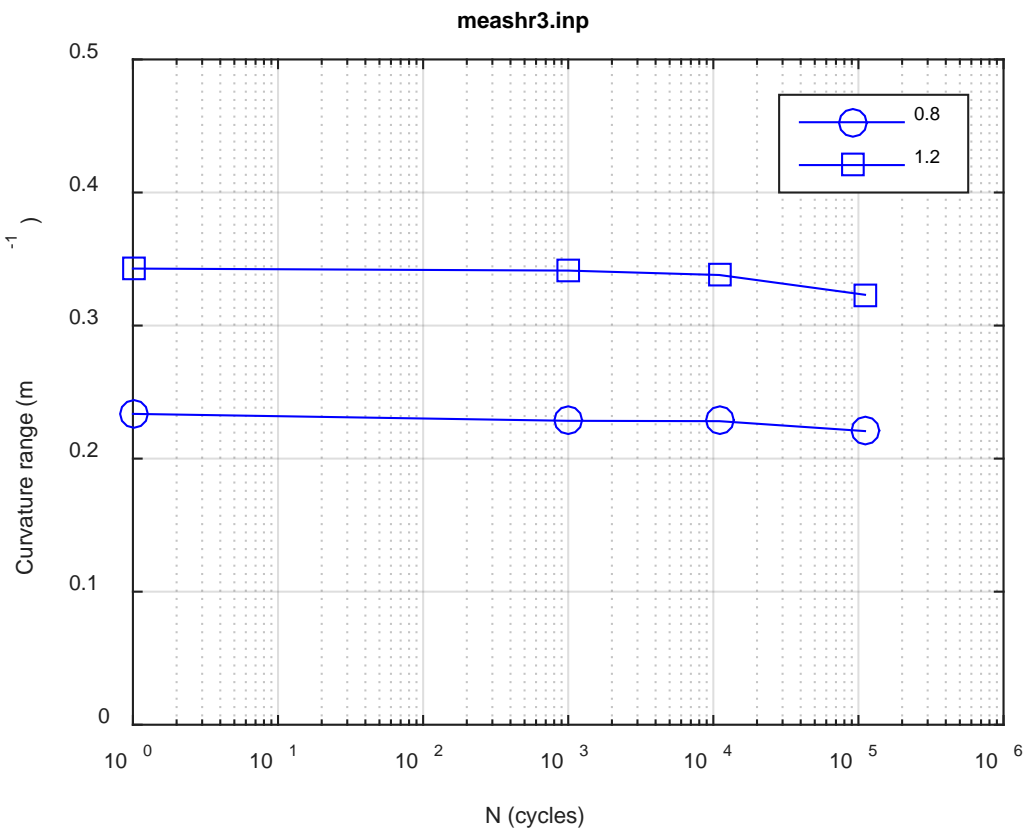

(a)

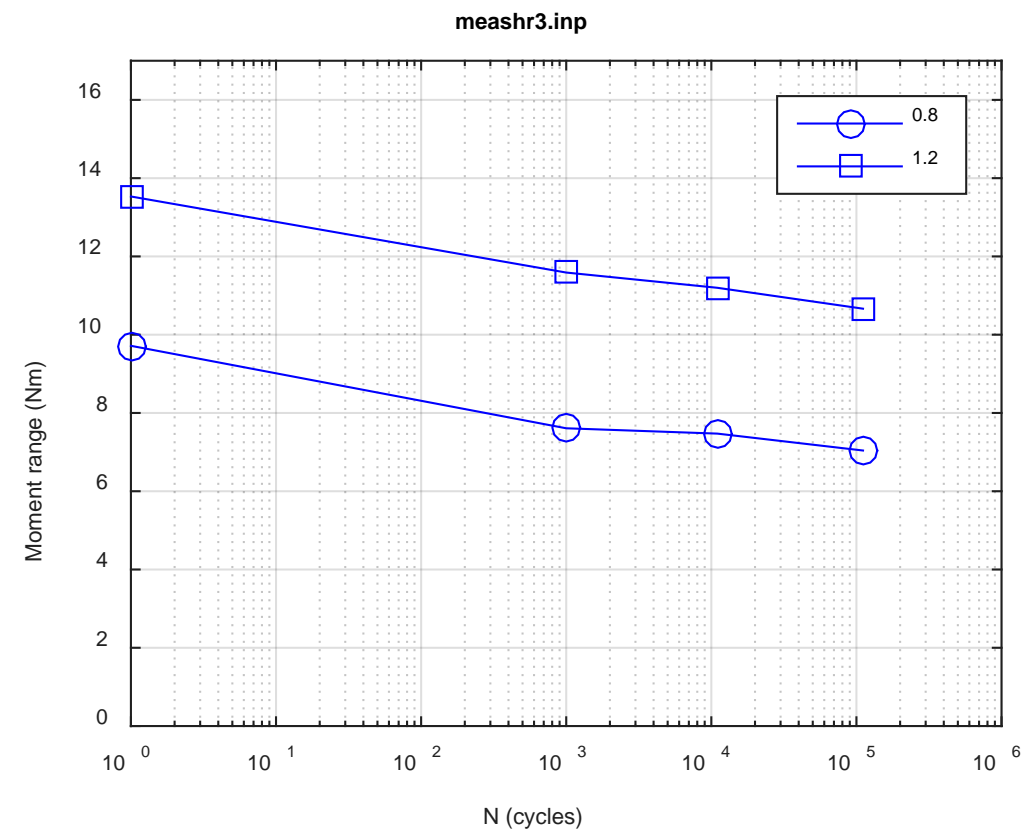

(b) 


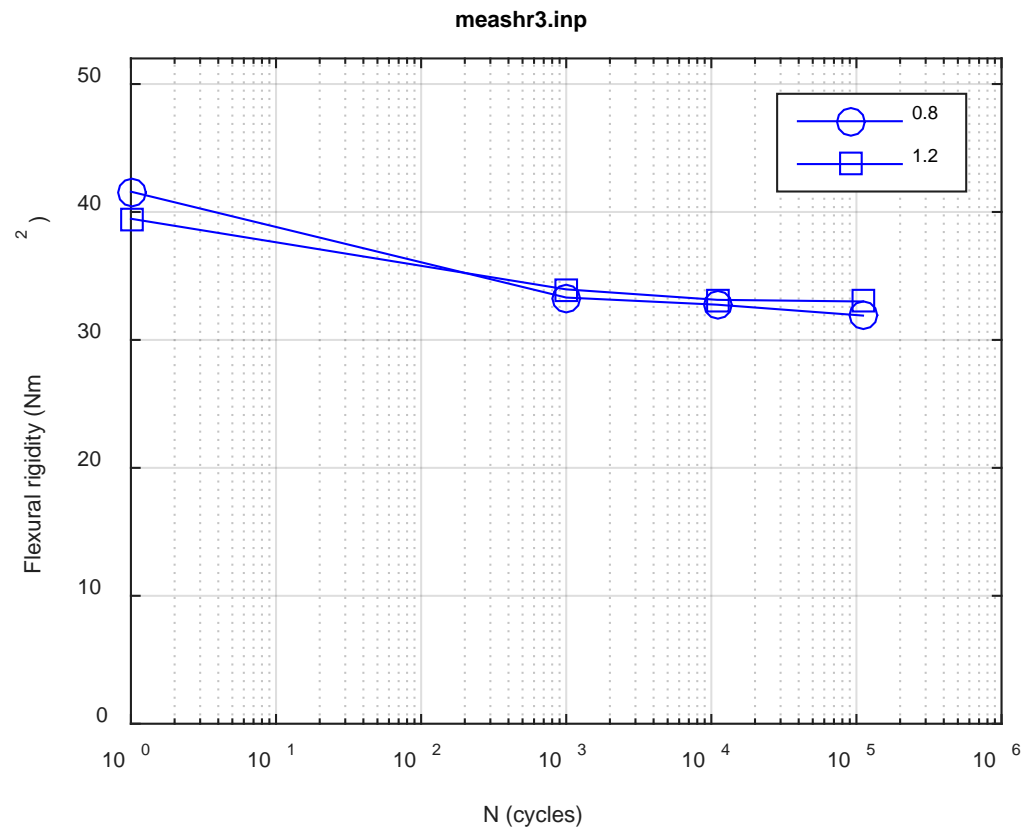

(c)

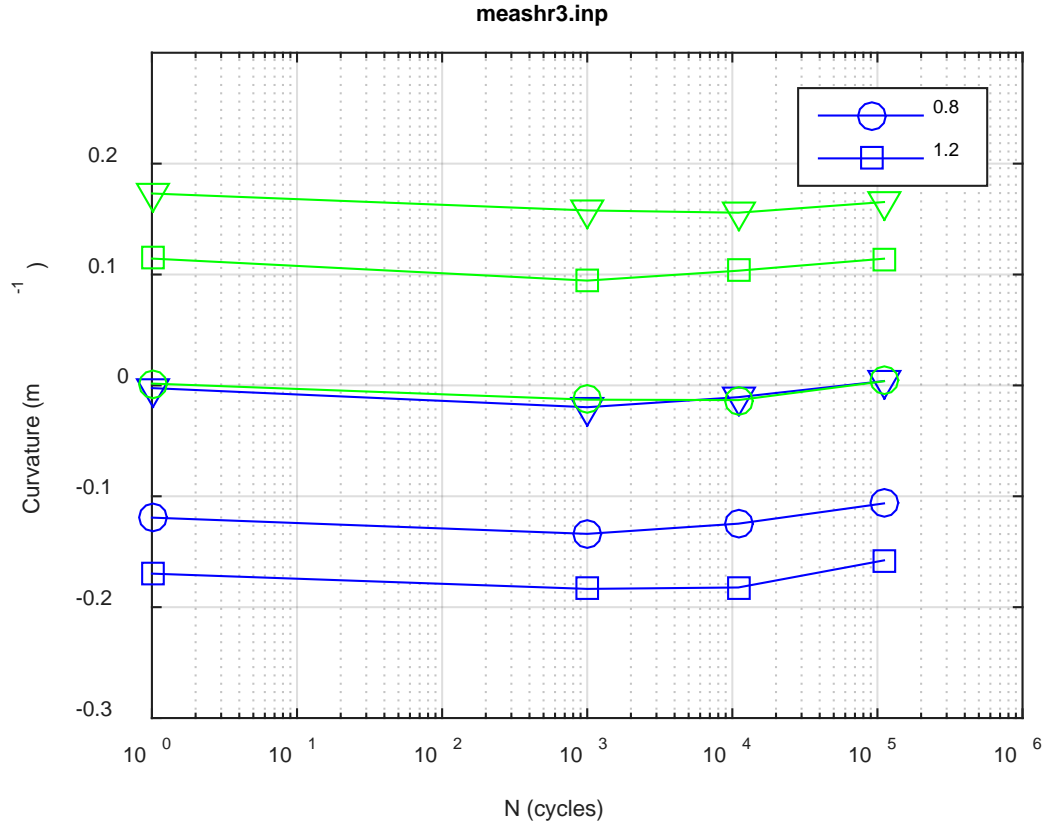

(d) 


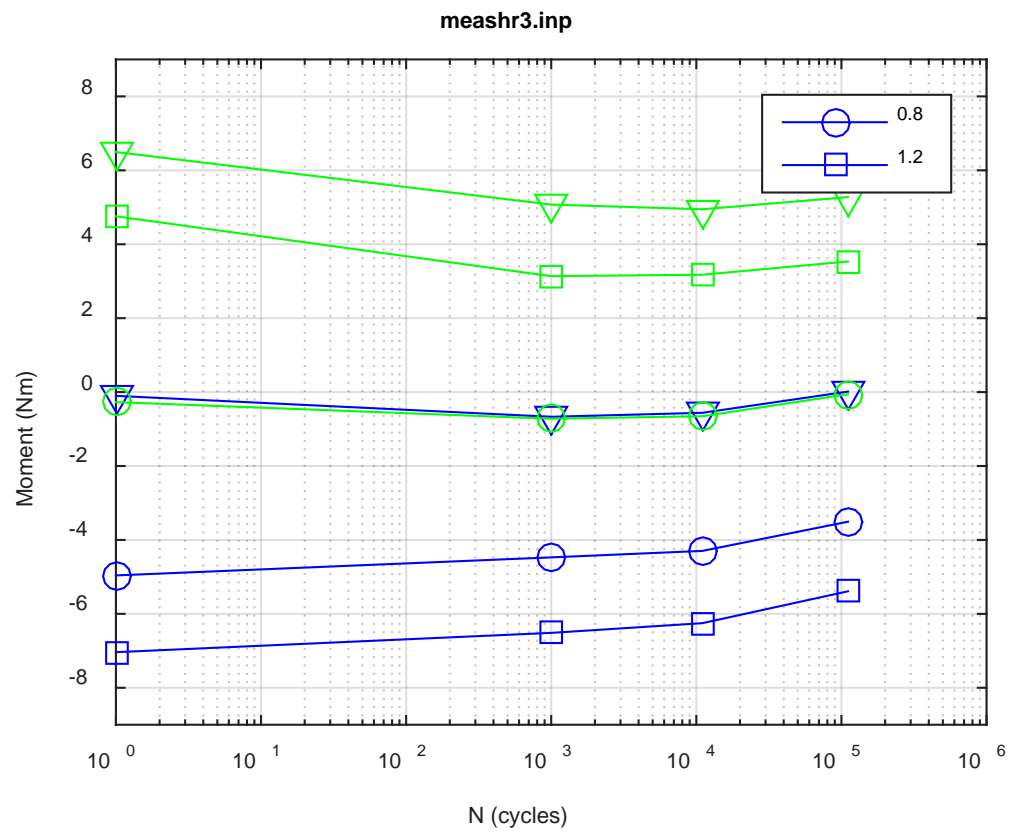

(e)

Fig. F.9 Measurement-based responses: (a) curvature range, (b) moment range, (c) rigidity, (d) curvature peak/valley, (e) moment peak/valley, HR3, 10.16 Nm. 


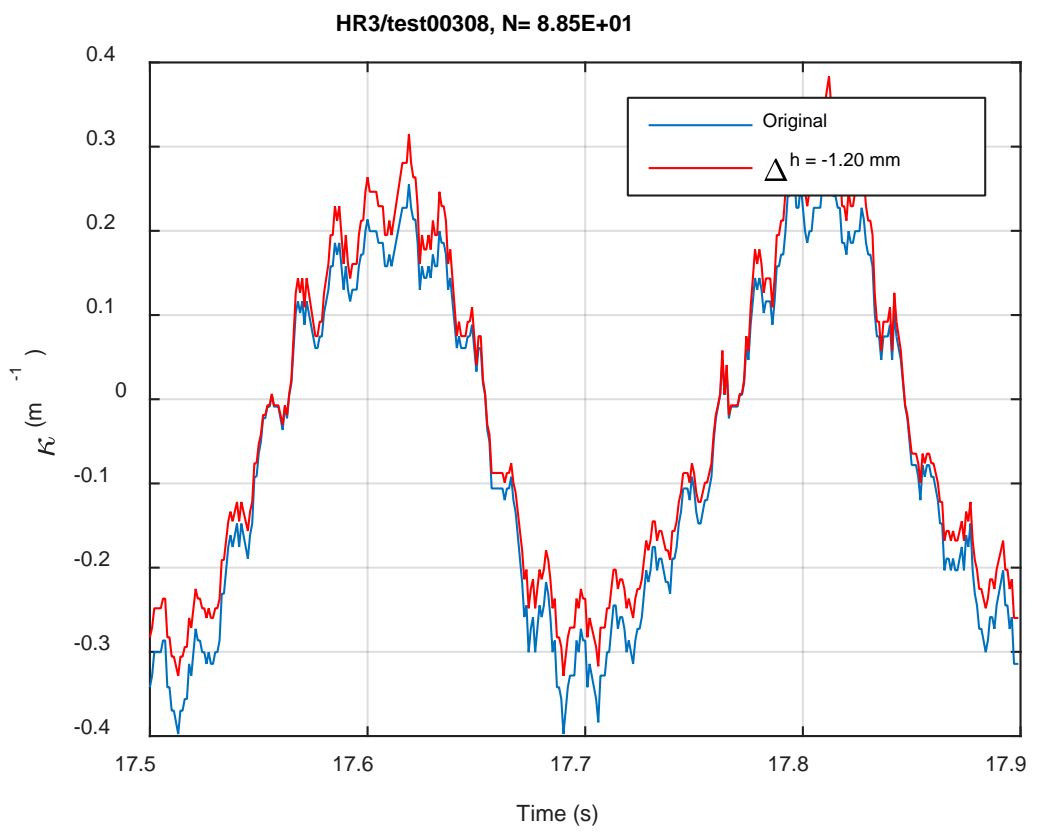

(a)

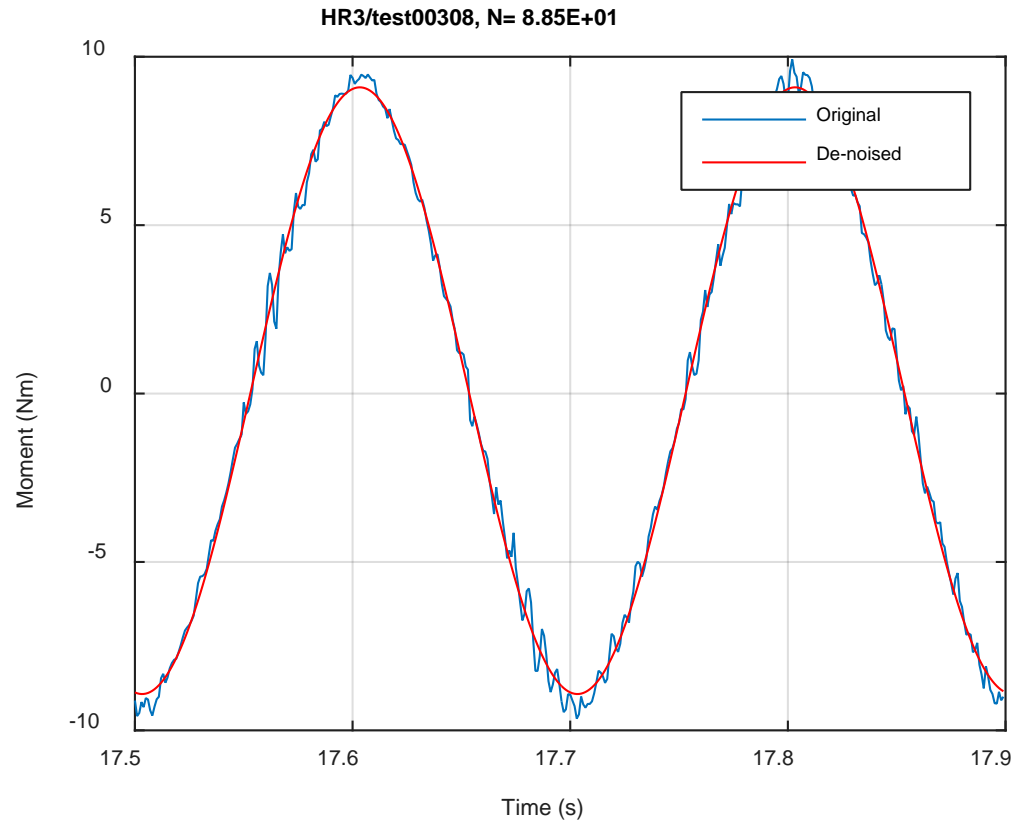

(b) 


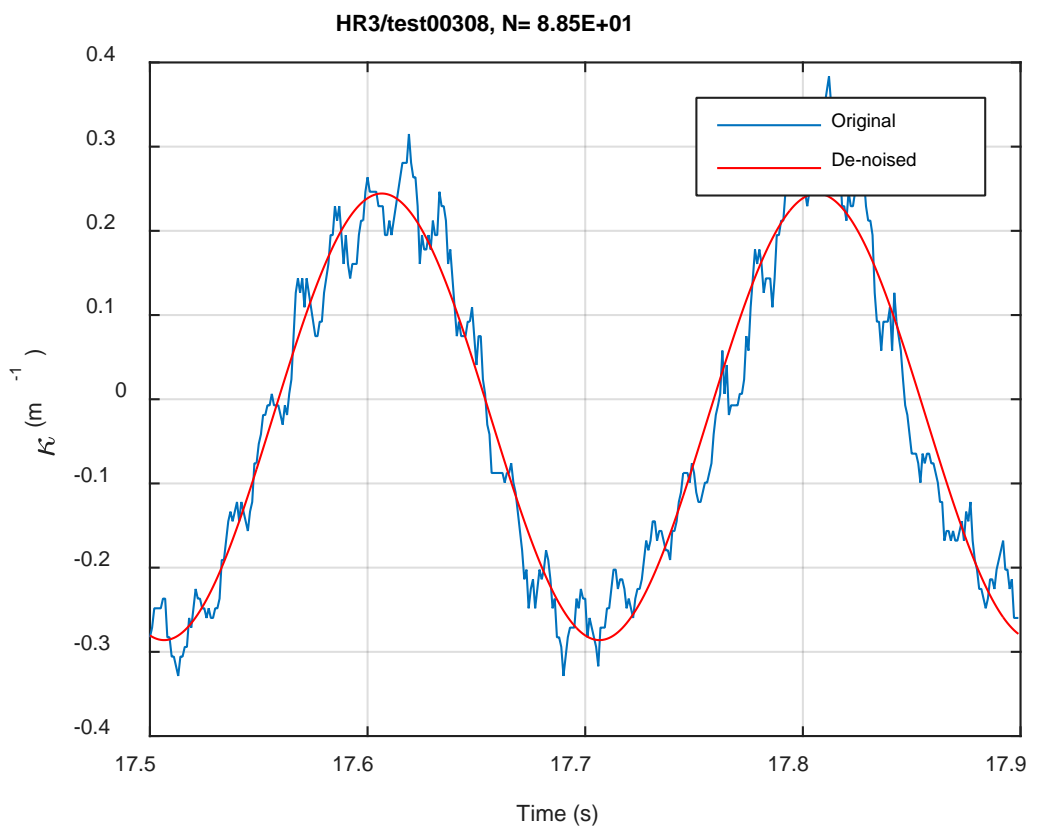

(c)

Fig. F.10 Monitoring-based responses: (a) curvature, (b) moment, (c) curvature, HR3, 10.16 Nm, Ns $=8.85 \mathrm{E}+01$ cycles. 


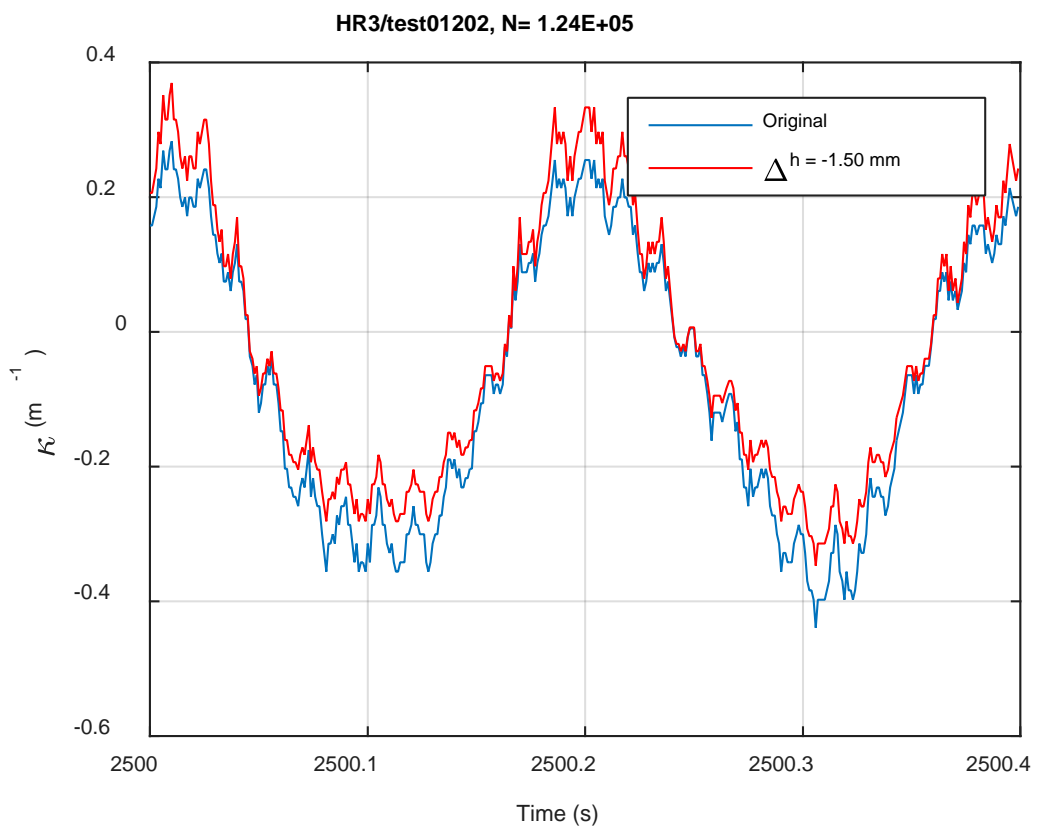

(a)

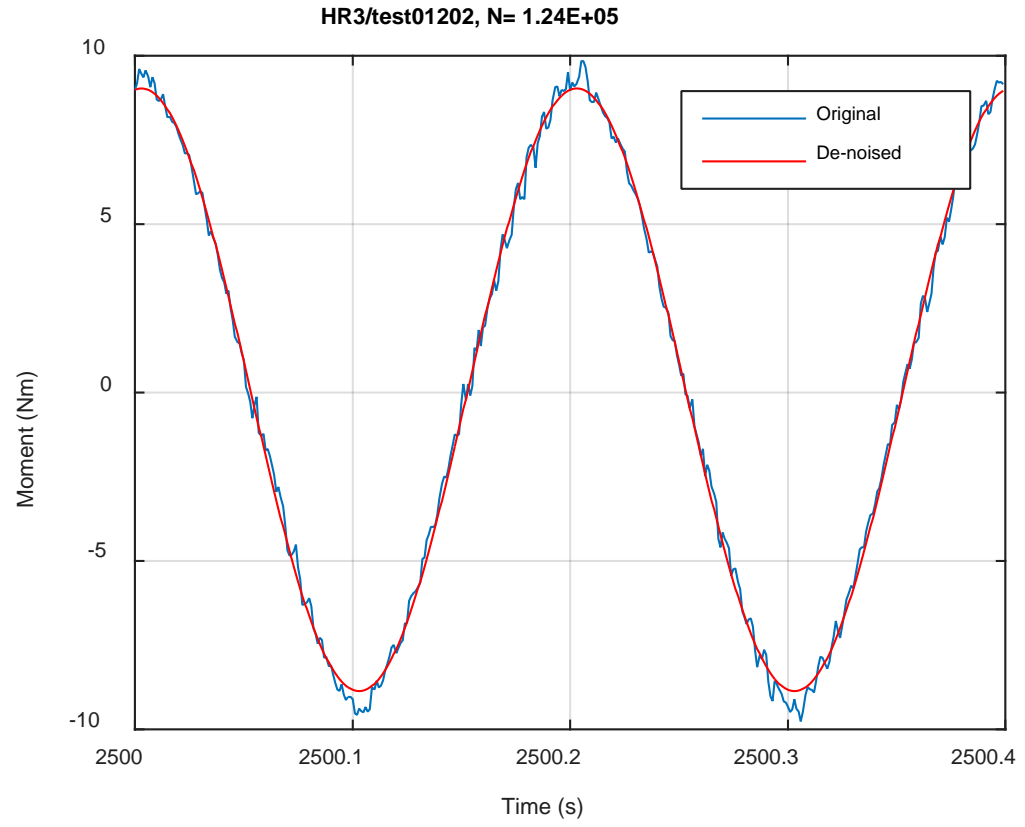

(b) 


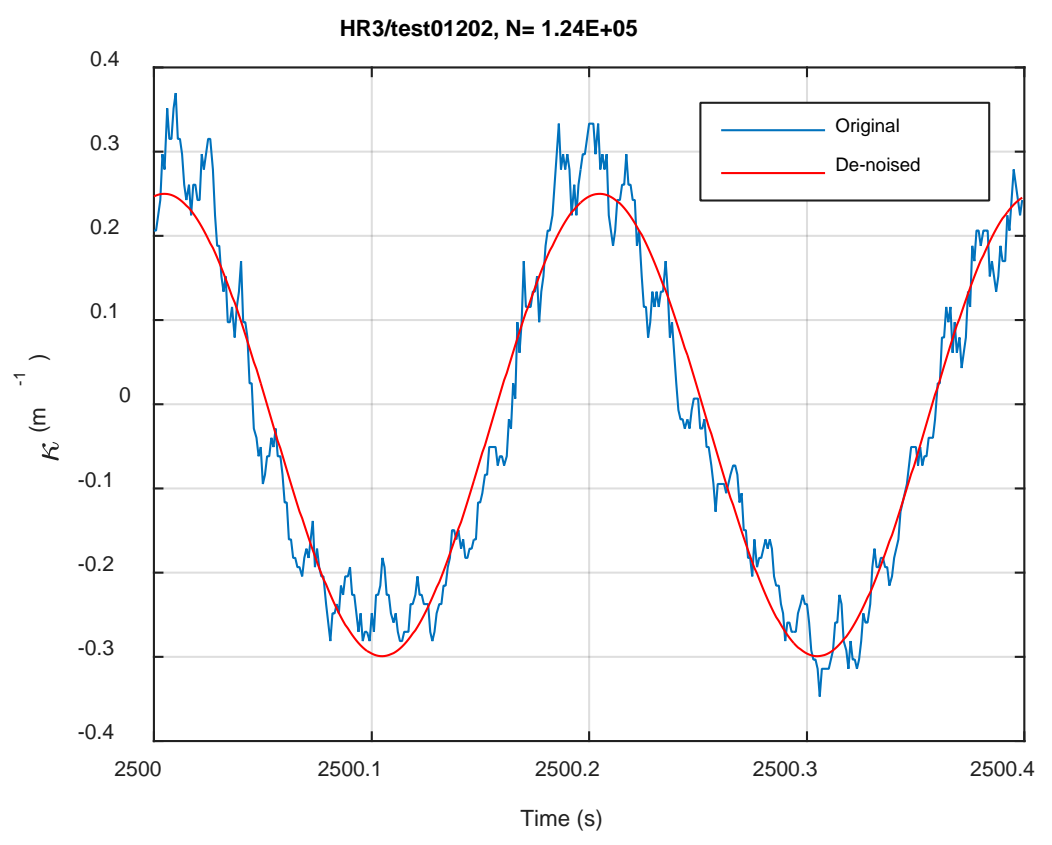

(c)

Fig. F.11 Monitoring-based responses: (a) curvature, (b) moment, (c) curvature, HR3, 10.16 Nm, $\mathrm{Ns}=1.24 \mathrm{E}+05$ cycles. 


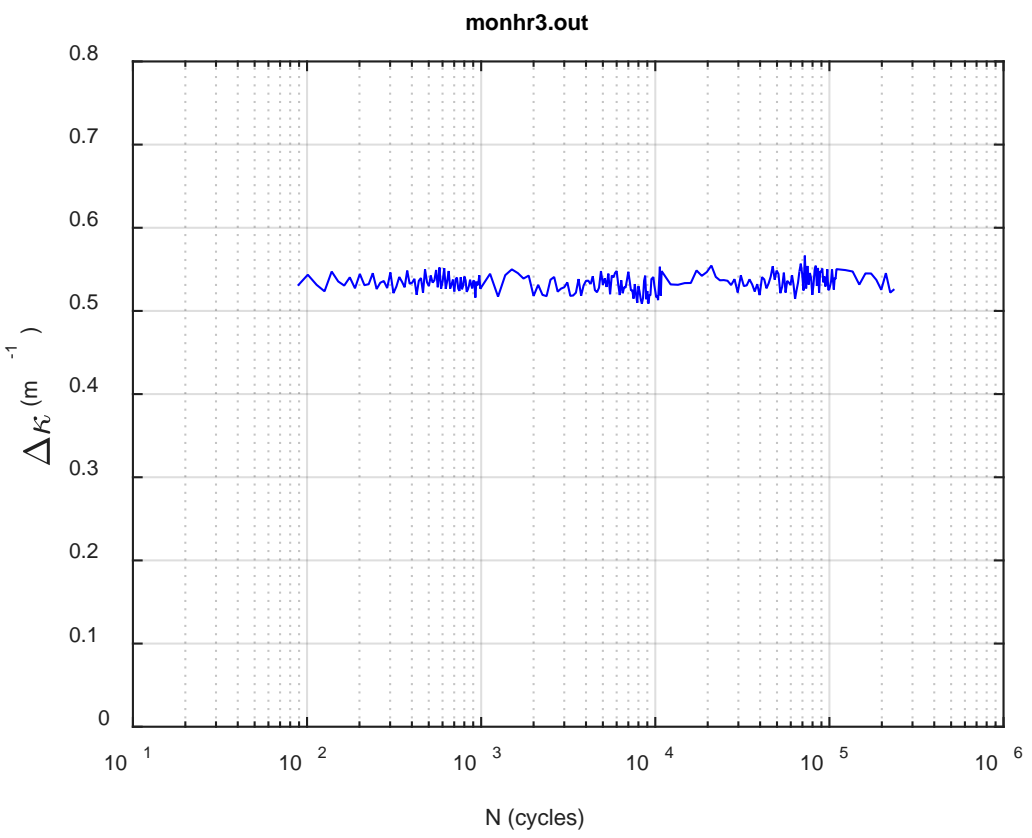

(a)

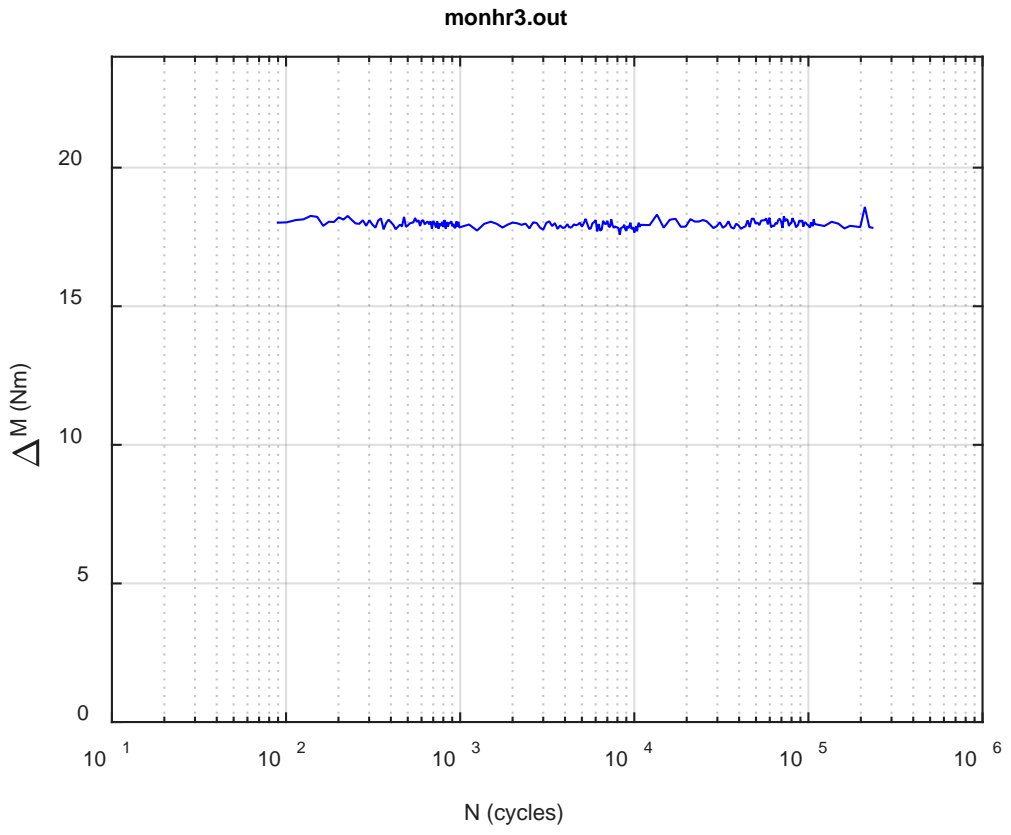

(b) 


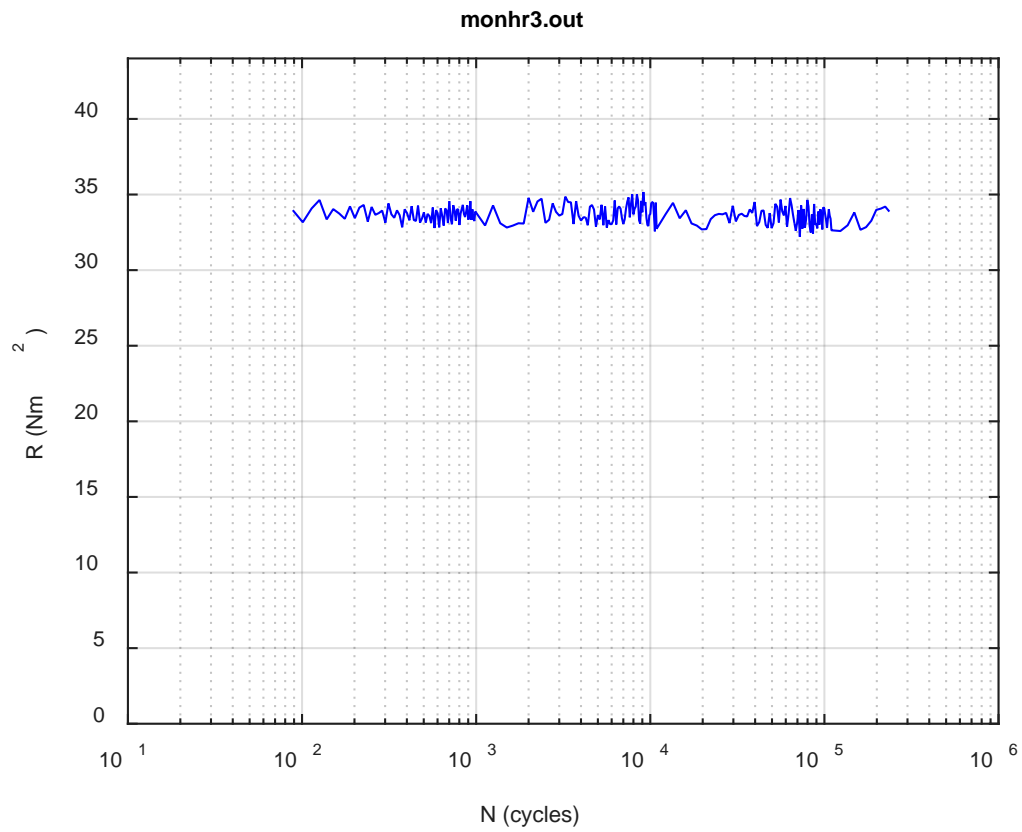

(c)

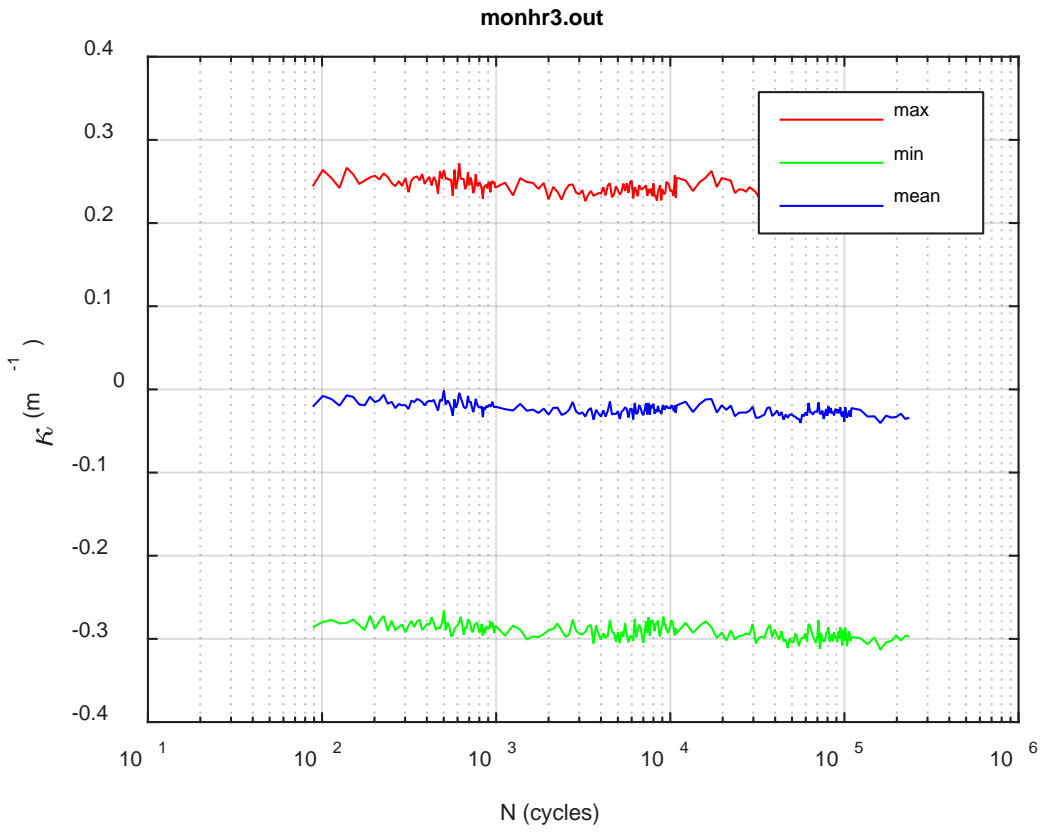

(d) 


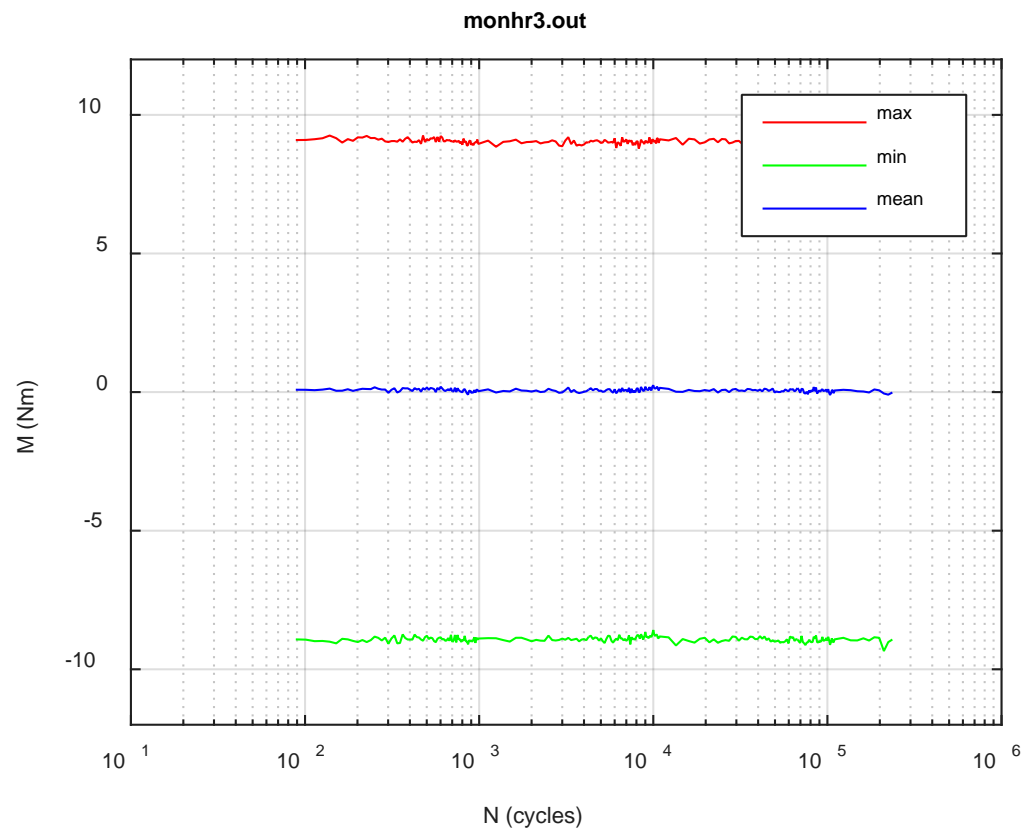

(e)

Fig. F.12 Monitoring-based responses: (a) curvature range, (b) moment range, (c) rigidity, (d) curvature peak/valley, (e) moment peak/valley, HR3, $10.16 \mathrm{Nm}, \mathrm{Nf}=2.44 \mathrm{E}+05$ cycles. 


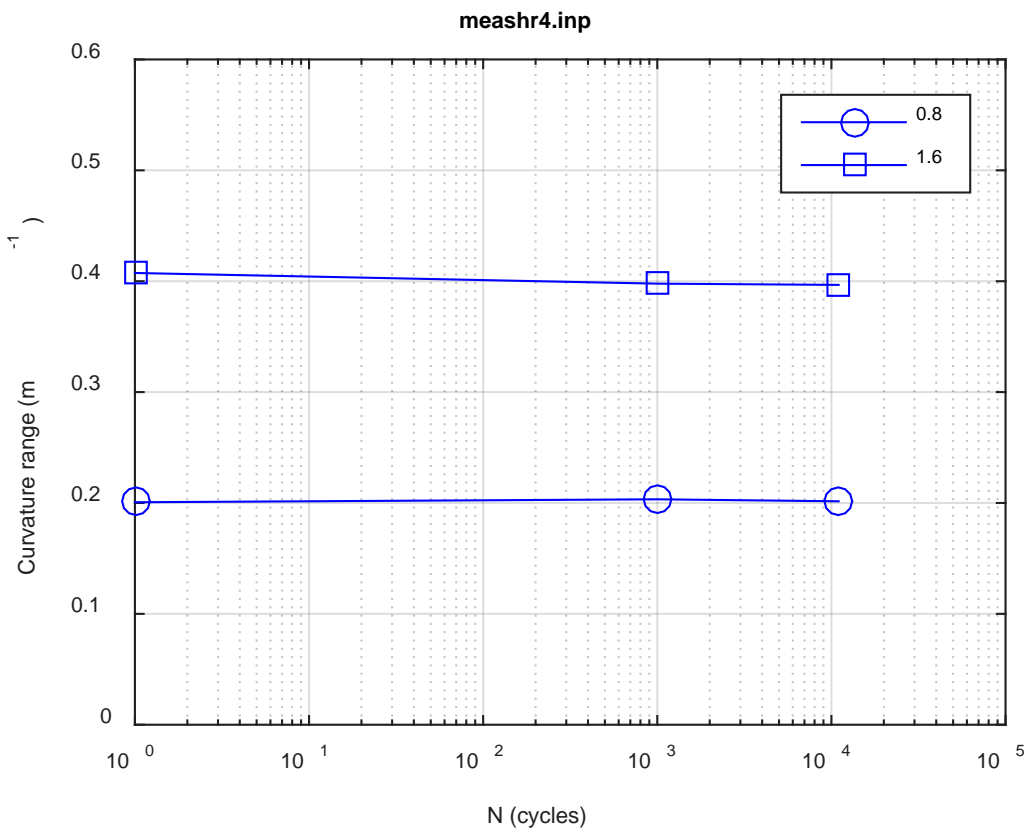

(a)

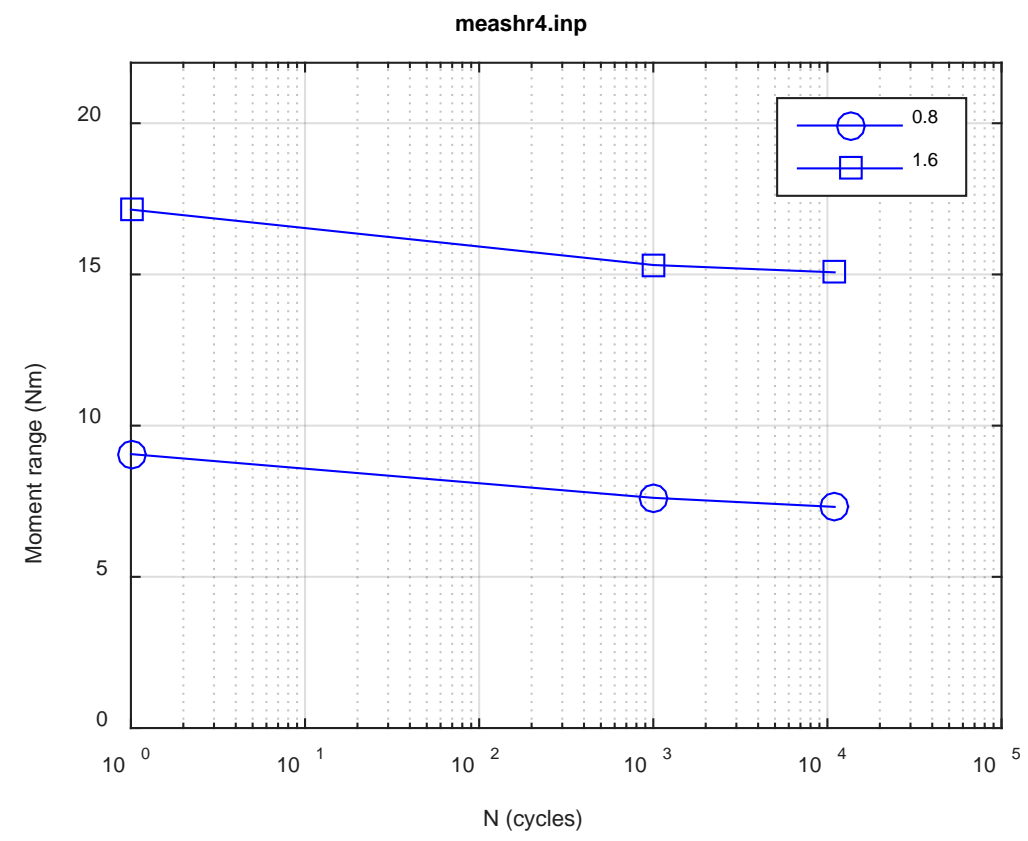

(b) 


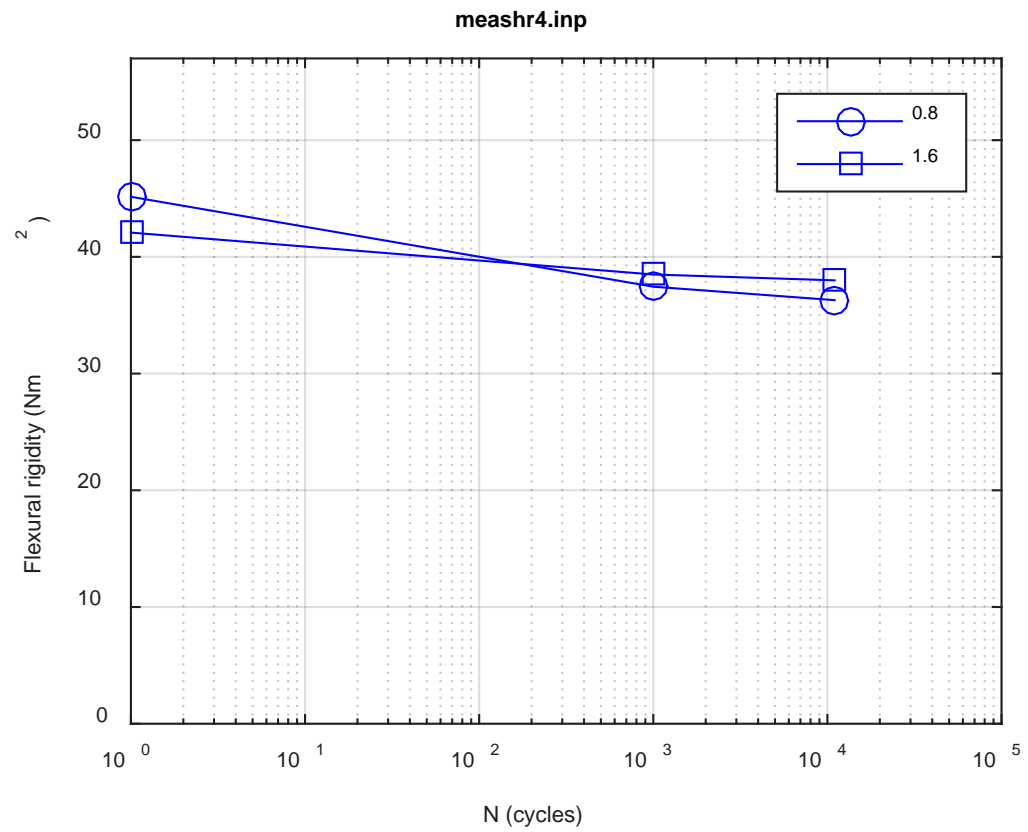

(c)

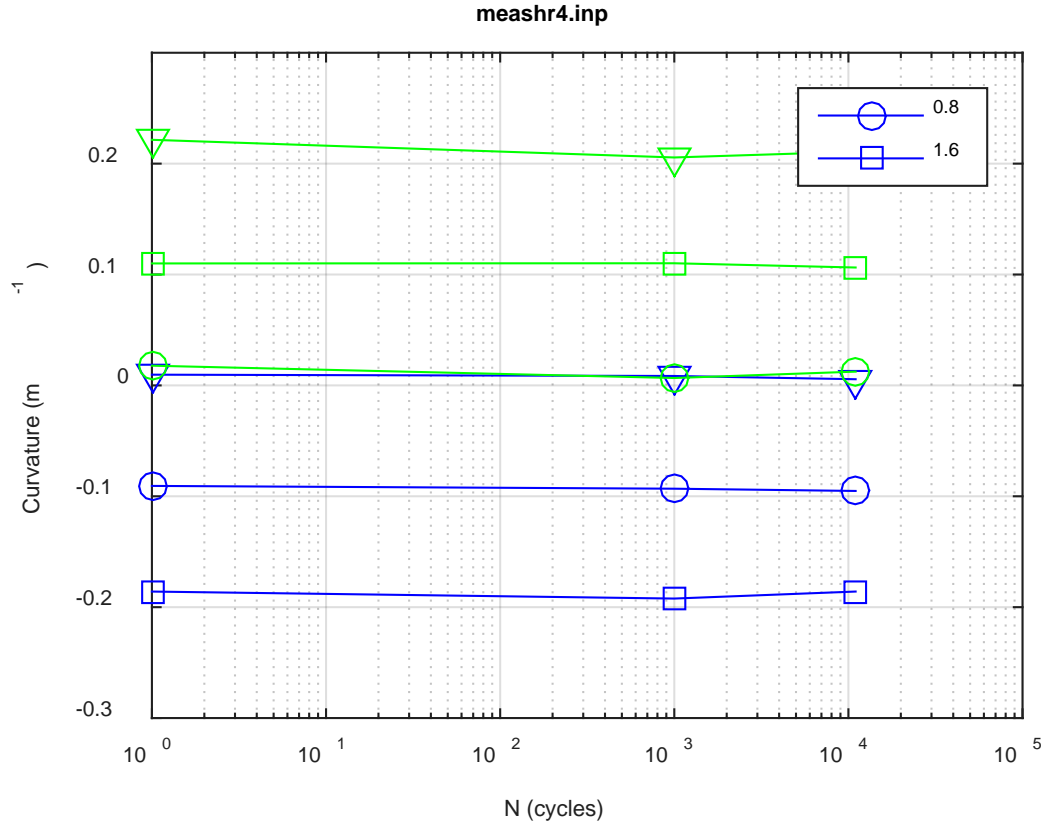

(d) 


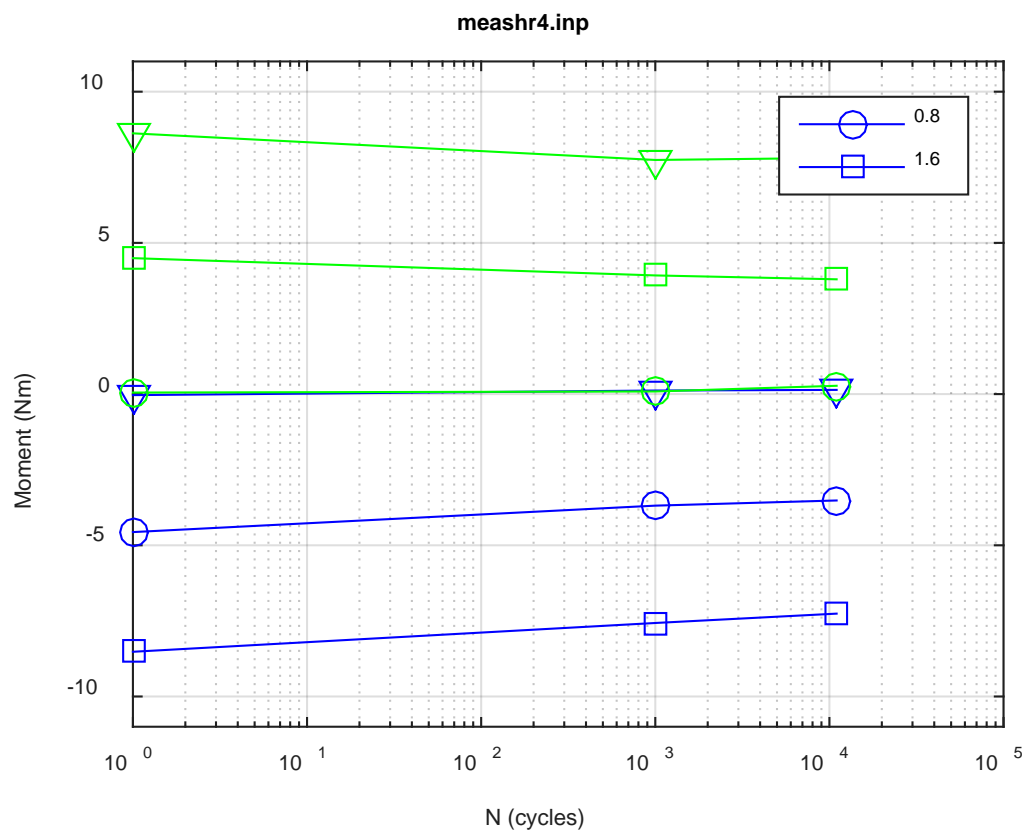

(e)

Fig. F.13 Measurement-based responses: (a) curvature range, (b) moment range, (c) rigidity, (d) curvature peak/valley, (e) moment peak/valley, HR4, 16.26 Nm. 


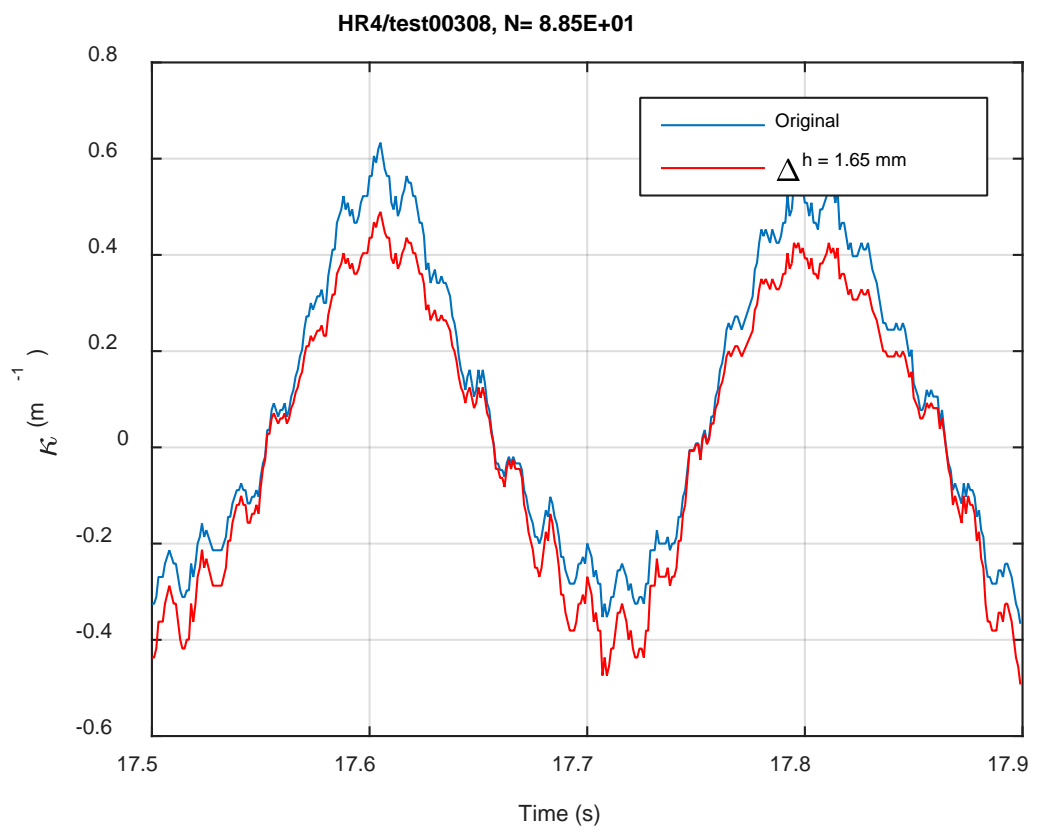

(a)

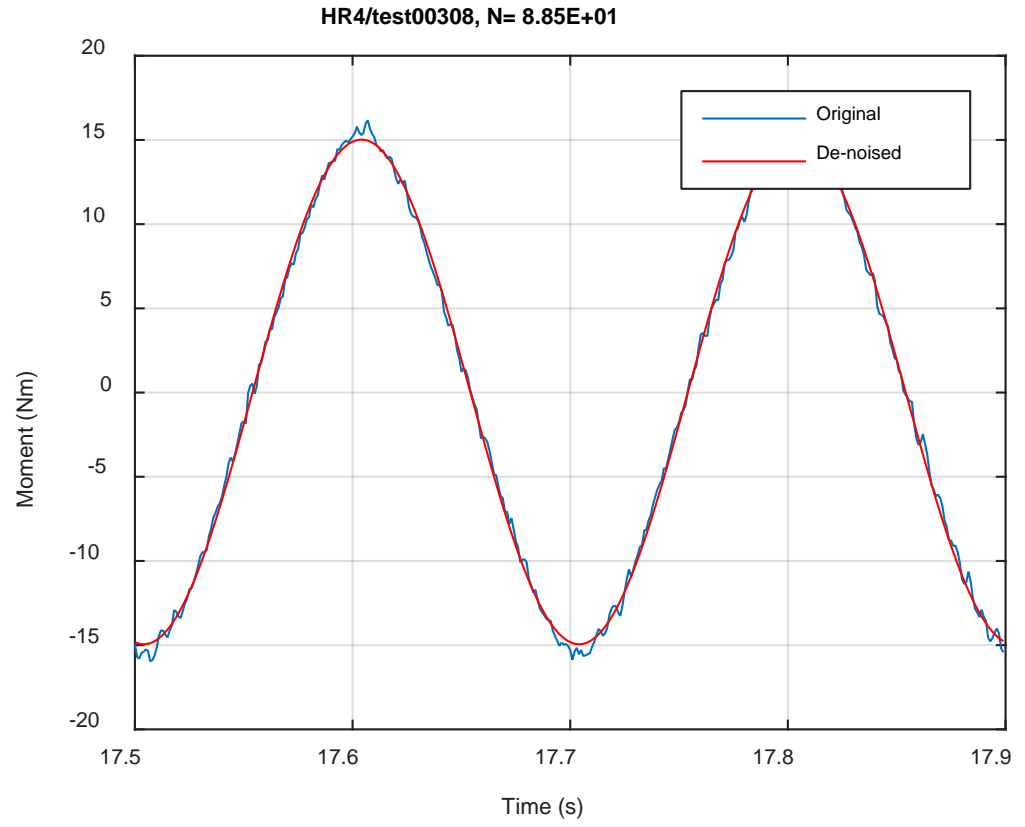

(b) 


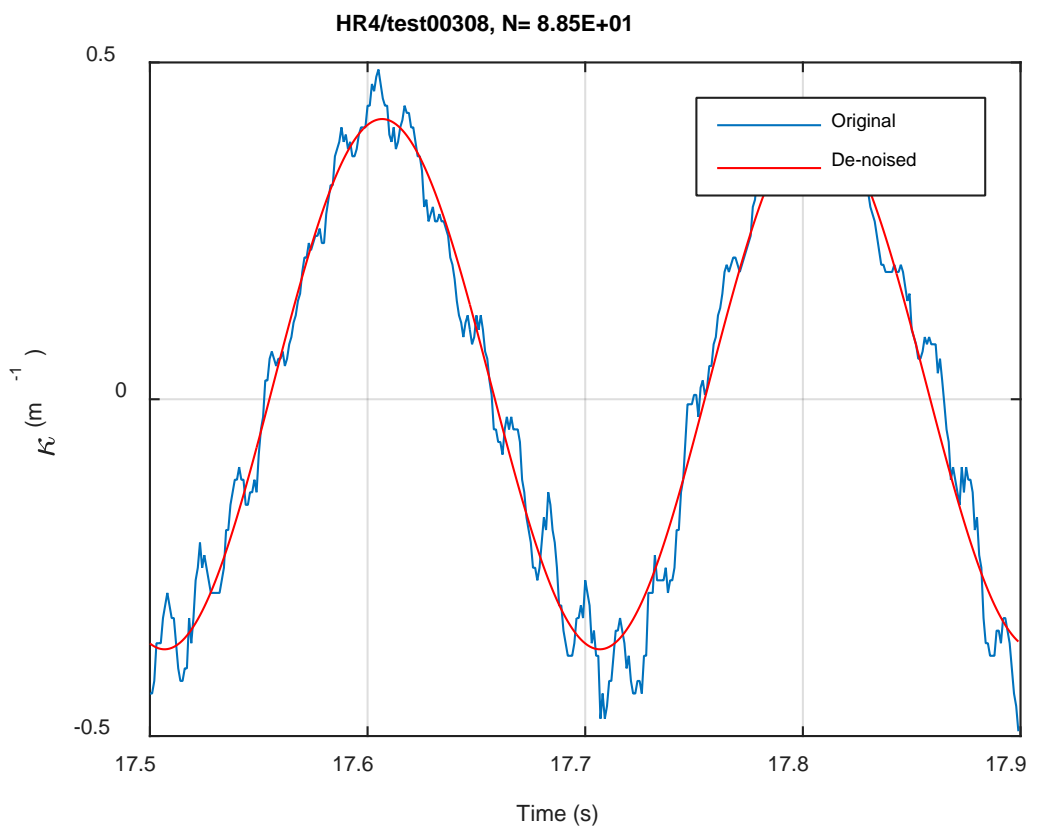

(c)

Fig. F.14 Monitoring-based responses: (a) curvature, (b) moment, (c) curvature, HR4, 16.26 Nm, Ns $=8.85 \mathrm{E}+01$ cycles. 


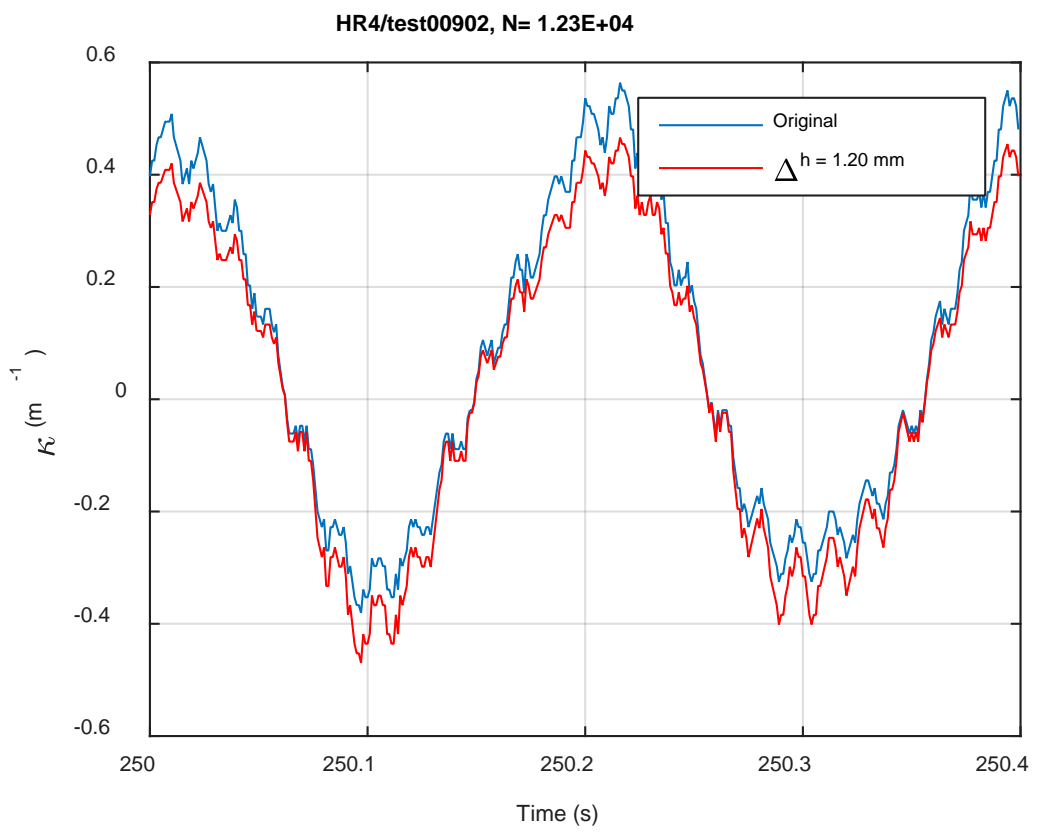

(a)

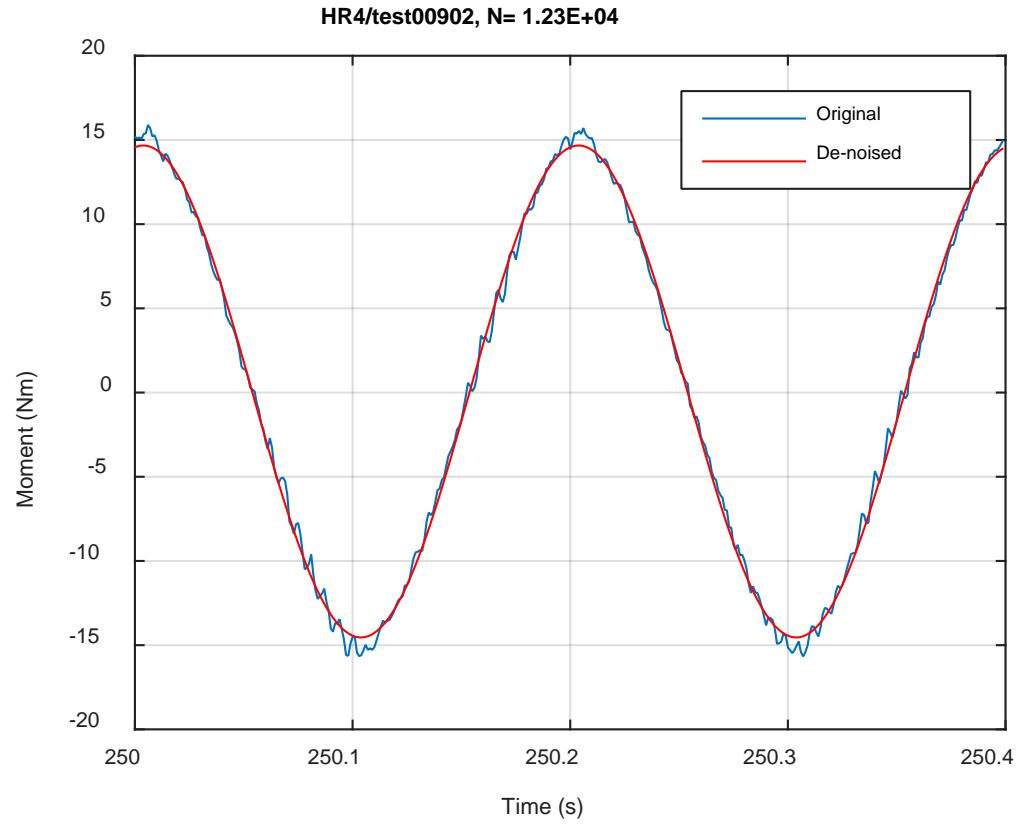

(b) 


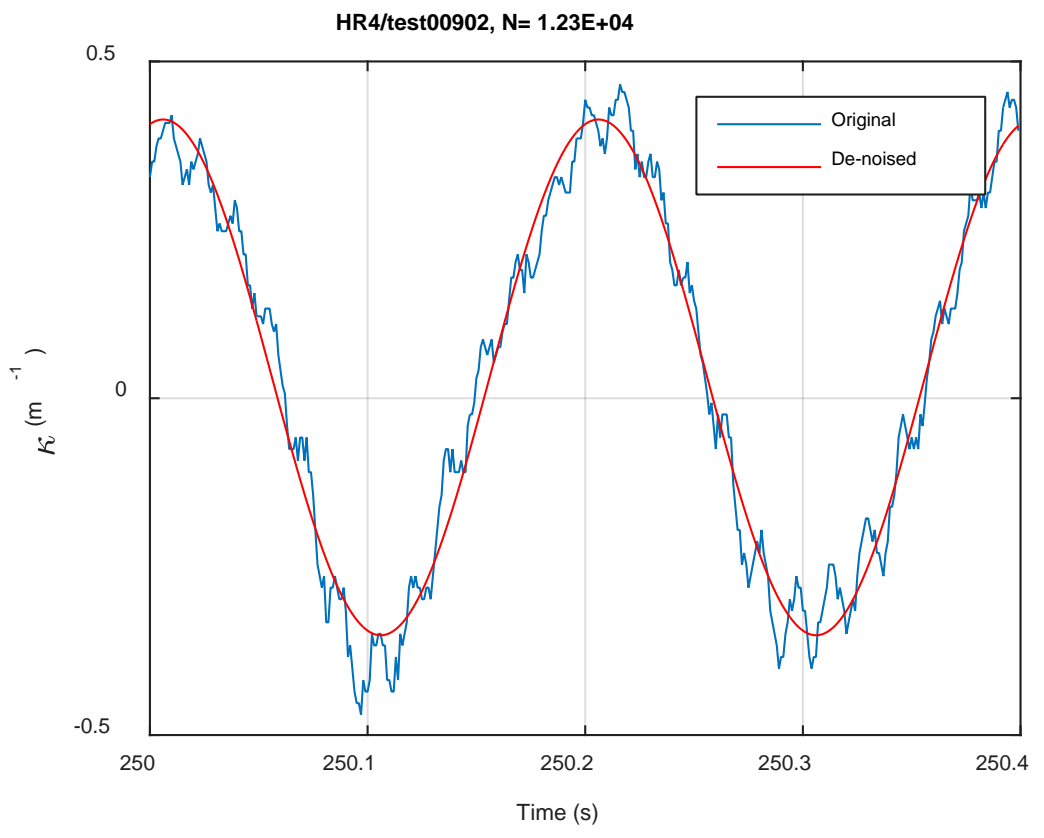

(c)

Fig. F.15 Monitoring-based responses: (a) curvature, (b) moment, (c) curvature, HR4, 16.26 Nm, $\mathrm{Ns}=1.23 \mathrm{E}+04$ cycles. 


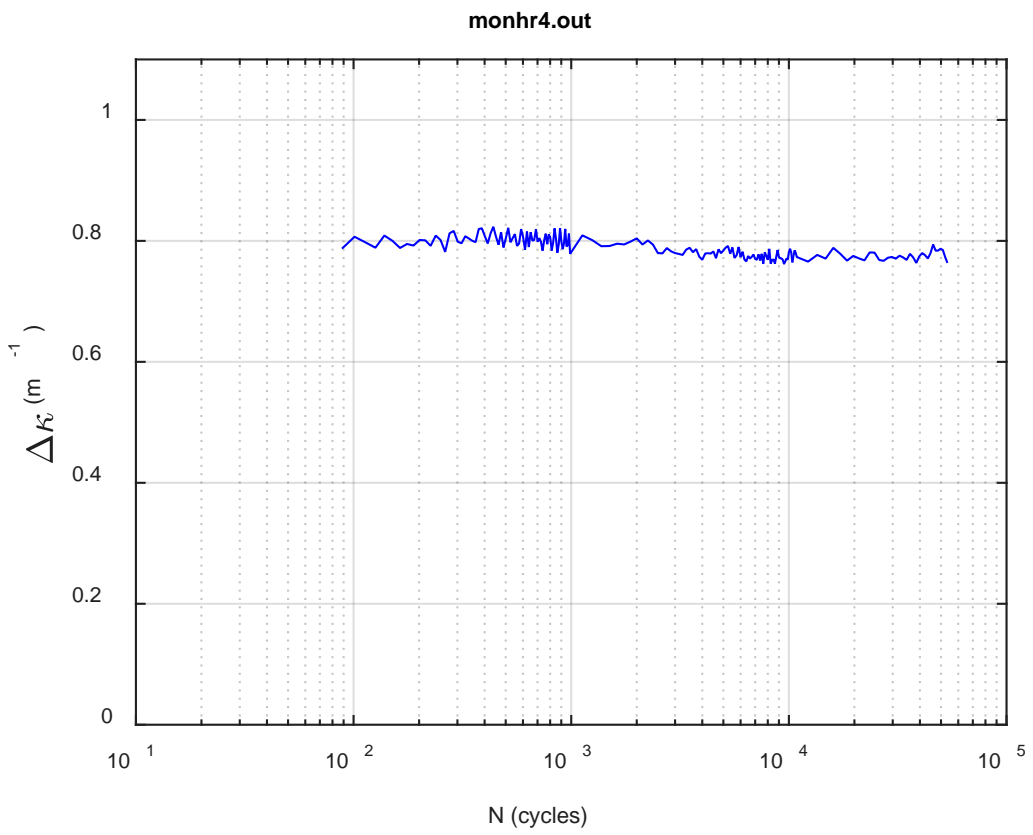

(a)

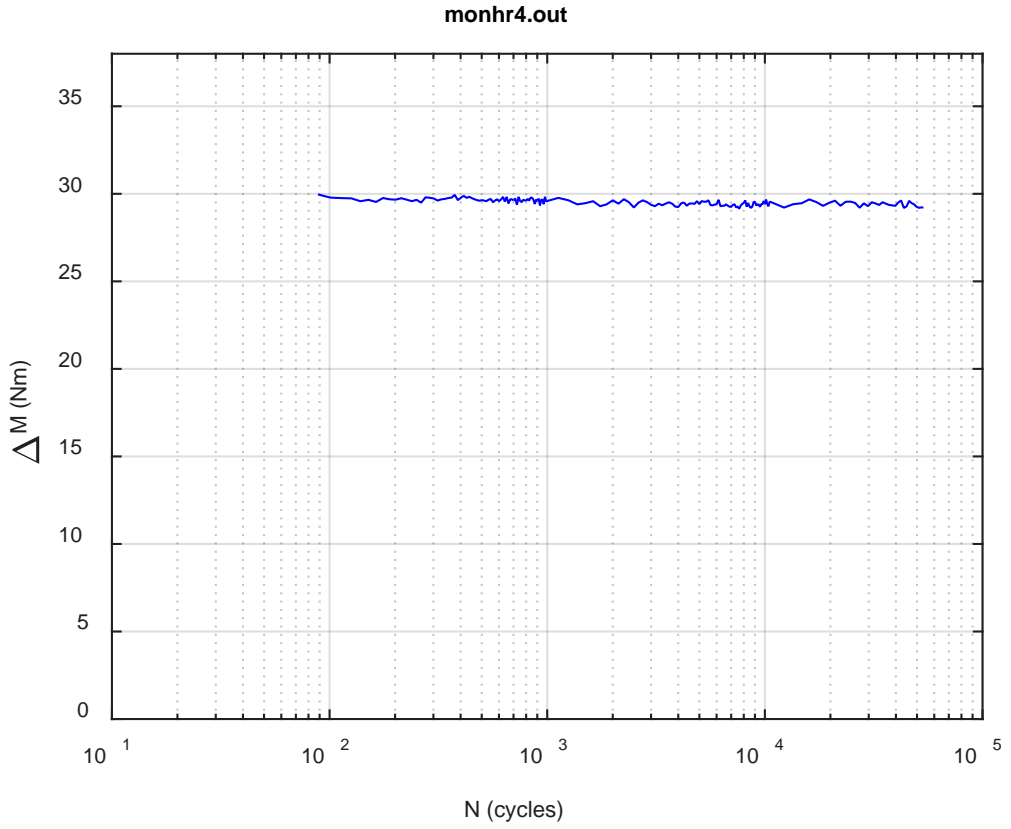

(b) 


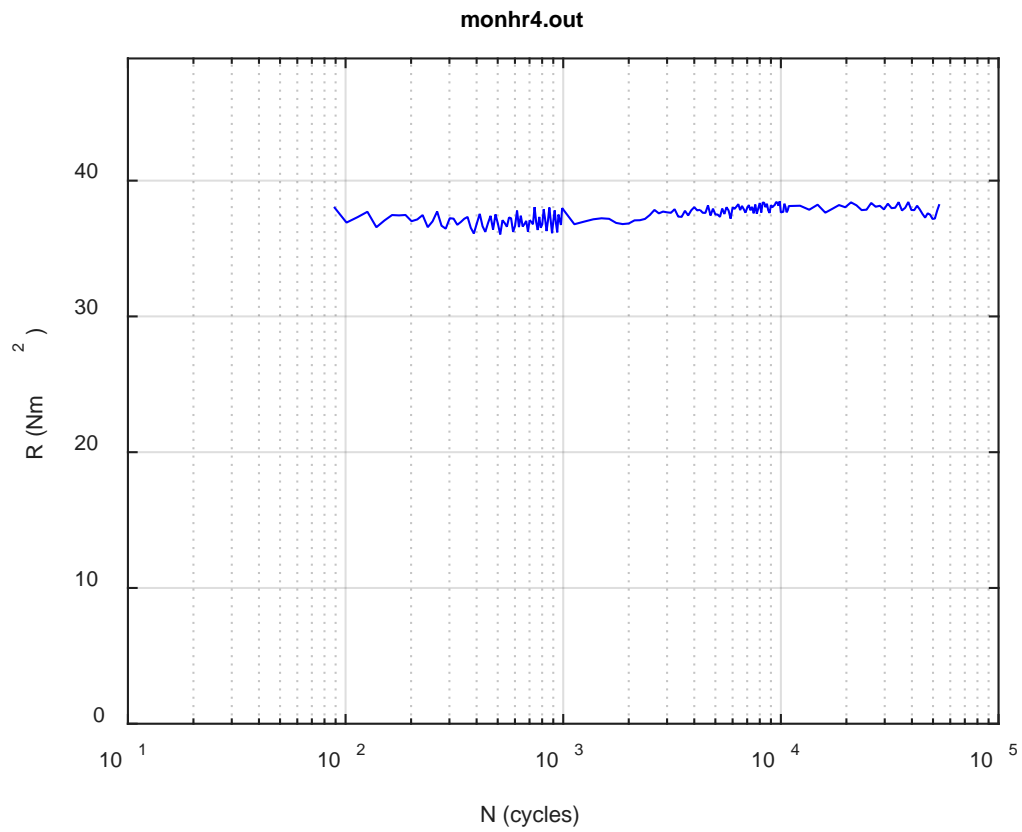

(c)

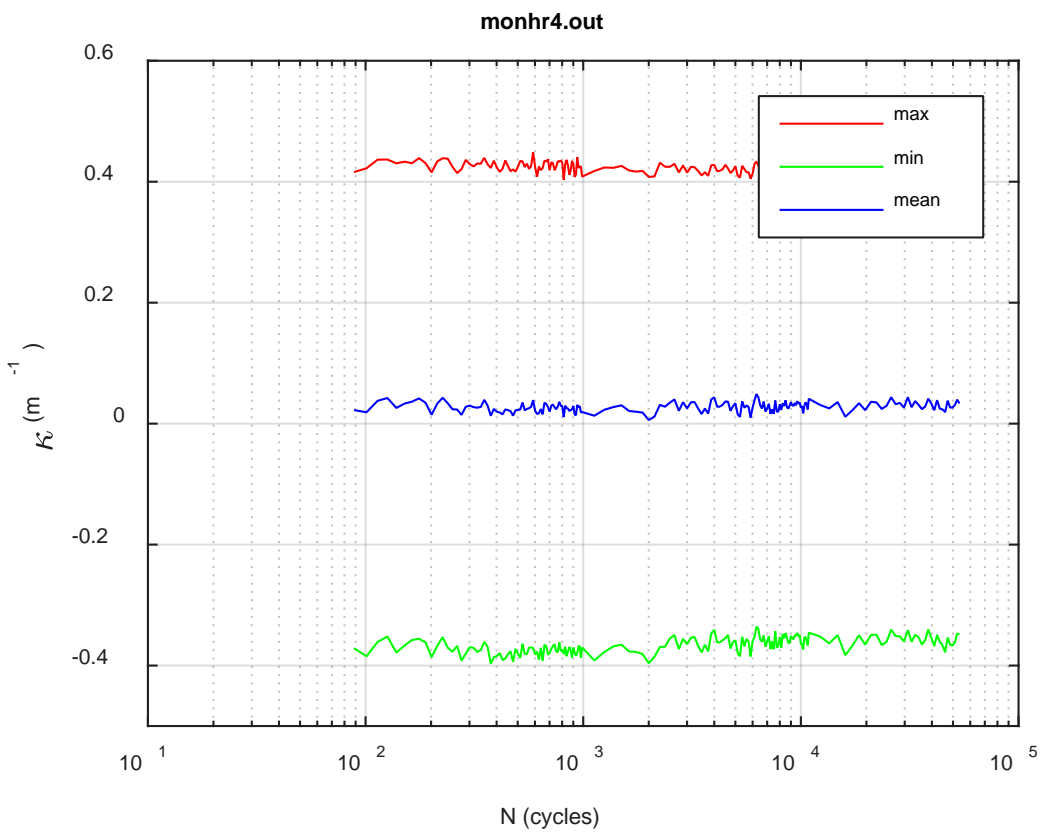

(d) 


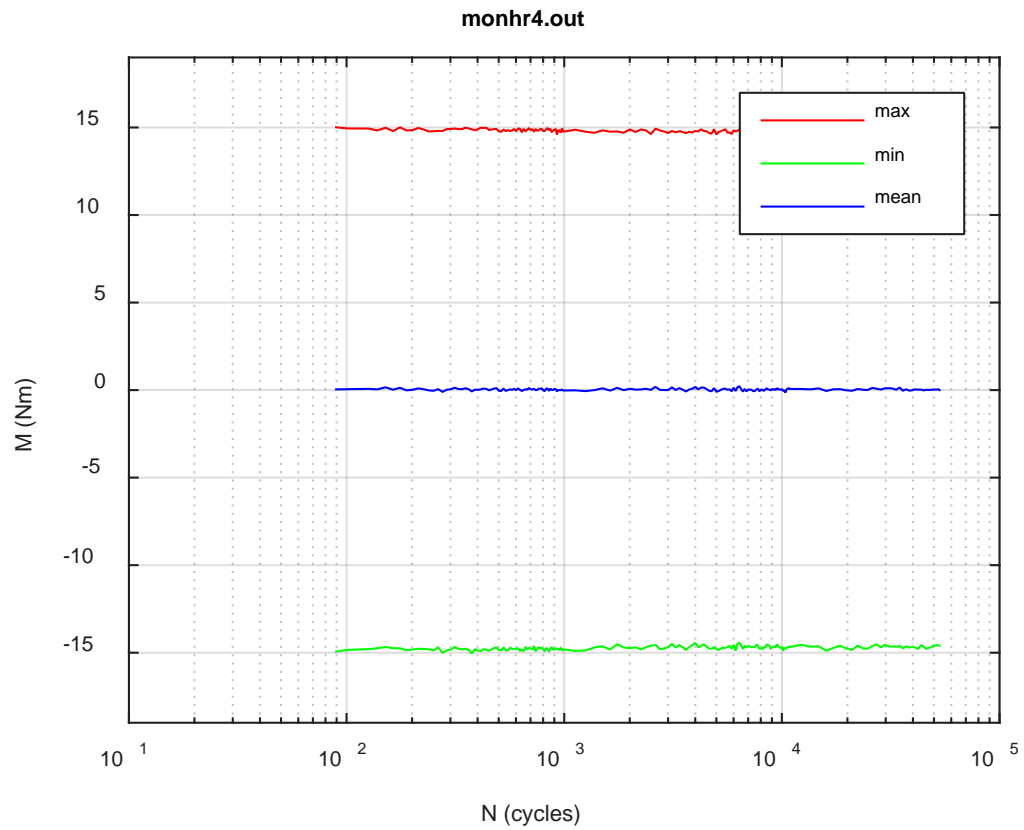

(e)

Fig. F.16 Monitoring-based responses: (a) curvature range, (b) moment range, (c) rigidity, (d) curvature peak/valley, (e) moment peak/valley, HR4, 16.26 Nm, $\mathrm{Nf}=5.47 \mathrm{E}+04$ cycles. 
This page intentionally left blank. 